Controlling the Lewis Acidity and Polymerizing Effectively

Prevent Frustrated Lewis Pairs from Deactivation in the

\title{
Hydrogenation of Terminal Alkynes
}

Qiang Liu, Liu Yang, Chenfei Yao, Jiao Geng*, Youting Wu*, and Xingbang $\mathrm{Hu}^{*}$

School of Chemistry and Chemical Engineering, Nanjing University, Nanjing 210093,

China

*Jiao Geng - Email: gengjiao@nju.edu.cn

*Youting Wu -Email: ytwu@nju.edu.cn

*Xingbang Hu -Email: huxb@nju.edu.cn

Index

1. Experimental details

2. Additional data

3. Original NMR spectra

4. Original MS data

5. Theoretical calculation method

6. Cartesians coordinates of the optimized structures 


\section{Experimental details}

\subsection{Materials}

Phenylmagnesium bromide ( $\mathrm{Ph}-\mathrm{MgBr}$, Energy Chemical, $3 \mathrm{~mol} / \mathrm{L}$ in diethyl ether), Boron (tri) fluoride etherate $\left(\mathrm{BF}_{3} \cdot \mathrm{Et}_{2} \mathrm{O}\right.$, Macklin Chemical, $\left.48 \% \mathrm{BF}_{3}\right)$, Anhydrous 1,2-dichloroethane $\left(\mathrm{C}_{2} \mathrm{H}_{4} \mathrm{Cl}_{2}\right.$, Meryer Chemical, $\left.99.5 \%\right)$, 1-Chloropropane $\left(\mathrm{C}_{3} \mathrm{H}_{7} \mathrm{Cl}\right.$, Meryer Chemical, $99 \%$ ), Phenylacetylene ( $\mathrm{Ph}-\mathrm{C} \equiv \mathrm{CH}$, Aladdin Chemical, $97 \%$ ), Aluminim trichloride $\left(\mathrm{AlCl}_{3}\right.$, Aladdin Chemical, $99 \%$ ), Pyridine (Py, Aladdin Chemical, 98 \%), Methanol $\left(\mathrm{CH}_{3} \mathrm{OH}\right.$, Macklin Chemical, $\left.99.5 \%\right)$, Trichloromethane $\left(\mathrm{HCCl}_{3}\right.$, Nanjing Chemical Reagent, $\left.99 \%\right)$, Ethyl ether $\left(\mathrm{Et}_{2} \mathrm{O}\right.$, Nanjing Chemical Reagent, 99 \%). Toluene $\left(\mathrm{C}_{7} \mathrm{H}_{8}\right.$, Nanjing Chemical Reagent, $\left.99 \%\right)$. The other terminal Alkynes were purchased from BoKa Chemistry with purities $\geqslant 99 \%$ and the bases were provided by Energy Chemical with purities $\geqslant 99 \%$. The $\mathrm{Et}_{2} \mathrm{O}$ and toluene were dried over $\mathrm{Na}$ and freshly distilled prior to use. In addition, all of the other chemicals were commercially available and were used without further purification.

\subsection{Synthesis}

\subsubsection{Synthesis of $\mathrm{BPh}_{3}$}

The $\mathrm{BPh}_{3}$ was synthesized as follows: in an argon atmosphere, $\mathrm{Ph}-\mathrm{MgBr}$ (45 mmol, 3 eq, $15 \mathrm{~mL}$ of $3 \mathrm{~mol} / \mathrm{L}$ solution in $\mathrm{Et}_{2} \mathrm{O}$ diluted by $40 \mathrm{~mL} \mathrm{Et}_{2} \mathrm{O}$ ) was slowly added into the $\mathrm{BF}_{3}$ solution ( $15 \mathrm{mmol}, 2.13 \mathrm{~g} \mathrm{BF}_{3} \cdot \mathrm{Et}_{2} \mathrm{O}$ diluted by $20 \mathrm{~mL} \mathrm{Et}_{2} \mathrm{O}$ ) at $0{ }^{\circ} \mathrm{C}$. After being stirred for additional 2 hours at $0{ }^{\circ} \mathrm{C}$, the mixture solution was slowly warmed to room temperature and stirred overnight. After that, the ether was removed under vacuum at $40{ }^{\circ} \mathrm{C}$ oil bath to ensure that the volatiles were completely removed. Then white fluffy $\mathrm{BPh}_{3}(1.2 \mathrm{~g}$, yield $32 \%)$ was obtained by sublimation under vacuo at $90{ }^{\circ} \mathrm{C}$ oil bath. ${ }^{1} \mathrm{H}$ NMR (400 MHz, $\left.\mathrm{CDCl}_{3}\right) \delta$ 7.67-7.59 (m, 2H), 7.58-7.49 (m, 1H), 7.49-7.40 (m, 2H). $\left.{ }^{13} \mathrm{C} \mathrm{NMR} \mathrm{( \delta ,} \mathrm{ppm,} \mathrm{CDCl}_{3}, 101 \mathrm{MHz}\right): 143.4,138.9,131.6$, 127.7. ${ }^{11} \mathrm{~B} \mathrm{NMR}\left(\delta, \mathrm{ppm}, \mathrm{CDCl}_{3}, 128 \mathrm{MHz}\right): 67.3 \mathrm{ppm}(\mathrm{br}, \mathrm{s})$. 


\subsubsection{Synthesis of $\mathrm{P}-\mathrm{BPh}_{3}$}

In the glove box, $1.5 \mathrm{~g} \mathrm{BPh}_{3}$ and $2 \mathrm{~g} \mathrm{AlCl}_{3}$ were added into a $100 \mathrm{~mL}$ pressure bottle. Then, $10 \mathrm{~mL}$ of $\mathrm{C}_{2} \mathrm{H}_{4} \mathrm{Cl}_{2}$ was injected into pressure bottle and the mixture was stirred vigorously for 5 hours at room temperature. After that, slowly opened the bottle cap in the fume hood to release the $\mathrm{HCl}$ gas generated by the reaction. Then, the reaction mixture was quenched by slowly adding $20 \mathrm{~mL}$ methanol (Caution: reaction between $\mathrm{AlCl}_{3}$ and methanol is highly exothermic). The mixture was stirred for another 2 hours at room temperature for the complete quenching of $\mathrm{AlCl}_{3}$ to obtain yellow suspended matter. To remove all remaining salts, the mixture was extracted with chloroform Soxhlet at $90{ }^{\circ} \mathrm{C}$ oil bath for at least 24 hours. After that, the solid was vacuum dried at $120^{\circ} \mathrm{C}$ for 24 hours to give yellow powder $\mathrm{P}-\mathrm{BPh}$.

Scheme S1. Synthesis of $\mathrm{BPh}_{3}$ and $\mathrm{P}^{-\mathrm{BPh}_{3}}$.

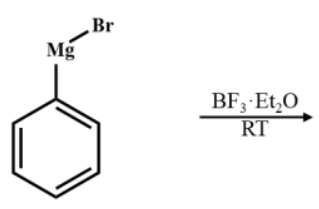<smiles>c1ccc(N(c2ccccc2)c2ccccc2)cc1</smiles>

$\mathrm{BPh}_{3}$
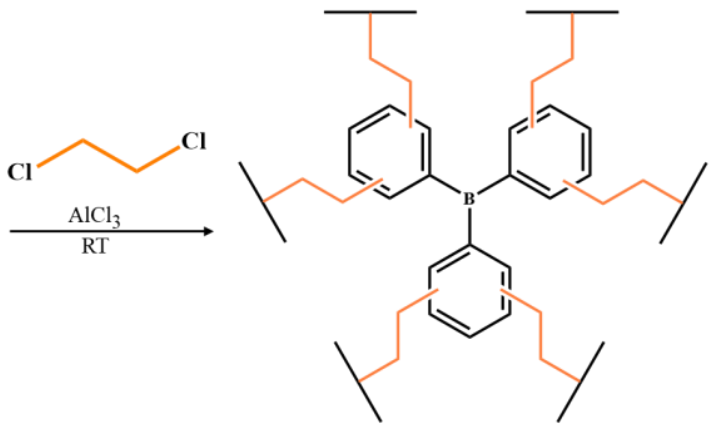

$\mathrm{P}^{-\mathrm{BPh}_{3}}$

\section{3 Characterization}

The liquid NMR spectra were recorded on a Bruker Avance II 400 spectrometer at 298 K. Fourier transform infrared spectroscopy (FT-IR) spectra were collected using a Bruker Tenson-27 FT-IR spectrometer. Solid-state nuclear magnetic resonance measurements were carried out using a Bruker AVIII NMR spectrometer (400 MHz). Scanning electron microscopy (SEM) and energy dispersive X-ray spectroscopy (EDS) elemental analysis were conducted by a Hitachi SEM-4800. Powder X-ray diffraction (PXRD) was recorded by a D8 Advance equipped with a $\mathrm{Cu} K \alpha$ source $(\lambda=1.5428$ $\AA$ ). Elemental analysis was conducted on a vario EL III elemental analyzer. 
Thermogravimetric analysis (TGA) was performed under $\mathrm{N}_{2}$ on a TGA Q 500, V20.13 with a balance gas flow of $10 \mathrm{~mL} / \mathrm{min}$ and a sample gas flow of $25 \mathrm{~mL} / \mathrm{min}$. X-ray photoelectron spectroscopy (XPS) analysis was performed by PHI 5000 Versa Probe (ULVAC-PHI, JPN).

\subsection{The characterization of $\mathrm{P}-\mathrm{BPh} 3$}

The structure of $\mathrm{P}-\mathrm{BPh} 3$ was confirmed by solid-state ${ }^{13} \mathrm{C}$ NMR spectrum. As shown in Figure 3, there are two types of the carbon: aromatic and aliphatic. The peaks at $126.2 \mathrm{ppm}$ can be assigned to unsubstituted aromatic carbons of $\mathrm{BPh}_{3}$, and the peaks at $139.9 \mathrm{ppm}$ belong to the substituted aromatic carbons of $\mathrm{BPh}_{3}{ }^{[1]}$. The peaks at 36.3 ppm represent the methylene carbons, which belong to dichloroethane ${ }^{[1]}$, demonstrating the monomer linked like the drawing structure in Scheme 2. In addition, the aliphatic $\mathrm{C}-\mathrm{C}$ bond of the connector on $\mathrm{P}-\mathrm{BPh}_{3}$ can also be evidenced by XPS at $284.7 \mathrm{eV}^{[2]}$ (Figure S4) and the FT-IR at $1450 \mathrm{~cm}^{-1}{ }^{[3]}$ (Figure S5). The C, H, and B contents of $\mathrm{P}-\mathrm{BPh}_{3}$, determined by elemental analysis and energy-dispersive $\mathrm{X}$-ray spectroscopy (EDX) equipped on Scan electron microscopy (SEM) (Table S1), are $90.3 \mathrm{wt} \%, 7.7 \mathrm{wt} \%$, and $4.4 \mathrm{wt} \%$ respectively. In addition, the content of $\mathrm{C}$ and $\mathrm{H}$ are increased, while the content of B is decreased, comparing with the theoretical content of $\mathrm{BPh}_{3}$, further proving the structure of $\mathrm{P}-\mathrm{BPh}_{3}$. To further understand the physical structure of $\mathrm{P}_{-} \mathrm{BPh}_{3}$, the SEM and powder X-ray diffraction (PXRD) were measured. The morphology of $\mathrm{P}-\mathrm{BPh}_{3}$ displayed in SEM image with the size estimated at around $1 \mu \mathrm{m}$ (Figure S6). Furthermore, the PXRD analyses verify the amorphous powder of $\mathrm{P}-\mathrm{BPh} 3$ provided by Figure $\mathrm{S} 7^{[1,4]}$.

1.5 Experimental detail for catalytic hydrogenation of the terminal alkynes and the catalyst recycle experiment

In a glove box, $1 \mathrm{mmol}$ terminal alkynes and $1 \mathrm{~mL}$ of toluene was added into a high pressure reactor. $\mathrm{P}_{-\mathrm{BPh}}$ (10\% of the mass of the substrate) and the bases $(0.5 \mathrm{mmol})$ were added into the above system and stirred 10 minutes. Then, the reactor was pressurized with $5 \mathrm{MPa}$ of $\mathrm{H}_{2}$ at ambient temperature. The hydrogenation reaction 
was carried out at $120{ }^{\circ} \mathrm{C}$ for 12 hours. After the reaction, the conversion and selectivity were determined by GC and GC-MS. The hydrogenation products were isolated by flash chromatography on silica gel (eluent: 10/90 ethyl acetate/petroleum ether), and the isolated yields were calculated based on the dosage of the terminal alkynes. The weights and percentages (molar ratio) of the hydrogenation products $\mathrm{Ph}-\mathrm{CH}=\mathrm{CH}_{2}, \quad \mathrm{CH}_{3}-\mathrm{Ph}-\mathrm{CH}=\mathrm{CH}_{2}, \quad 2-\mathrm{Cl}-\mathrm{Ph}-\mathrm{CH}=\mathrm{CH}_{2}, \quad 4-\mathrm{CH}_{3}-\mathrm{O}-\mathrm{Ph}-\mathrm{CH}=\mathrm{CH}_{2}$ were $0.074 \mathrm{~g} / 71 \%, 0.089 \mathrm{~g} / 76 \%, 0.112 \mathrm{~g} / 81 \%, 0.110 \mathrm{~g} / 82 \%$, respectively.

The recycle experiment was carried out according to the following procedure. In order to reduce the loss of catalyst in the recycle process, the volatiles (including solvent and products) were removed under vacuum after the catalytic reaction. Then, the recovered catalyst was reused in the next cycling catalysis experiment without further treatment. 


\section{Additional data}

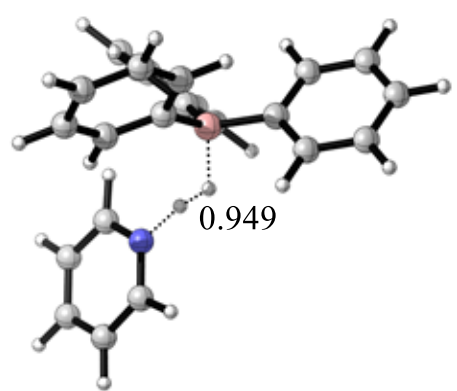

$26.2 \mathrm{kcal} / \mathrm{mol}$

TS $_{\text {BPh3 }}$

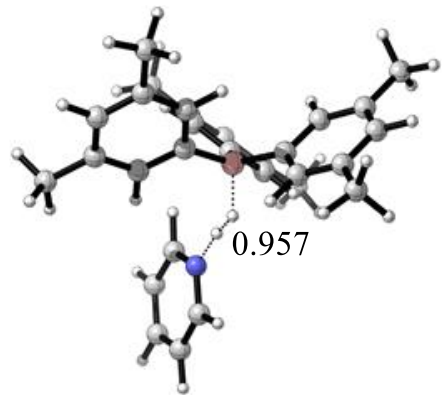

$26.1 \mathrm{kcal} / \mathrm{mol}$

$\mathbf{T S}_{\mathrm{B}(\mathrm{DiMe}) \mathbf{P h} 3}$

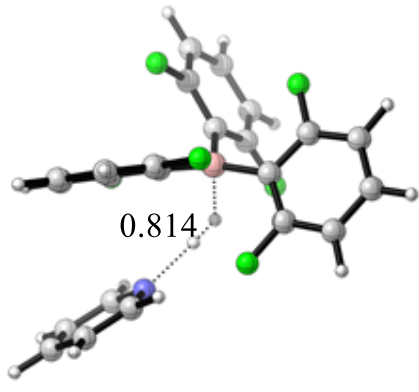

$25.2 \mathrm{kcal} / \mathrm{mol}$

$\mathrm{TS}_{\mathrm{B}(\mathrm{C} 6 \mathrm{~F} 2 \mathrm{H} 3) 3}$

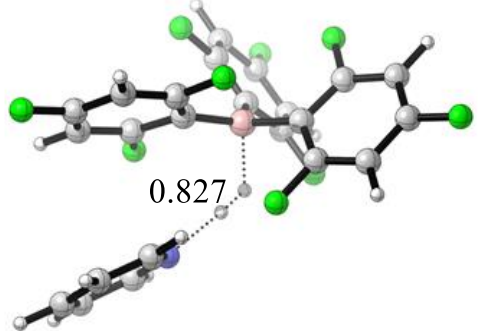

$24.6 \mathrm{kcal} / \mathrm{mol}$

$\mathbf{T S}_{\mathrm{B}(\mathrm{C} 6 \mathrm{~F} 3 \mathrm{H} 2) 3}$

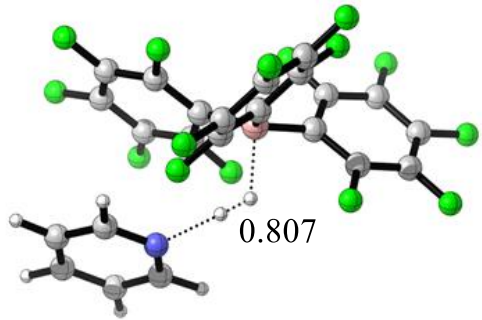

$27.2 \mathrm{kcal} / \mathrm{mol}$

$\mathbf{T S}_{\mathrm{B}(\mathrm{C6F5)3}}$

Figure S1. The optimized structures of transition states of $\mathrm{H}_{2}$ activation. The italic values are activation energies in $\mathrm{kcal} / \mathrm{mol}$. The other values are distance in $\AA$. See section 5 for calculation details. 


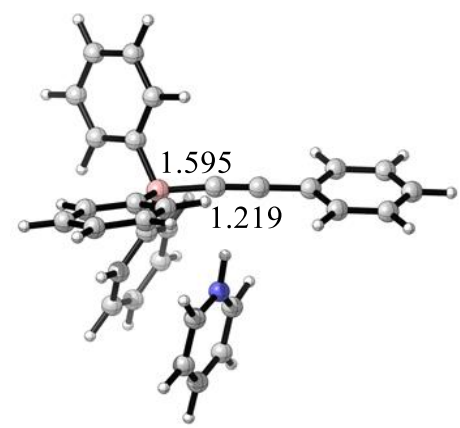

$13.9 \mathrm{kcal} / \mathrm{mol}$

$\mathbf{B P h}_{\mathbf{3}}+\mathbf{P h}-\mathbf{C} \equiv \mathbf{C H}+\mathbf{P y}$

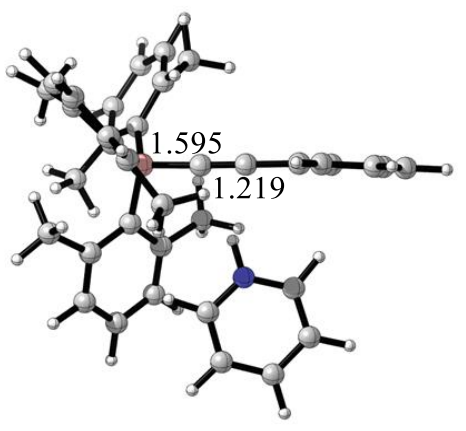

$14.6 \mathrm{kcal} / \mathrm{mol}$

$\mathbf{B}(\mathrm{DiMe}) \mathbf{P h}_{\mathbf{3}}+\mathbf{P h}-\mathbf{C} \equiv \mathbf{C H}+\mathbf{P y}$

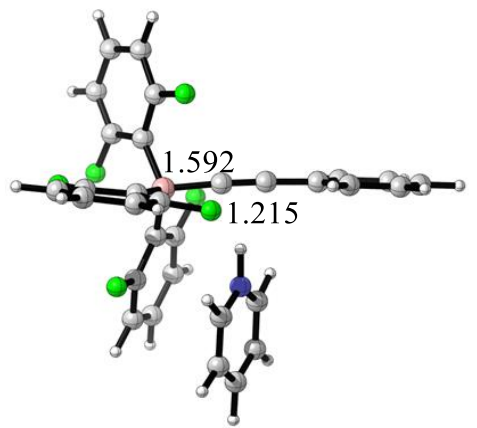

$6.8 \mathrm{kcal} / \mathrm{mol}$

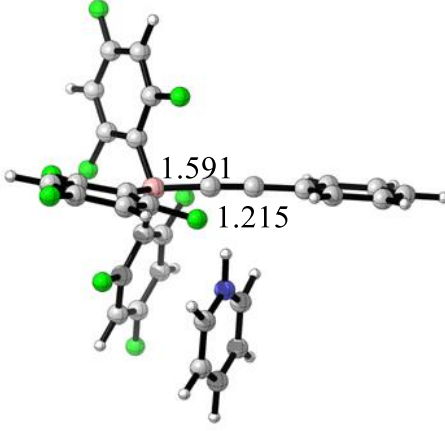

$5.0 \mathrm{kcal} / \mathrm{mol}$

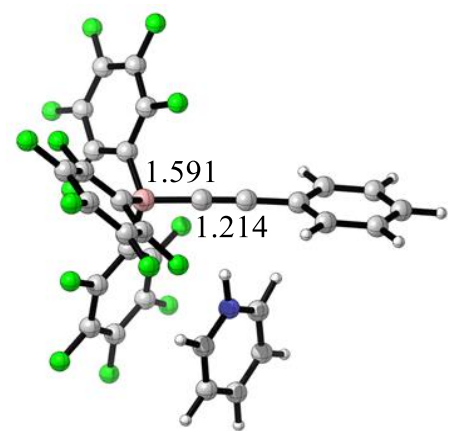

$-6.1 \mathrm{kcal} / \mathrm{mol}$

$\mathrm{B}\left(\mathrm{C}_{6} \mathrm{~F}_{2} \mathrm{H}_{3}\right)_{3}+\mathrm{Ph}-\mathrm{C} \equiv \mathrm{CH}+\mathrm{Py} \quad \mathrm{B}\left(\mathrm{C}_{6} \mathrm{~F}_{3} \mathrm{H}_{2}\right)_{3}+\mathrm{Ph}-\mathrm{C} \equiv \mathrm{CH}+\mathrm{Py} \quad \mathrm{B}\left(\mathrm{C}_{6} \mathrm{~F}_{5}\right)_{3}+\mathrm{Ph}-\mathrm{C} \equiv \mathrm{CH}+\mathrm{Py}$

Figure S2. The optimized structures of different Lewis acids $+\mathrm{Ph}-\mathrm{C} \equiv \mathrm{CH}+\mathrm{Py}$ complexes. The italic values are Gibbs free energy changes in kcal/mol. The other values are distance in $\AA$. See section 5 for calculation details.
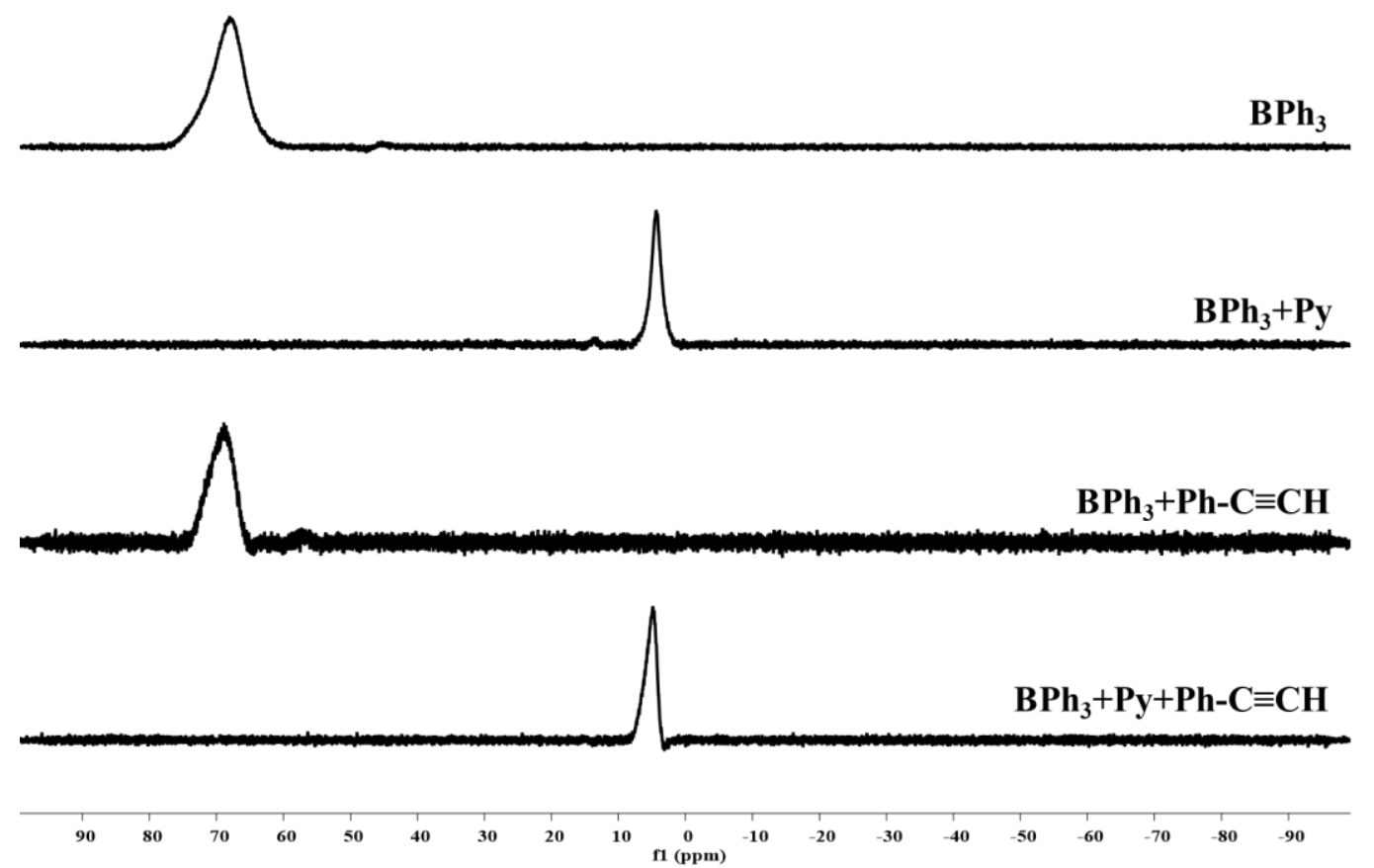
Figure $\mathrm{S} 3 .{ }^{11} \mathrm{~B}$ spectra of $\mathrm{B}(\mathrm{Ph})_{3}$ in the presence of equivalent $\mathrm{Ph}-\mathrm{C} \equiv \mathrm{CH}$, Py and $\mathrm{Ph}-\mathrm{C} \equiv \mathrm{CH} / \mathrm{Py}$ respectively (in $\mathrm{CDCl}_{3}, 128 \mathrm{MHz}$ ) (samples were treated at $120^{\circ} \mathrm{C}$ for 12 hours).

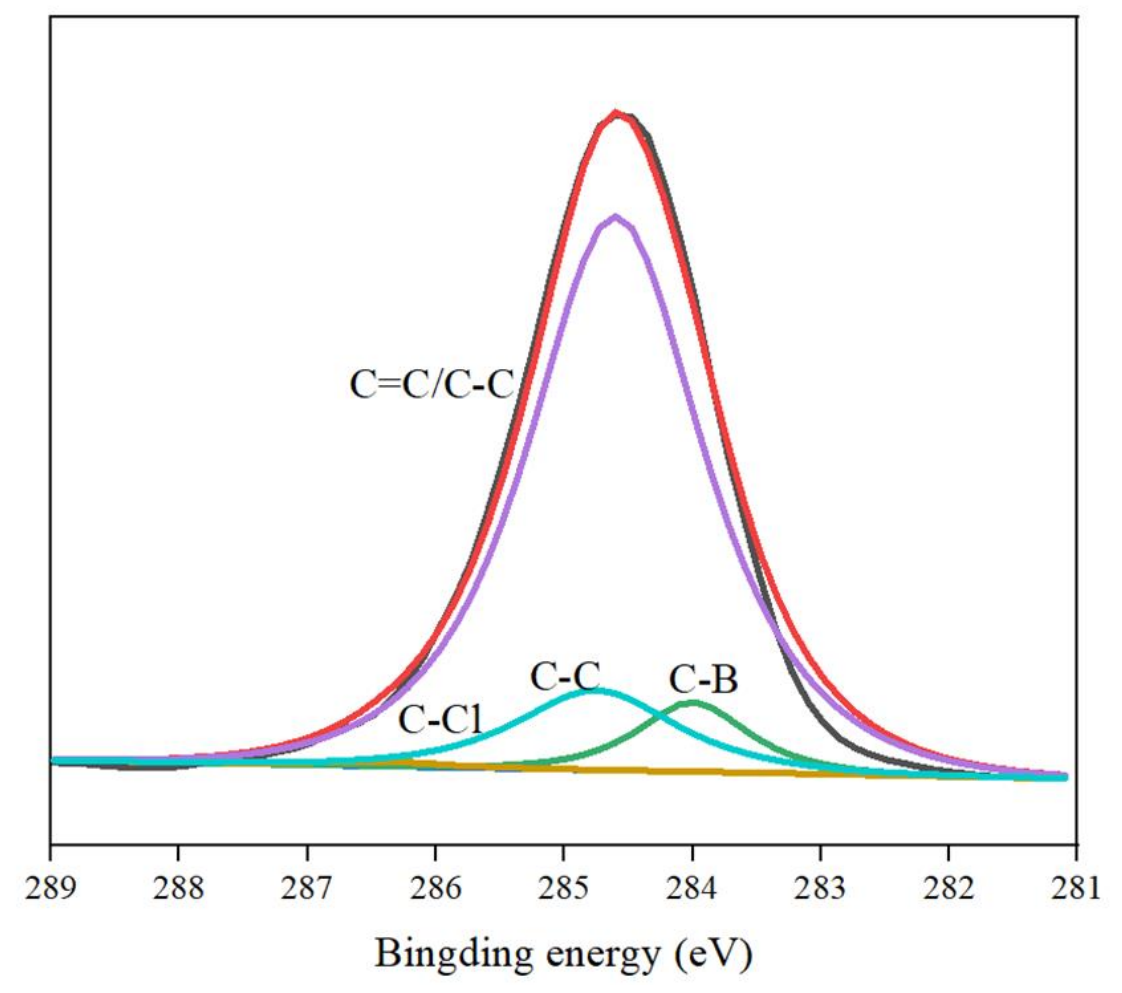

Figure S4. XPS spectra of $\mathrm{P}-\mathrm{BPh} 3$.

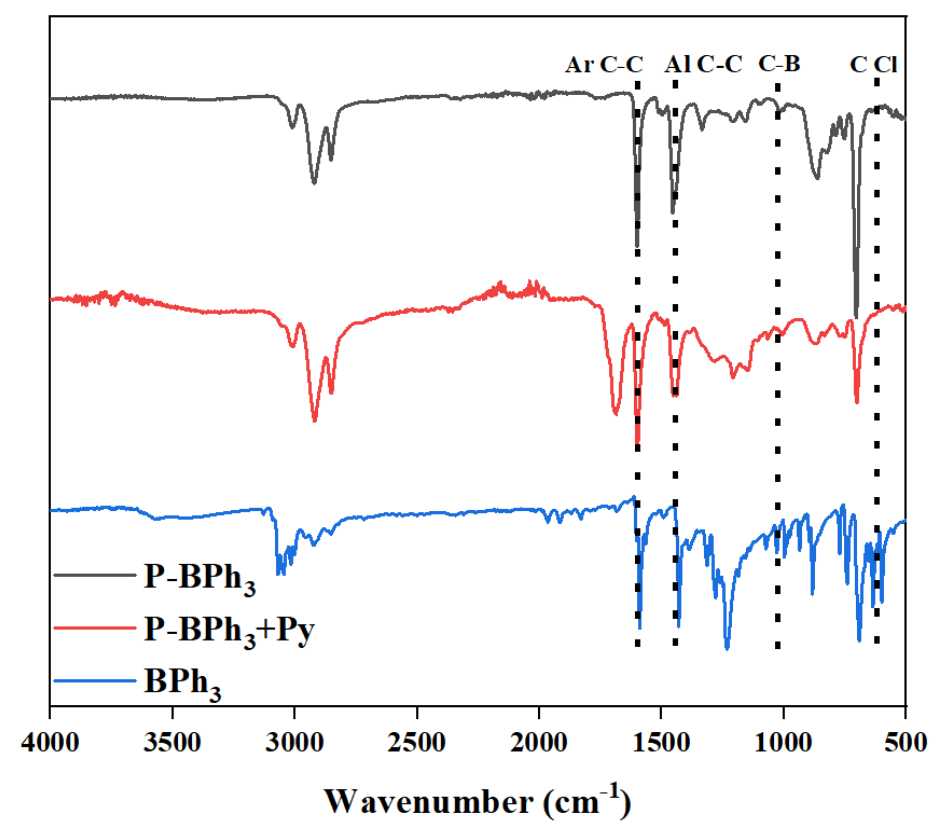


Figure S5. FT-IR spectra of $\mathrm{P}-\mathrm{BPh}_{3}, \mathrm{P}-\mathrm{BPh}_{3}+\mathrm{Py}$ and $\mathrm{BPh}_{3}$.

Table S1. Elemental contents of $\mathrm{BPh}_{3}$ and $\mathrm{P}-\mathrm{BPh}_{3}$.

\begin{tabular}{ccccccc}
\hline & & $\mathrm{C}(\mathrm{wt} \%)$ & $\mathrm{H}(\mathrm{wt} \%)$ & $\mathrm{B}(\mathrm{wt} \%)$ & $\mathrm{Cl}(\mathrm{wt} \%)$ & $\mathrm{Al}(\mathrm{wt} \%)$ \\
\hline $\mathrm{BPh}_{3}$ & Theoretical & 89.3 & 6.2 & 4.5 & $\sim$ & $\sim$ \\
$\mathrm{P}^{-B P h} 3$ & Experimental & $90.3^{[\mathrm{a}]}$ & $7.7^{[\mathrm{a}]}$ & $4.4^{[\mathrm{b}]}$ & $1.6^{[\mathrm{b}]}$ & $0.1^{[\mathrm{b}]}$ \\
\hline
\end{tabular}

[a] Determined by elemental analyses. [b] Determined by energy-dispersive X-ray spectroscopy (EDX) equipped on SEM.

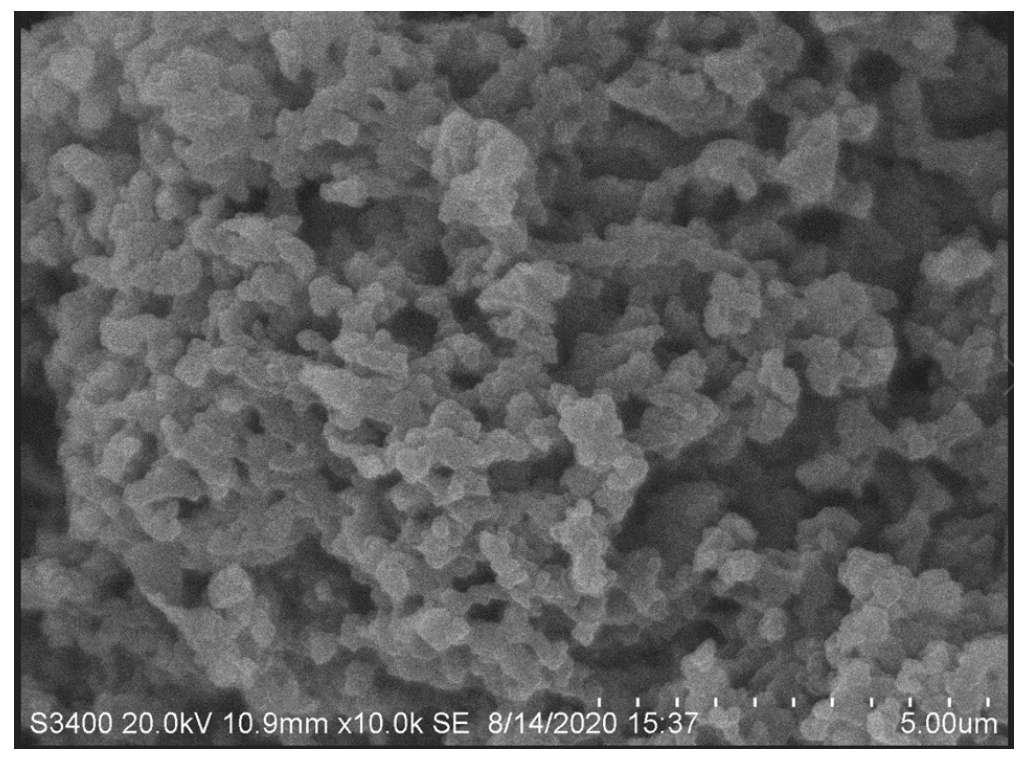

Figure S6. SEM image of $\mathrm{P}-\mathrm{BPh}_{3}$. 


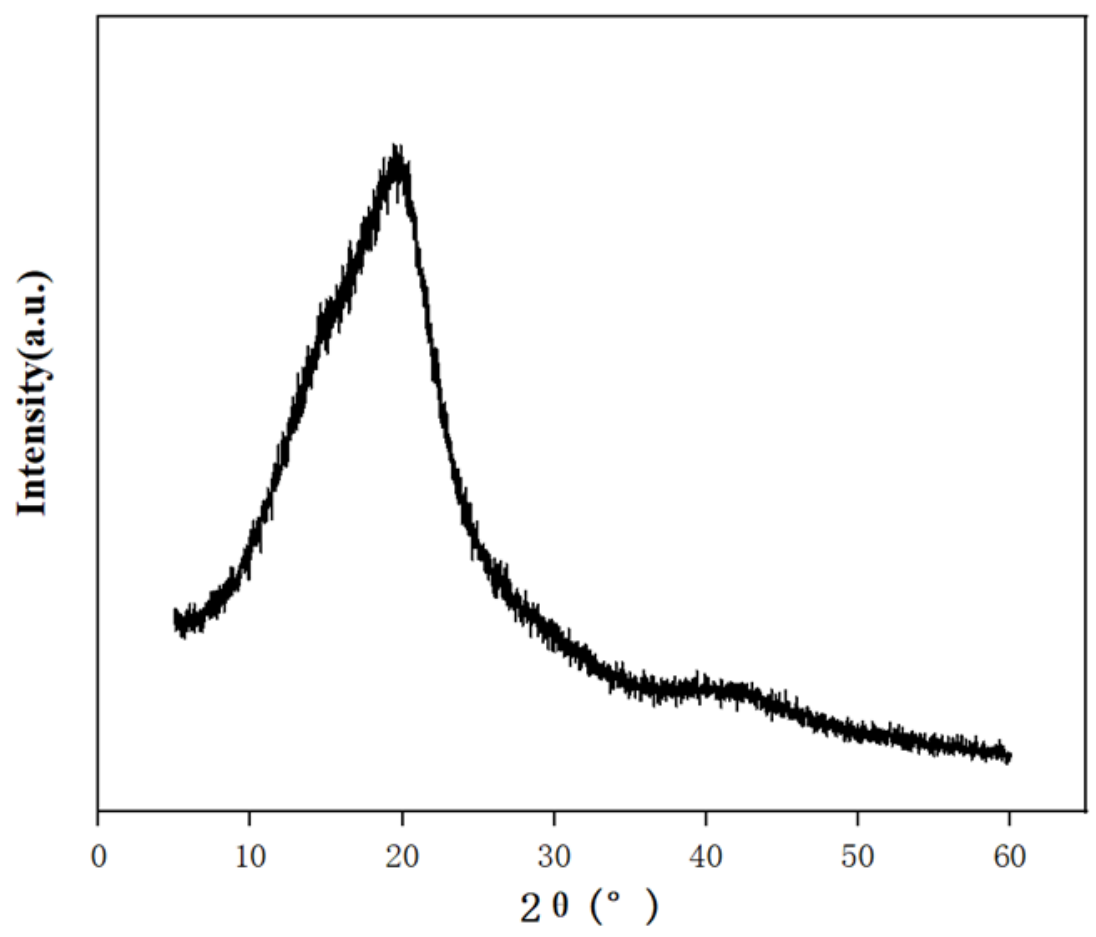

Figure S7. P-XRD spectra of $\mathrm{P}-\mathrm{BPh}_{3}$.

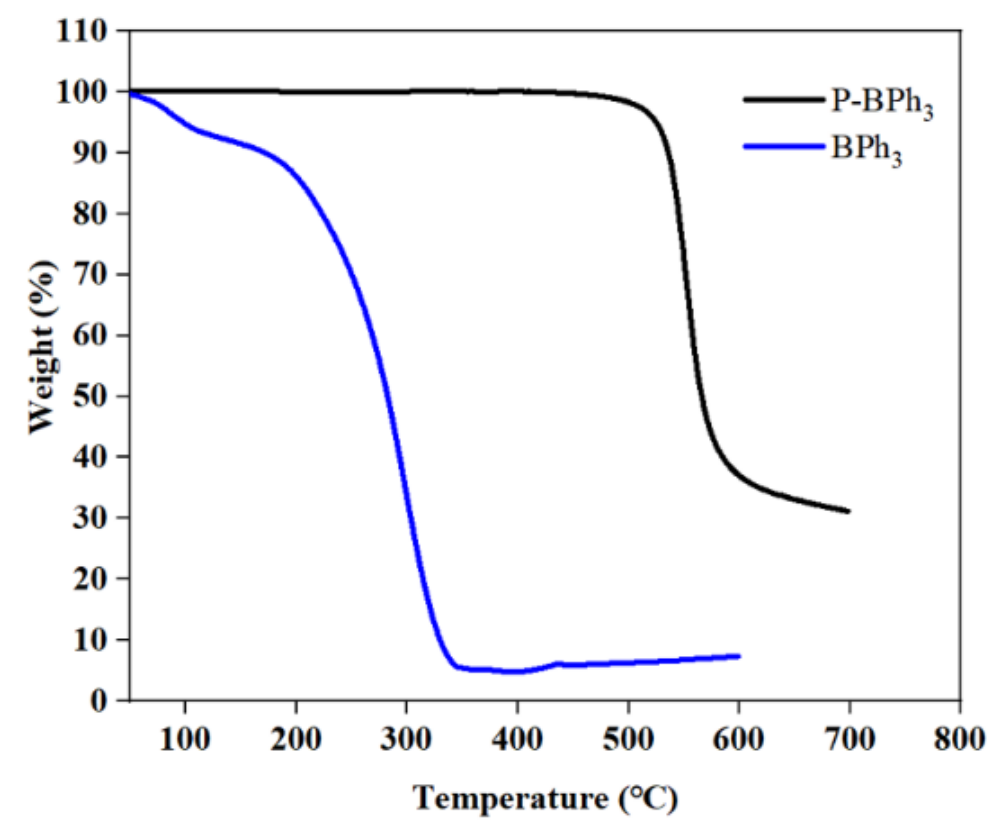

Figure S8. TGA of $\mathrm{P}-\mathrm{BPh} 3$ and $\mathrm{BPh}_{3}$.

Table S2. The 4-ethylphenylacetylene hydrogenation catalyzed by $\mathrm{P}-\mathrm{BPh}$ with different bases. ${ }^{\text {[a] }}$ 


\begin{tabular}{lllll}
\hline & & & \multicolumn{2}{l}{ Selectivity $(\%)^{[\mathrm{b}]}$} \\
\cline { 3 - 4 } & & & & \multicolumn{2}{c}{$\begin{array}{l}\text { Conversion } \\
(\%)^{[\mathrm{b}]}\end{array}$} & $\begin{array}{l}\text { Total } \\
(\%)\end{array}$ & $\begin{array}{l}\text { Alkene(\%):Alkane } \\
(\%)\end{array}$ \\
\hline 1 & Py & $>99$ & $>99$ & $88: 12$ \\
2 & 2-Me-Py & $>99$ & $>99$ & $88: 12$ \\
3 & 3,5-DiMe-Py & $>99$ & $>99$ & $91: 9$ \\
4 & 3-Cl-Py & 2 & $>99$ & $88: 12$ \\
5 & 2,6-DiMe-Py & 1 & $>99$ & $64: 36$ \\
6 & TEA & 33 & $>99$ & $94: 6$ \\
7 & PPI & 40 & $>99$ & $93: 7$ \\
8 & PPh3 & 6 & $>99$ & $93: 7$ \\
\hline
\end{tabular}

[a] Reaction conditions: 4-ethylphenylacetylene (1 mmol, $0.13 \mathrm{~g}), \mathrm{P}-\mathrm{BPh} 3(0.013 \mathrm{~g}, 10$ $\mathrm{wt} \%$ of the substrate), base $(0.5 \mathrm{mmol})$, solvent toluene $(1 \mathrm{~mL})$, pressure of $\mathrm{H}_{2}: 5 \mathrm{Mpa}$, $120{ }^{\circ} \mathrm{C}, 12$ h. Note: Py (Pyridine), 2-Me-Py (2-Methylpyridine), 3,5-DiMe-Py (3,5-Dimethylpyridine), 3-Cl-Py (3-Chloropyridine), 2,6-DiMe-Py (2,6-Dimethylpyridine), TEA (Triethylamine), PPI (Pempidine), PPh3 (Triphenylphosphine). [b] Determined by GC and GC-MS.

Table S3. The 4-ethylphenylacetylene hydrogenation catalyzed by $\mathrm{P}-\mathrm{BPh}$ with different loading levels. ${ }^{[a]}$

\begin{tabular}{|c|c|c|c|c|}
\hline \multirow[b]{2}{*}{ Entry } & \multirow{2}{*}{$\begin{array}{ll}\text { Loading level } \\
(\mathrm{w} / \mathrm{w} \%)\end{array}$} & \multirow{2}{*}{$\begin{array}{l}\text { Conversion } \\
(\%)^{[\mathrm{b}]}\end{array}$} & \multicolumn{2}{|c|}{ Selectivity $(\%)^{[\mathrm{b}]}$} \\
\hline & & & $\begin{array}{l}\text { Total } \\
(\%)\end{array}$ & $\begin{array}{l}\text { Alkene(\%):Alkane } \\
(\%)\end{array}$ \\
\hline 1 & 2.5 & 25 & $>99$ & 99: \\
\hline 2 & 5 & 42 & $>99$ & $98: 2$ \\
\hline 3 & 7.5 & 72 & $>99$ & $95: 5$ \\
\hline 4 & 10 & 99 & $>99$ & $88: 12$ \\
\hline
\end{tabular}

[a] Reaction conditions: 4-ethylphenylacetylene (1 mmol), Py $(0.5 \mathrm{mmol})$, solvent toluene (1mL), pressure of $\mathrm{H}_{2}: 5 \mathrm{Mpa}, 120{ }^{\circ} \mathrm{C}, 12 \mathrm{~h}$. [b] Determined by $\mathrm{GC}$ and GC-MS. 

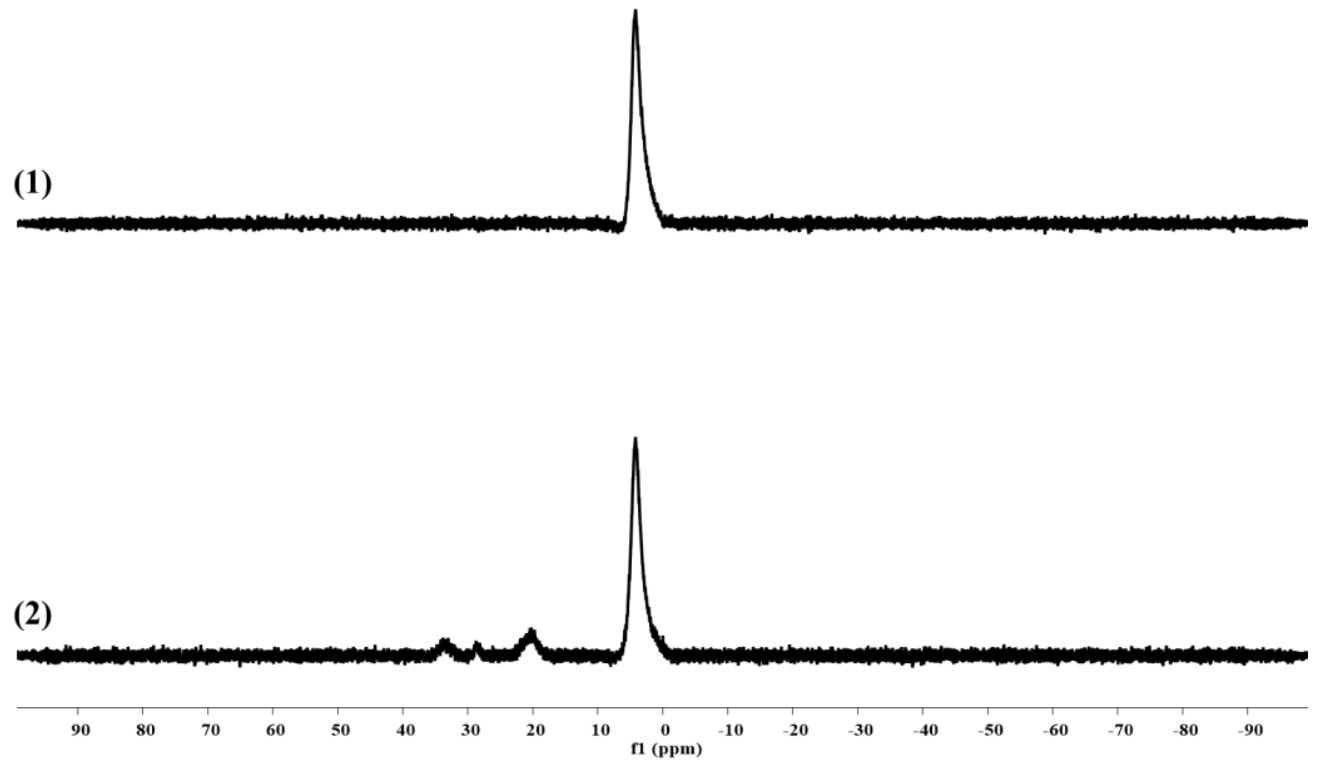

Figure S9. (1) ${ }^{11} \mathrm{~B}$ NMR spectrum of the fresh $\mathrm{BPh}_{3} / \mathrm{Py}$ (in $\mathrm{CDCl}_{3}, 128 \mathrm{MHz}$ ); (2) ${ }^{11} \mathrm{~B}$ $\mathrm{NMR}$ spectrum of the $\mathrm{BPh}_{3} / \mathrm{Py}$ after hydrogenation reaction (in $\mathrm{CDCl}_{3}, 128 \mathrm{MHz}$ ).

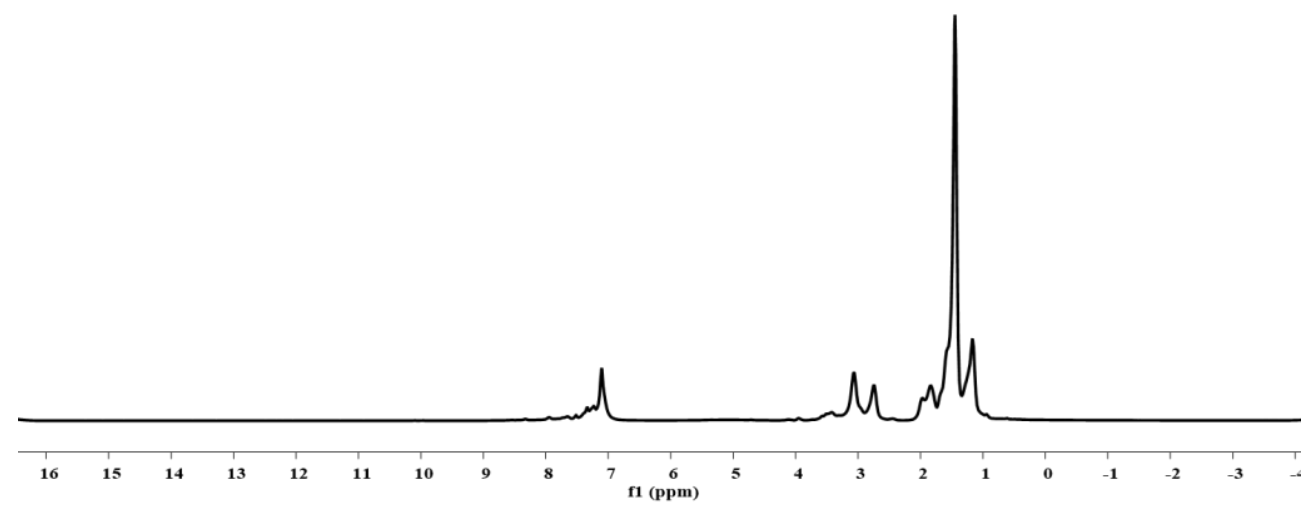

Figure S10. ${ }^{1} \mathrm{H}$ NMR spectrum of FC substitution on $\mathrm{BPh}_{3}$ to generate substituted boranes (in $\mathrm{CDCl}_{3}, 400 \mathrm{MHz}$ ). Reaction conditions: $\mathrm{BPh}_{3}\left(0.2 \mathrm{~g}\right.$ ), $\mathrm{Cl}_{-} \mathrm{CH}_{2} \mathrm{CH}_{2} \mathrm{CH}_{3}$ $(2 \mathrm{~mL}), \mathrm{AlCl}_{3}(0.02 \mathrm{~g}),-20^{\circ} \mathrm{C}$, remove the volatiles after 1 hour. The ${ }^{1} \mathrm{H}$ peaks at 1.2 , 1.8 and $3.1 \mathrm{ppm}$ belong to the n-propyl, and the ${ }^{1} \mathrm{H}$ peaks at 1.5 and $2.8 \mathrm{ppm}$ belong to the isopropyl.

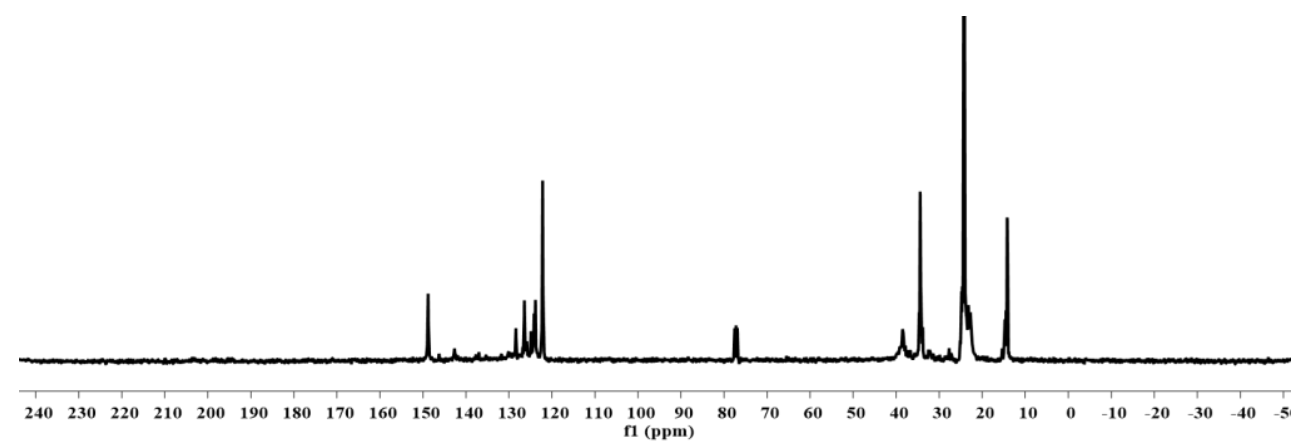


Figure S11. ${ }^{13} \mathrm{C}$ NMR spectrum of FC substitution on $\mathrm{BPh}_{3}$ to generate substituted boranes (in $\mathrm{CDCl}_{3}, 101 \mathrm{MHz}$ ). Reaction conditions: $\mathrm{BPh}_{3}\left(0.2 \mathrm{~g}\right.$ ), $\mathrm{Cl}_{-} \mathrm{CH}_{2} \mathrm{CH}_{2} \mathrm{CH}_{3}$ $(2 \mathrm{~mL}), \mathrm{AlCl}_{3}(0.02 \mathrm{~g}),-20{ }^{\circ} \mathrm{C}$, remove the volatiles after 1 hour. The ${ }^{13} \mathrm{C}$ peaks at 14.2 , 23.2 and $38.5 \mathrm{ppm}$ belong to the n-propyl, and the ${ }^{13} \mathrm{C}$ peaks at 24.2 and $34.4 \mathrm{ppm}$ belong to the isopropyl.

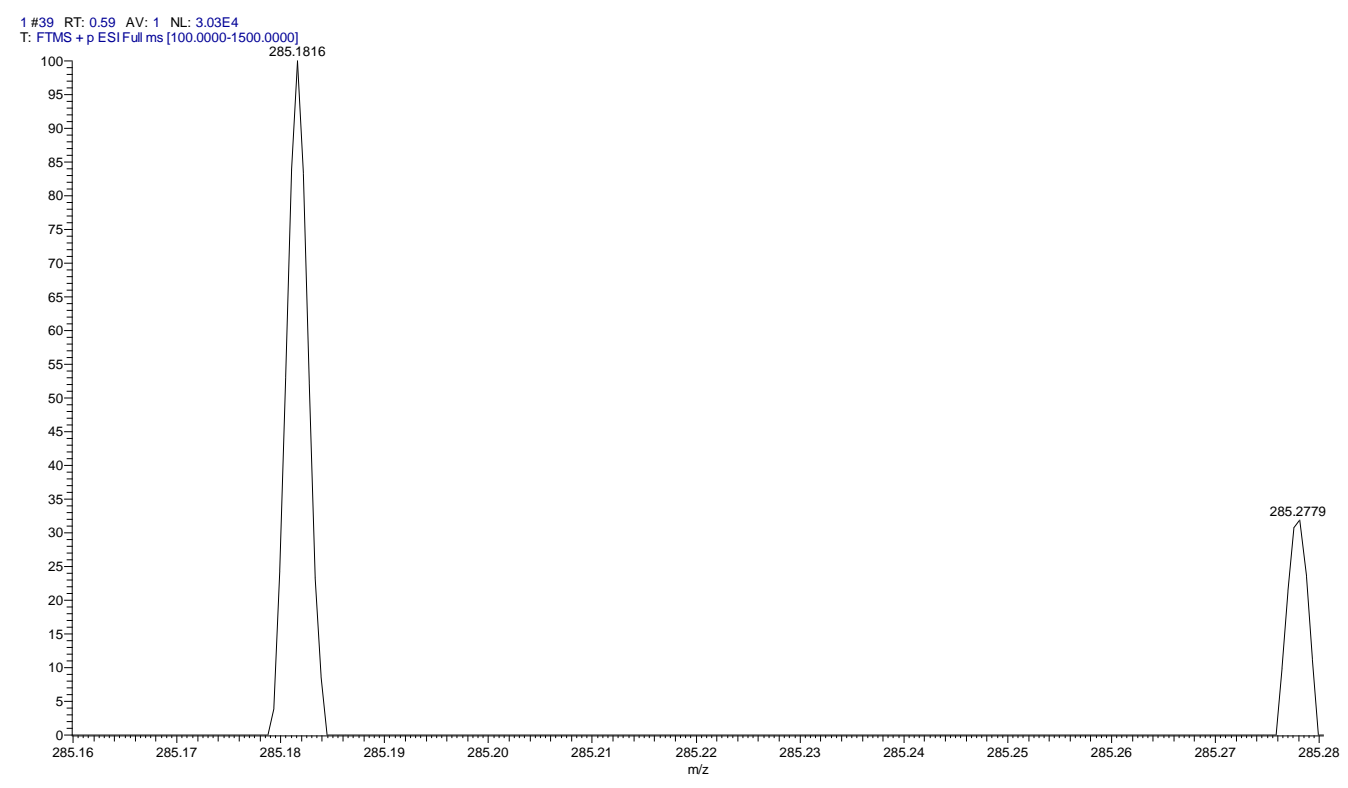

Figure S12. 1-substituted $\mathrm{B}\left(\mathrm{C}_{18} \mathrm{H}_{14}\right) \mathrm{C}_{3} \mathrm{H}_{7} \quad \mathrm{HRMS} \quad(\mathrm{m} / \mathrm{z}): \quad[\mathrm{M}+\mathrm{H}]^{+}$calcd for $\left[\mathrm{B}\left(\mathrm{C}_{18} \mathrm{H}_{14}\right) \mathrm{C}_{3} \mathrm{H}_{7} \mathrm{H}\right]^{+}, 285.1809$; found, 285.1816.

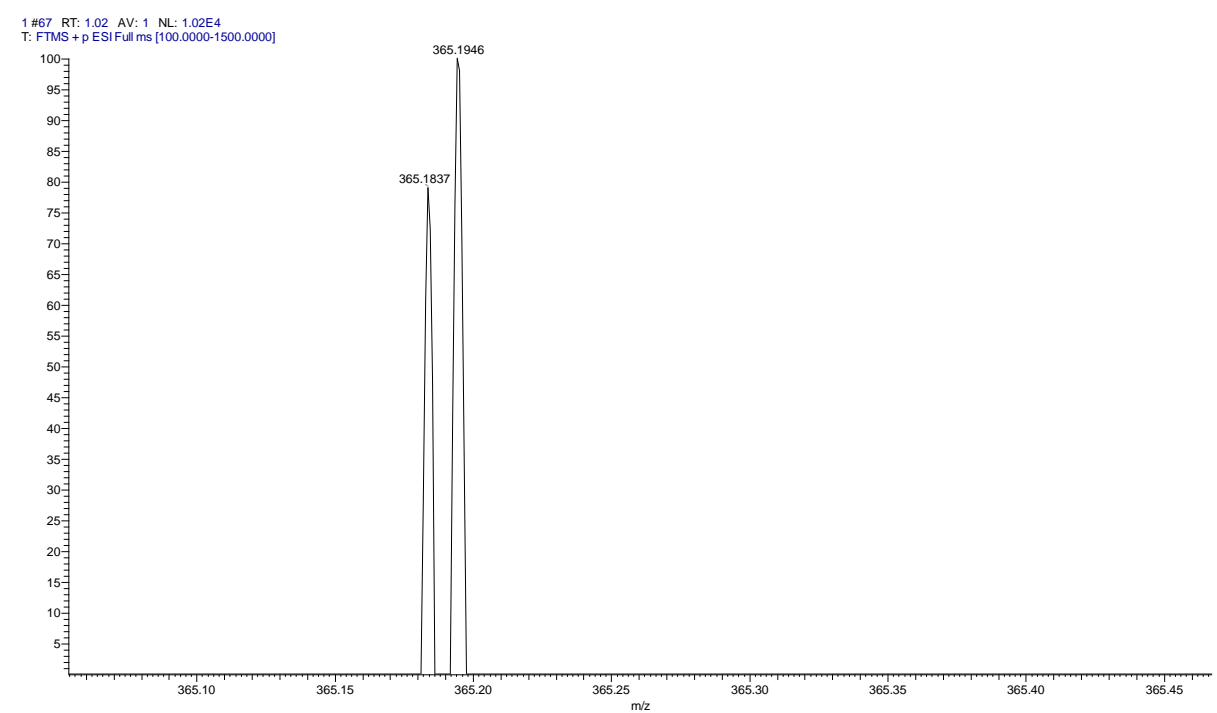

Figure S13. 2-substituted $\mathrm{B}\left(\mathrm{C}_{18} \mathrm{H}_{13}\right) \mathrm{C}_{6} \mathrm{H}_{14}$ HRMS (m/z): $[\mathrm{M}+\mathrm{K}]^{+}$calcd for $\left[\mathrm{B}\left(\mathrm{C}_{18} \mathrm{H}_{13}\right) \mathrm{C}_{6} \mathrm{H}_{14} \mathrm{~K}\right]^{+}, 365.1837$; found, 365.1837. 


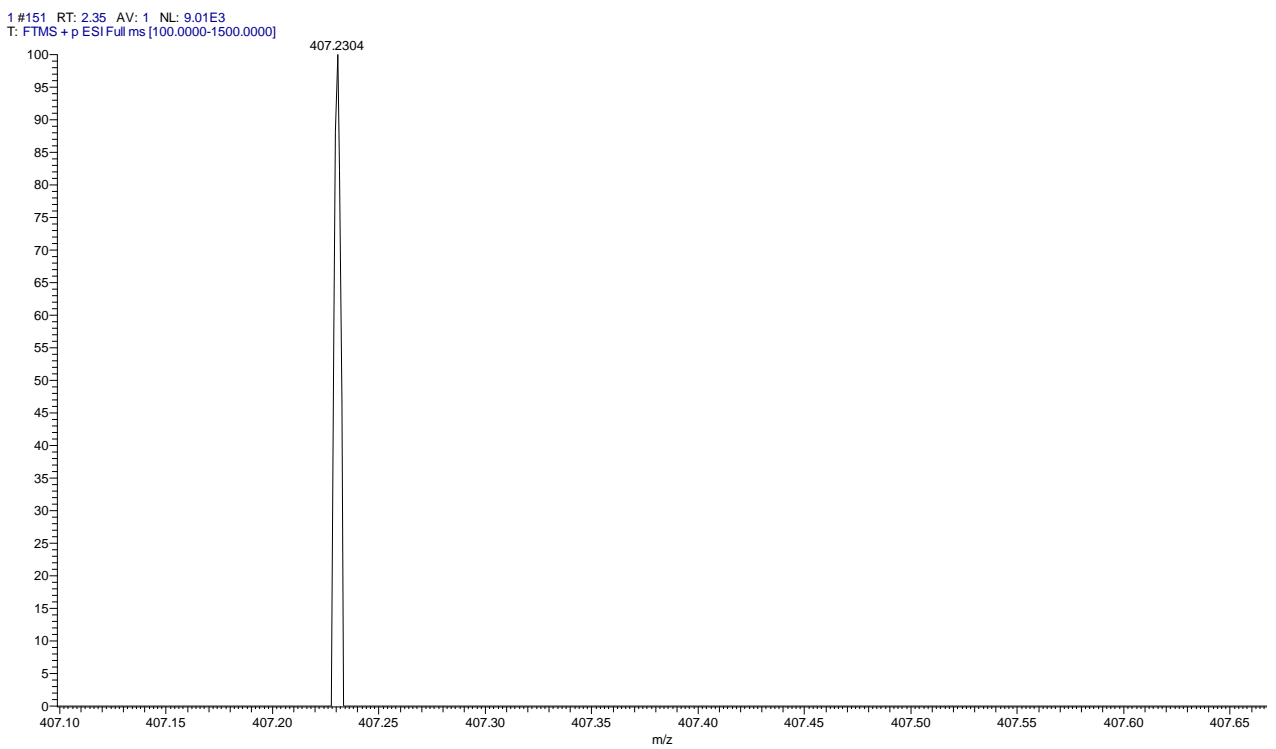

Figure S14. 3-substituted $\mathrm{B}\left(\mathrm{C}_{18} \mathrm{H}_{12}\right) \mathrm{C}_{9} \mathrm{H}_{21}$ HRMS $(\mathrm{m} / \mathrm{z}): \quad[\mathrm{M}+\mathrm{K}]^{+}$calcd for $\left[\mathrm{B}\left(\mathrm{C}_{18} \mathrm{H}_{12}\right) \mathrm{C}_{9} \mathrm{H}_{21} \mathrm{~K}\right]^{+}$, 407.2307; found, 407.2304.

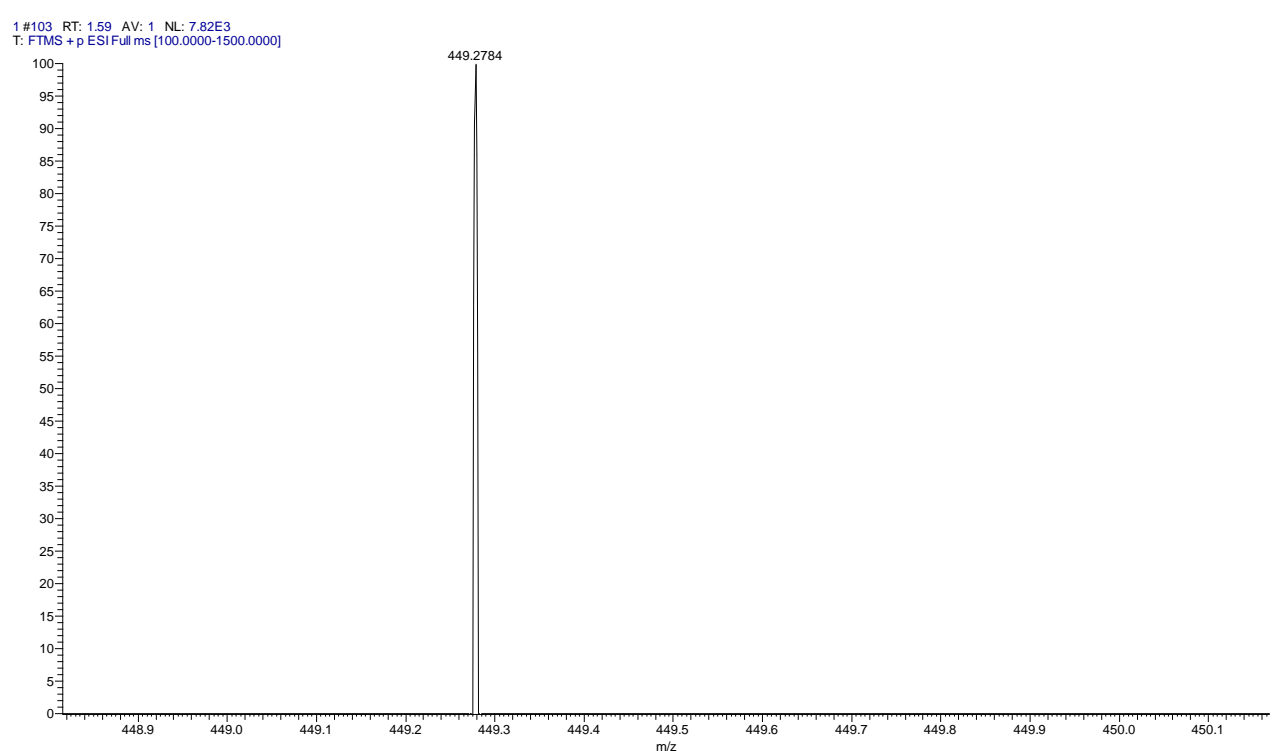

Figure S15. 4-substituted $\mathrm{B}\left(\mathrm{C}_{18} \mathrm{H}_{11}\right) \mathrm{C}_{12} \mathrm{H}_{28} \quad \mathrm{HRMS} \quad(\mathrm{m} / \mathrm{z}):[\mathrm{M}+\mathrm{K}]^{+}$calcd for $\left[\mathrm{B}\left(\mathrm{C}_{18} \mathrm{H}_{11}\right) \mathrm{C}_{12} \mathrm{H}_{28} \mathrm{~K}\right]^{+}$, 449.2776; found, 449.2784.

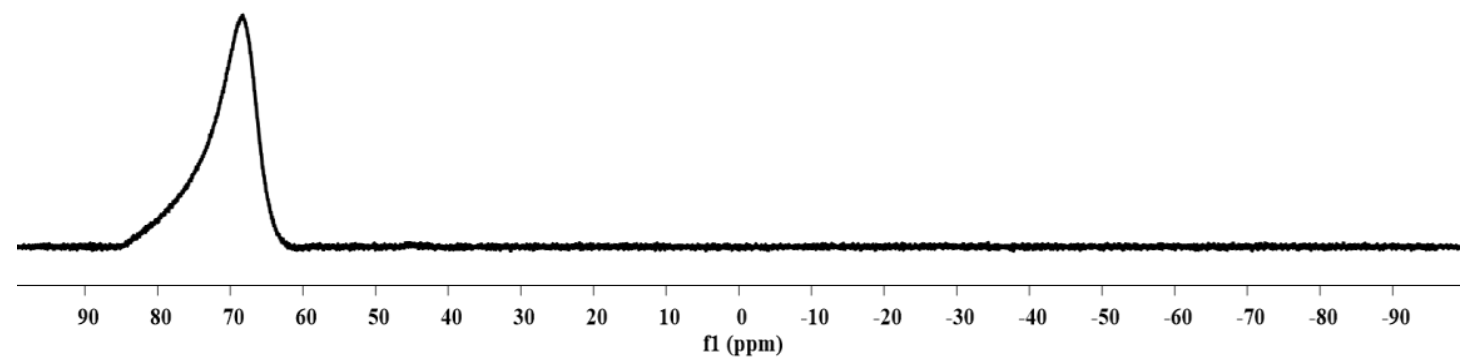

Figure S16. ${ }^{11} \mathrm{~B}$ NMR spectrum of the $\mathrm{BPh}_{3}$ after exposing to $\mathrm{HCl}$ atmosphere for 3 hours (in $\mathrm{CDCl}_{3}, 128 \mathrm{MHz}$ ). 


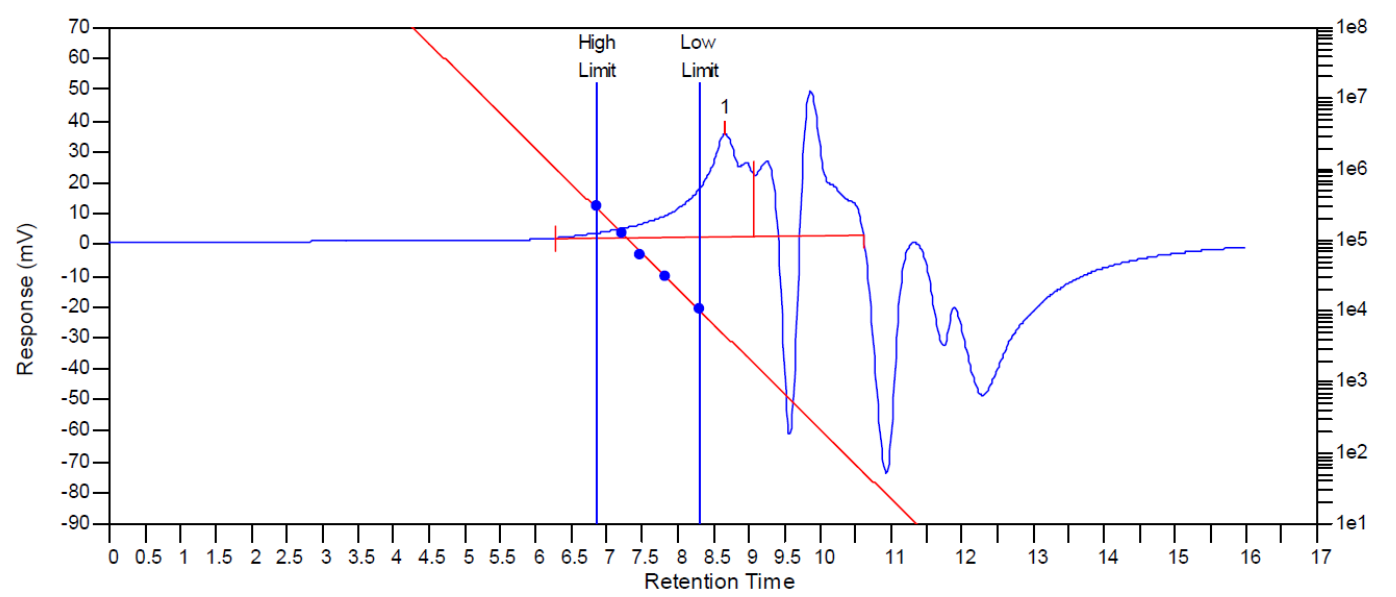

Figure S17. The Gel Permeation Chromatography data of $\mathrm{P}-\mathrm{BPh}_{3}$. Sample preparation method: the $\mathrm{P}-\mathrm{BPh}_{3} / \mathrm{DMF}$ system was placed in a autoclave for 48 hours $\left(200^{\circ} \mathrm{C}\right.$ /8MPa), and the insoluble matter was removed by the filter membrane.

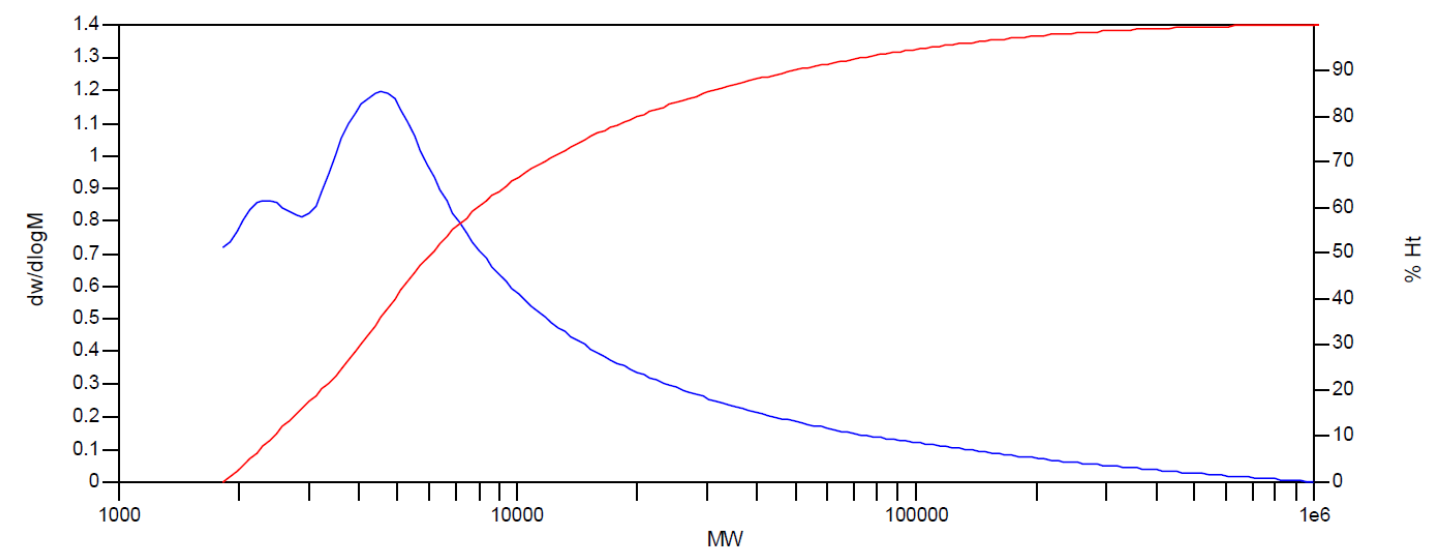

MW Averages

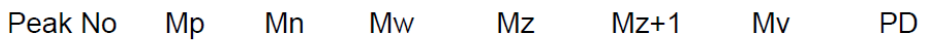

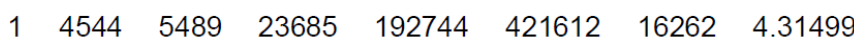

Figure S18. The molecular weight distribution plots of $\mathrm{P}-\mathrm{BPh}_{3}$. 


\section{Original NMR spectra}

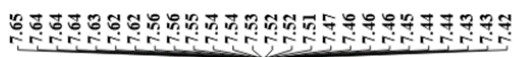
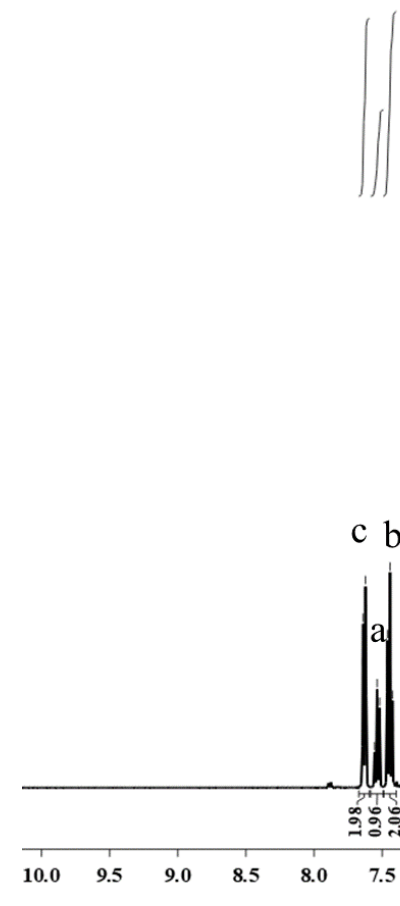

$\mathrm{c} b$

Figure $\mathrm{S} 19 .{ }^{1} \mathrm{H} \mathrm{NMR}$ spectrum of the $\mathrm{BPh}_{3}$ (in $\mathrm{CDCl}_{3}, 400 \mathrm{MHz}$ ).

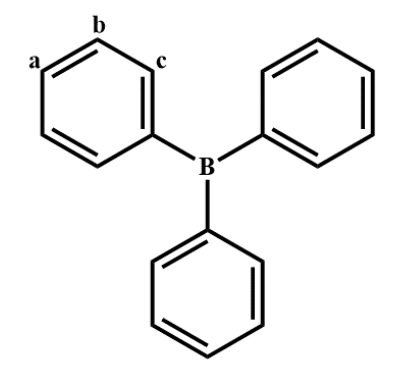

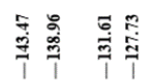

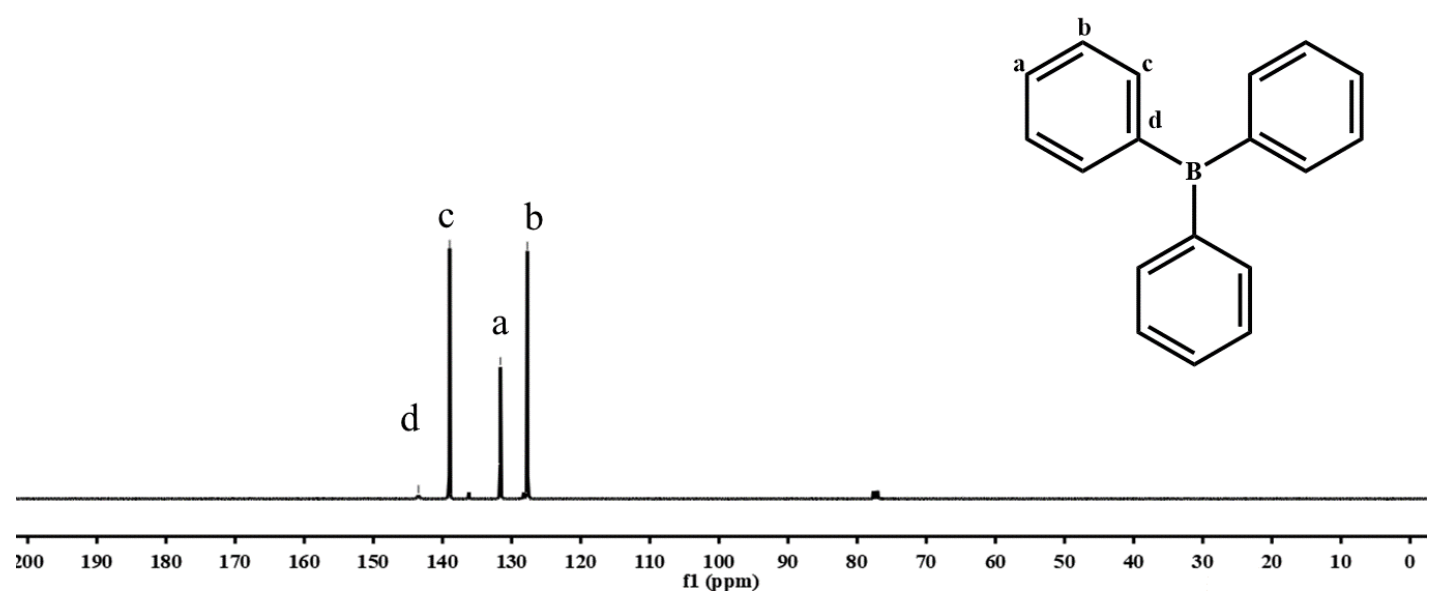

Figure $\mathrm{S} 20 .{ }^{13} \mathrm{C}$ NMR spectrum of the $\mathrm{BPh}_{3}\left(\right.$ in $\mathrm{CDCl}_{3}, 101 \mathrm{MHz}$ ). 


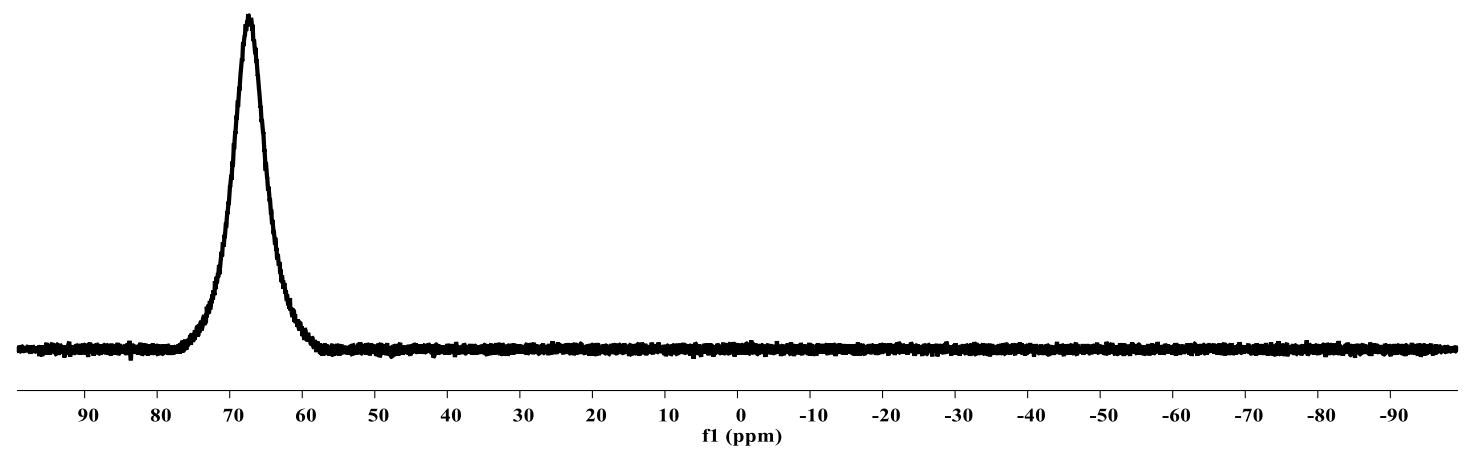

Figure $\mathrm{S} 21 .{ }^{11} \mathrm{~B}$ NMR spectrum of the $\mathrm{BPh}_{3}\left(\right.$ in $\mathrm{CDCl}_{3}, 128 \mathrm{MHz}$ ).

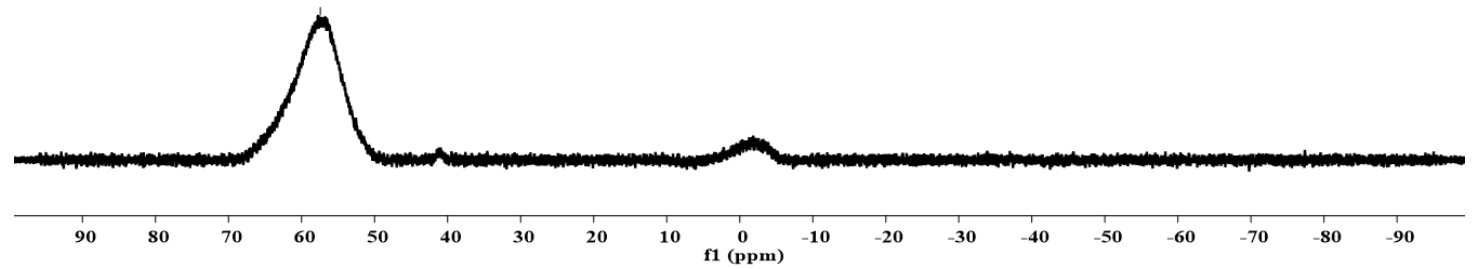

Figure $\mathrm{S} 22 .{ }^{11} \mathrm{~B}$ NMR spectrum of the $\mathrm{B}\left(\mathrm{C}_{6} \mathrm{~F}_{5}\right)_{3}$ (in $\mathrm{CDCl}_{3}, 128 \mathrm{MHz}$ ). 


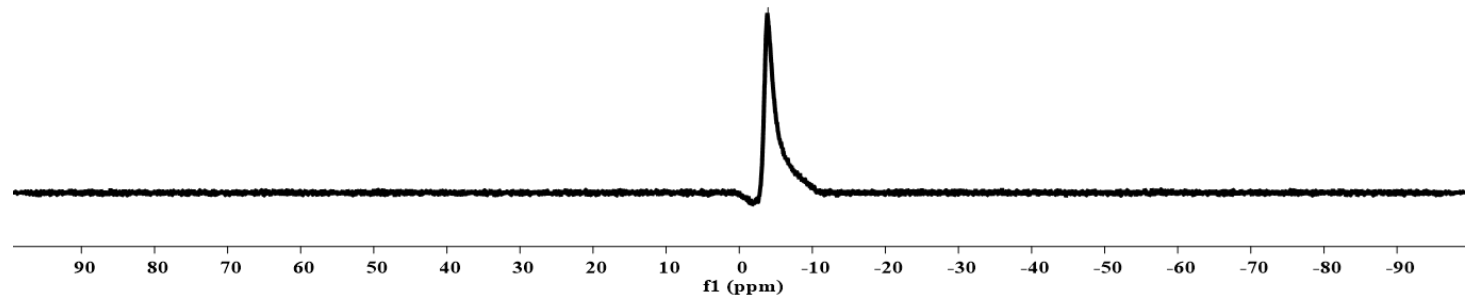

Figure $\mathrm{S} 23 .{ }^{11} \mathrm{~B}$ NMR spectrum of the $\mathrm{B}\left(\mathrm{C}_{6} \mathrm{~F}_{5}\right)_{3}$ in the presence of equivalent $\mathrm{Py}$ (in $\mathrm{CDCl}_{3}, 128 \mathrm{MHz}$ ).

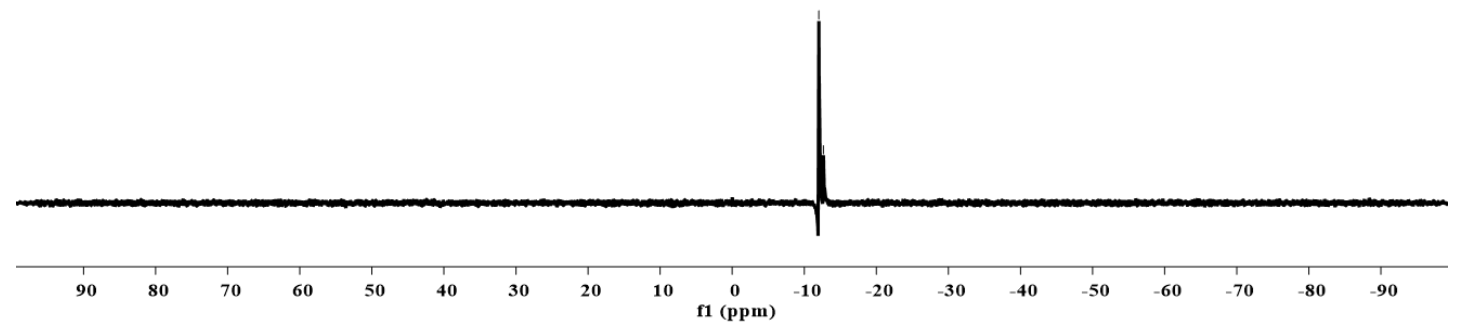

Figure $\mathrm{S} 24 .{ }^{11} \mathrm{~B}$ NMR spectrum of the $\mathrm{B}\left(\mathrm{C}_{6} \mathrm{~F}_{5}\right)_{3}$ in the presence of equivalent $\mathrm{Ph}-\mathrm{C} \equiv \mathrm{CH}$ (in $\left.\mathrm{CDCl}_{3}, 128 \mathrm{MHz}\right)$. 


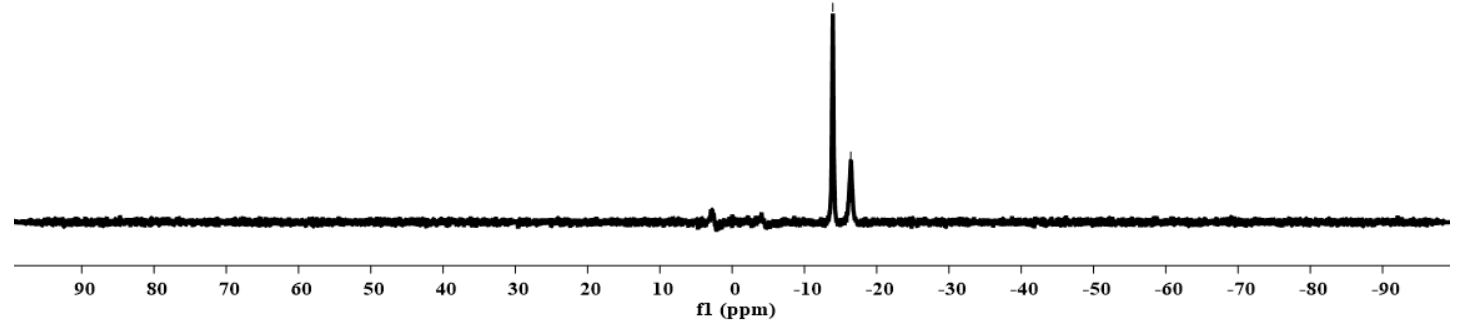

Figure $\mathrm{S} 25 .{ }^{11} \mathrm{~B}$ NMR spectrum of the $\mathrm{B}\left(\mathrm{C}_{6} \mathrm{~F}_{5}\right)_{3}$ in the presence of equivalent $\mathrm{Py}$ and $\mathrm{Ph}-\mathrm{C} \equiv \mathrm{CH}$ respectively (in $\mathrm{CDCl}_{3}, 128 \mathrm{MHz}$ ). 


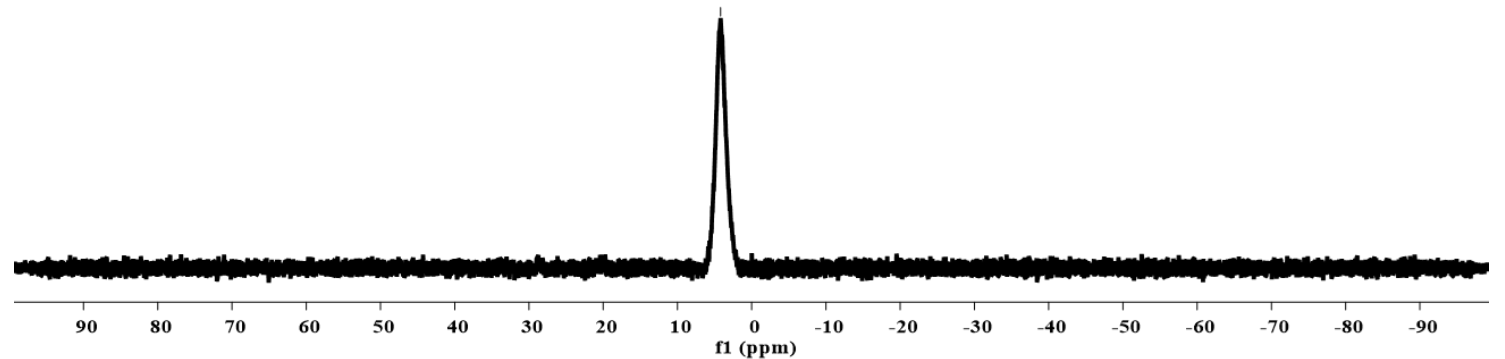

Figure $\mathrm{S} 26 .{ }^{11} \mathrm{~B}$ NMR spectrum of the $\mathrm{BPh}_{3}$ in the presence of equivalent $\mathrm{Py}$ (in $\left.\mathrm{CDCl}_{3}, 128 \mathrm{MHz}\right)$.

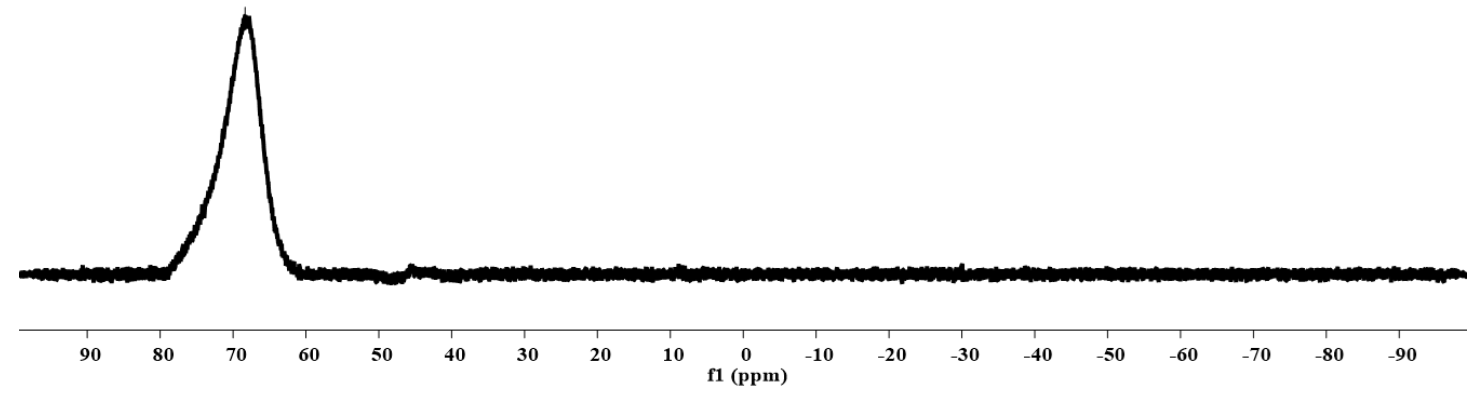

Figure $\mathrm{S} 27 .{ }^{11} \mathrm{~B}$ NMR spectrum of the $\mathrm{BPh}_{3}$ in the presence of equivalent $\mathrm{Ph}-\mathrm{C} \equiv \mathrm{CH}$ 
(in $\mathrm{CDCl}_{3}, 128 \mathrm{MHz}$ ).

$\stackrel{乛}{+}$

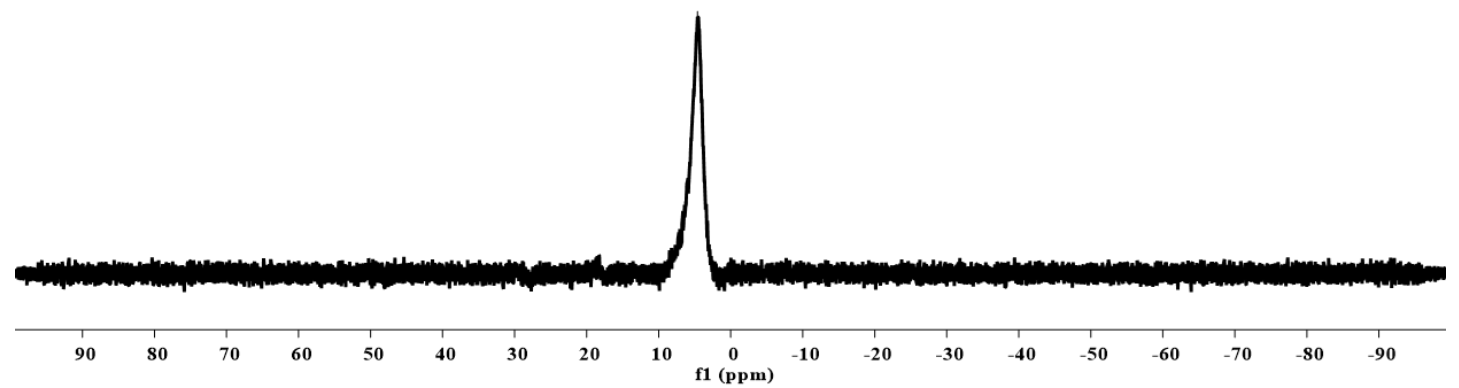

Figure S28. ${ }^{11} \mathrm{~B}$ NMR spectrum of the $\mathrm{BPh}_{3}$ in the presence of equivalent $\mathrm{Py}$ and $\mathrm{Ph}-\mathrm{C} \equiv \mathrm{CH}$ (in $\left.\mathrm{CDCl}_{3}, 128 \mathrm{MHz}\right)$. 


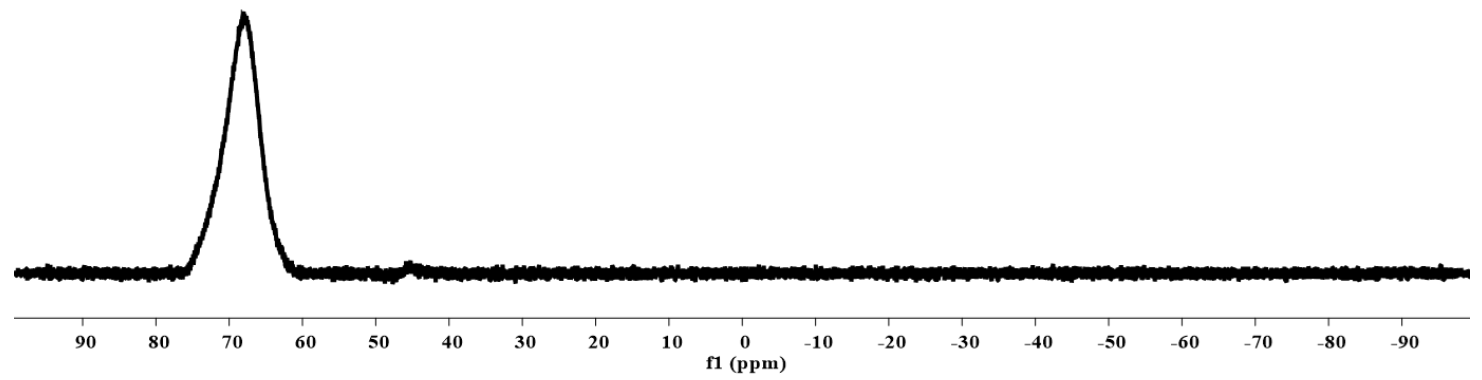

Figure S29. ${ }^{11} \mathrm{~B}$ NMR spectrum of the $\mathrm{BPh}_{3}$ after $120{ }^{\circ} \mathrm{C}$ for 12 hours (in $\mathrm{CDCl}_{3}, 128$ $\mathrm{MHz})$.

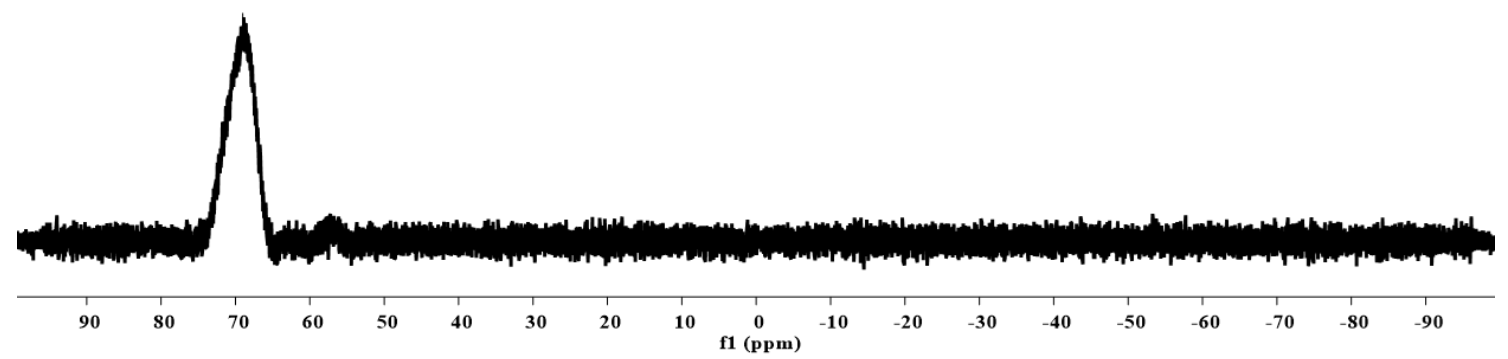


Figure $\mathrm{S} 30 .{ }^{11} \mathrm{~B}$ NMR spectrum of the $\mathrm{BPh}_{3}$ in the presence of equivalent $\mathrm{Ph}-\mathrm{C} \equiv \mathrm{CH}$ after $120^{\circ} \mathrm{C}$ for 12 hours (in $\mathrm{CDCl}_{3}, 128 \mathrm{MHz}$ ).

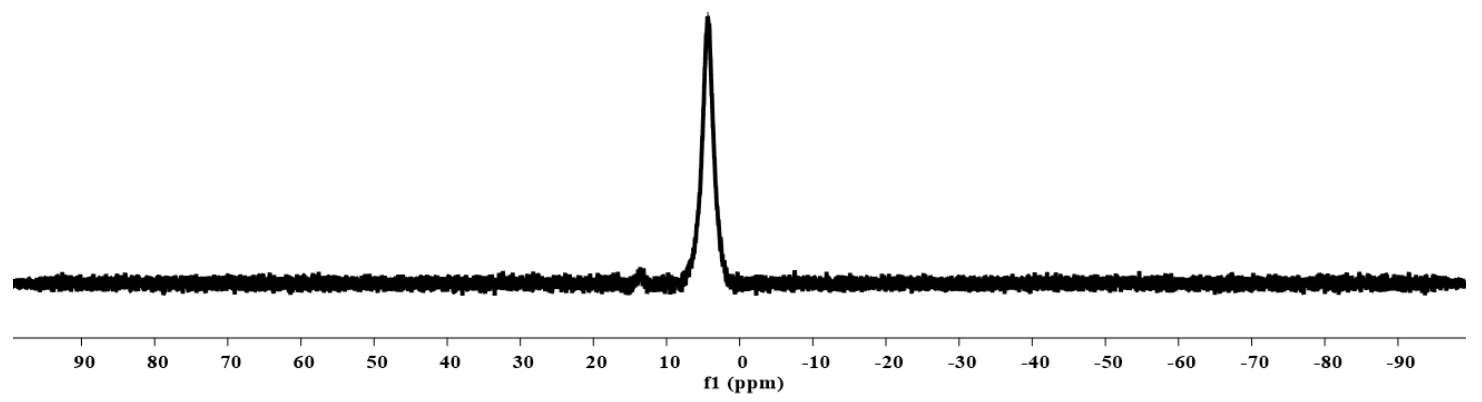

Figure $\mathrm{S} 31 .{ }^{11} \mathrm{~B}$ NMR spectrum of the $\mathrm{BPh}_{3}$ in the presence of equivalent $\mathrm{Py}$ after $120{ }^{\circ} \mathrm{C}$ for 12 hours (in $\mathrm{CDCl}_{3}, 128 \mathrm{MHz}$ ). 


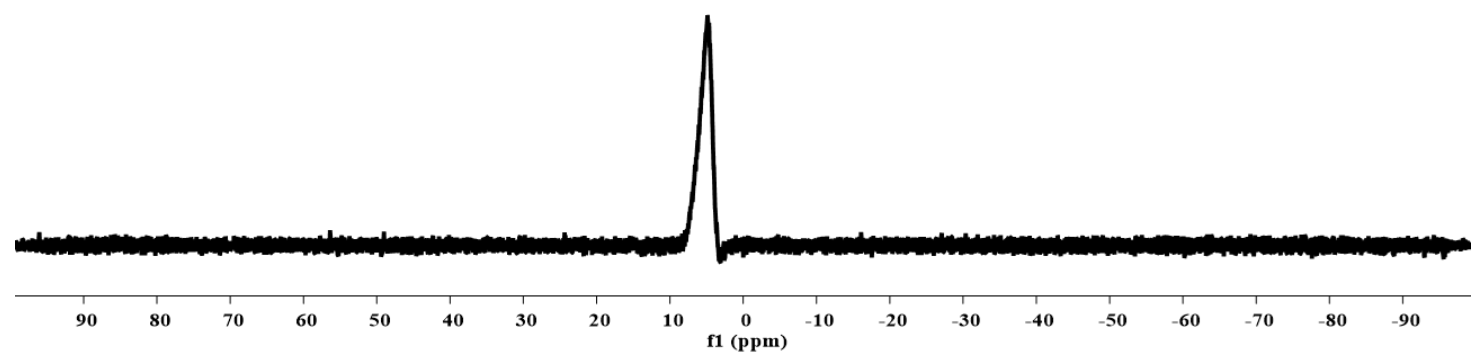

Figure $\mathrm{S} 32 .{ }^{11} \mathrm{~B}$ NMR spectrum of the $\mathrm{BPh}_{3}$ in the presence of equivalent $\mathrm{Py}$ and $\mathrm{Ph}-\mathrm{C} \equiv \mathrm{CH}$ after $120{ }^{\circ} \mathrm{C}$ for 12 hours (in $\mathrm{CDCl}_{3}, 128 \mathrm{MHz}$ ).

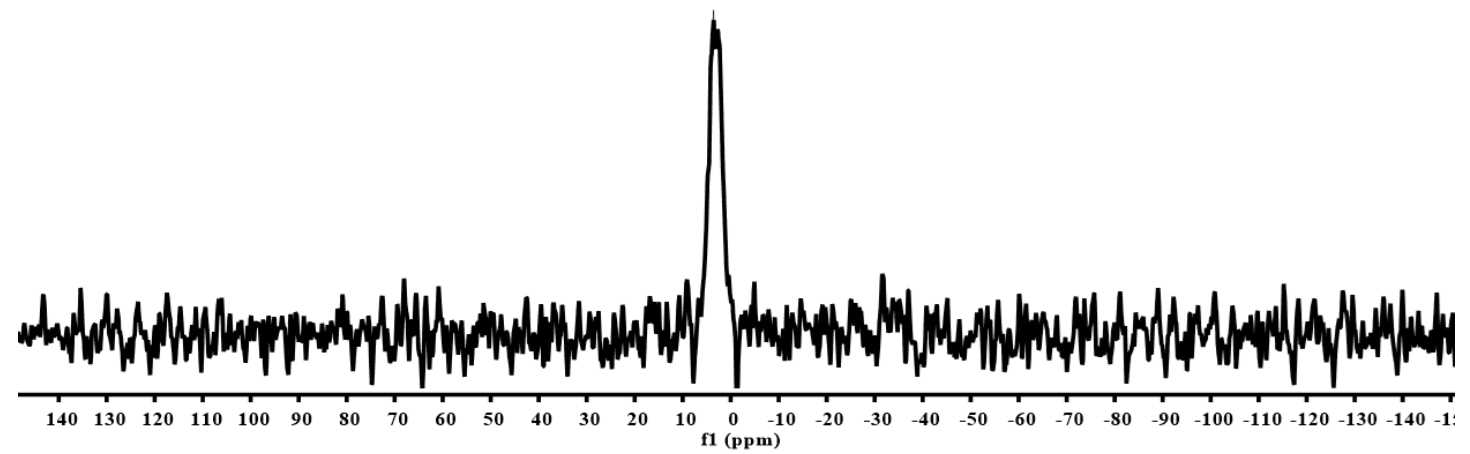


Figure S33. Solid-state ${ }^{11} \mathrm{~B}$ NMR spectrum of $\mathrm{P}-\mathrm{BPh}_{3} / \mathrm{Py}$. The sample was obtained by stirring the mixture $\mathrm{P}-\mathrm{BPh}_{3}$ and $\mathrm{Py}$ overnight at room temperature and then excess Py was removed under vacuum.

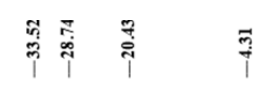

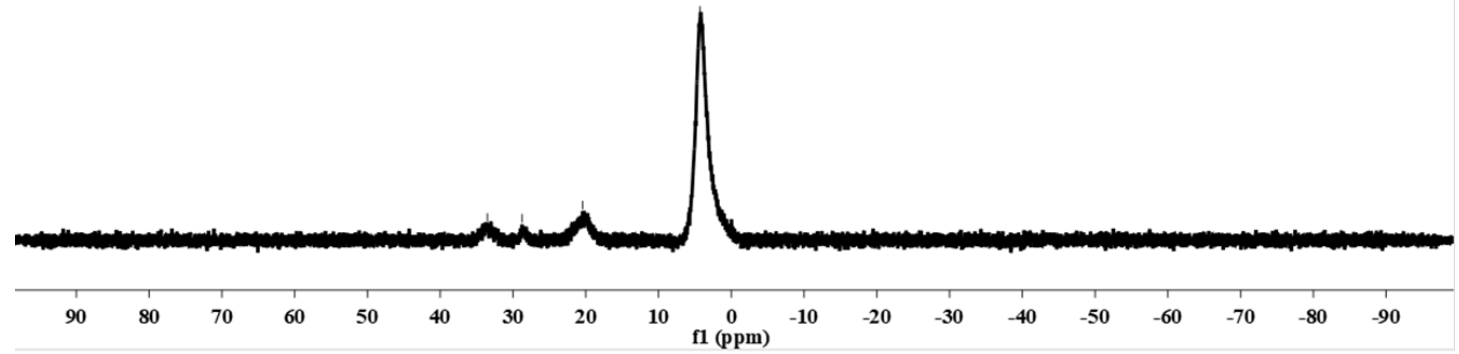

Figure S34. ${ }^{11} \mathrm{~B}$ NMR spectrum of the $\mathrm{BPh}_{3} / \mathrm{Py}$ after hydrogenation (in $\mathrm{CDCl}_{3}, 128$ $\mathrm{MHz})$. 


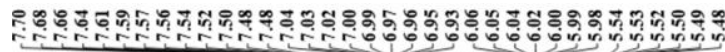
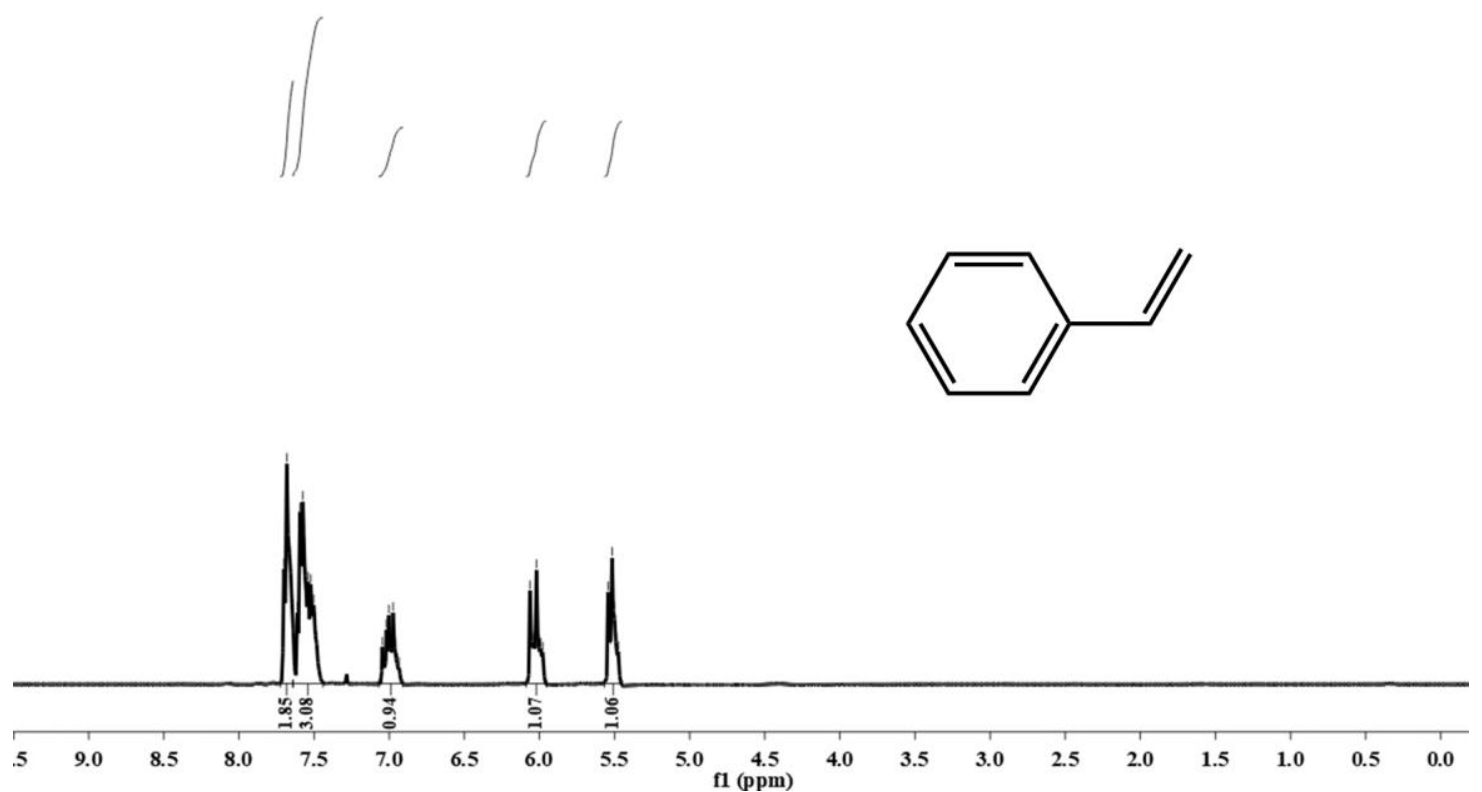

Figure S35. ${ }^{1} \mathrm{H}$ NMR spectrum of the $\mathrm{Ph}-\mathrm{CH}=\mathrm{CH}_{2}\left(\right.$ in $\mathrm{CDCl}_{3}, 400 \mathrm{MHz}$ ).
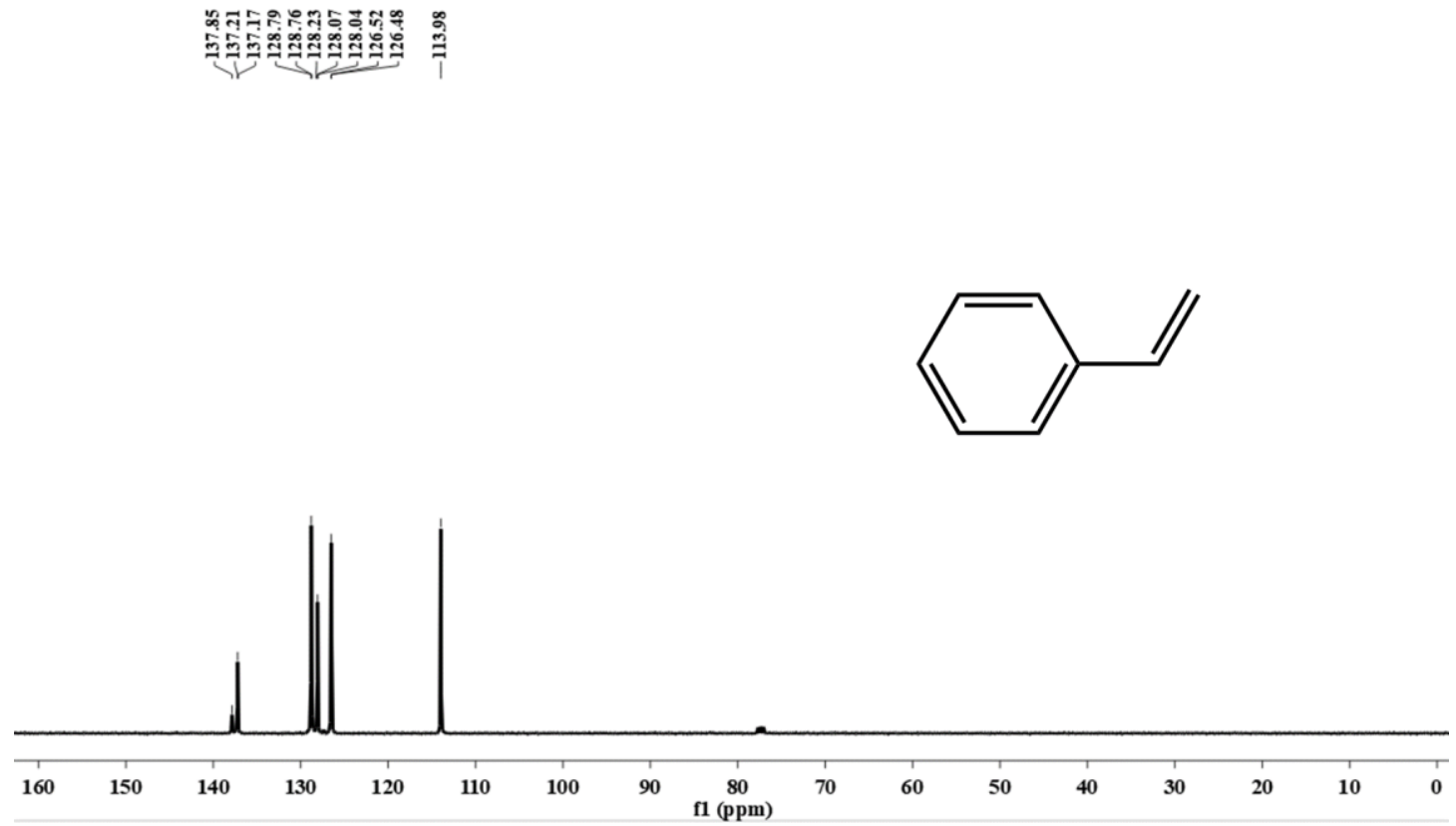

Figure $\mathrm{S} 36 .{ }^{13} \mathrm{C} \mathrm{NMR}$ spectrum of the $\mathrm{Ph}-\mathrm{CH}=\mathrm{CH}_{2}\left(\right.$ in $\left.\mathrm{CDCl}_{3}, 101 \mathrm{MHz}\right)$. 


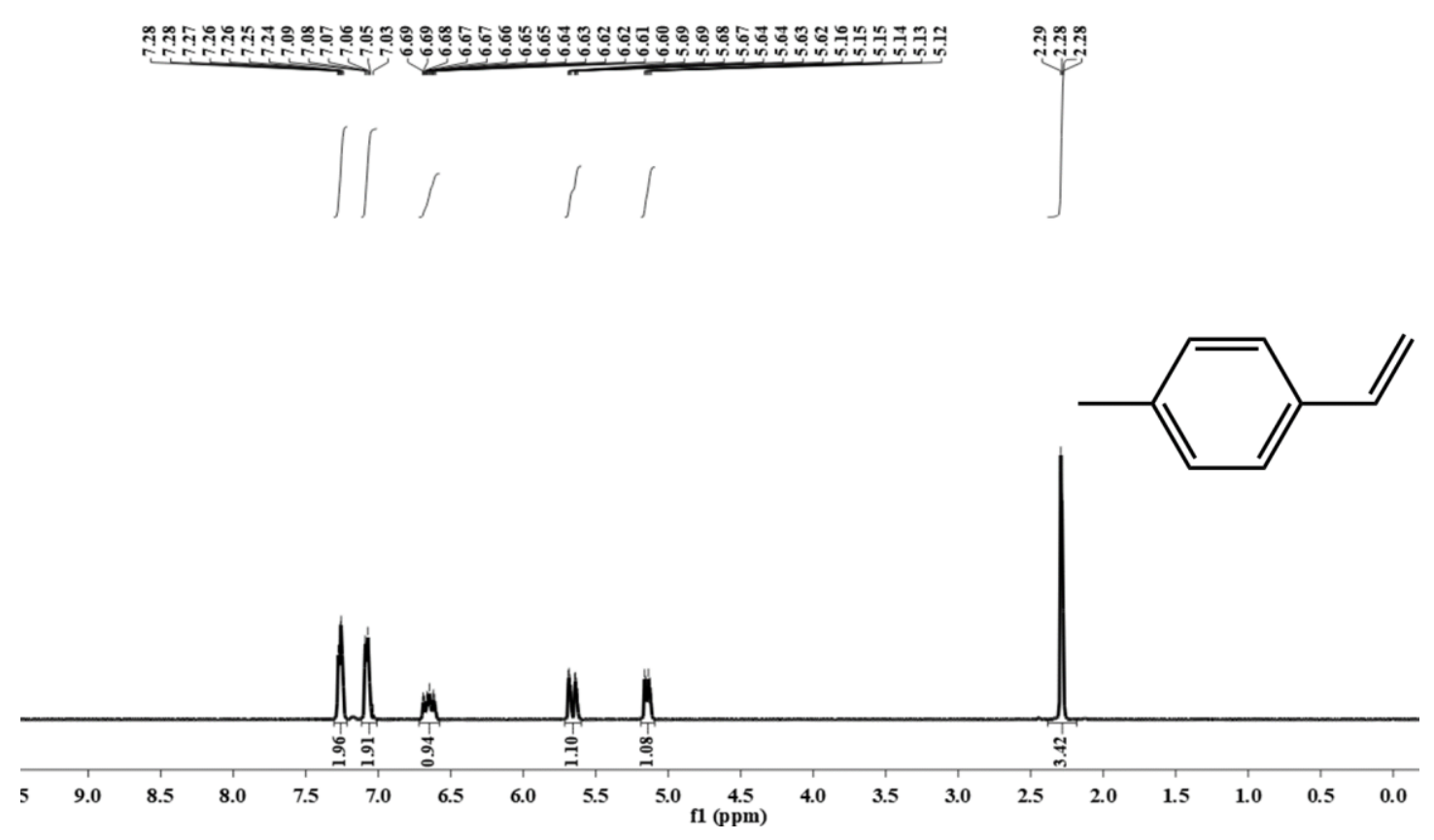

Figure S37. ${ }^{1} \mathrm{H}$ NMR spectrum of the $4-\mathrm{CH}_{3}-\mathrm{Ph}-\mathrm{CH}=\mathrm{CH}_{2}$ (in $\mathrm{CDCl}_{3}, 400 \mathrm{MHz}$ ).
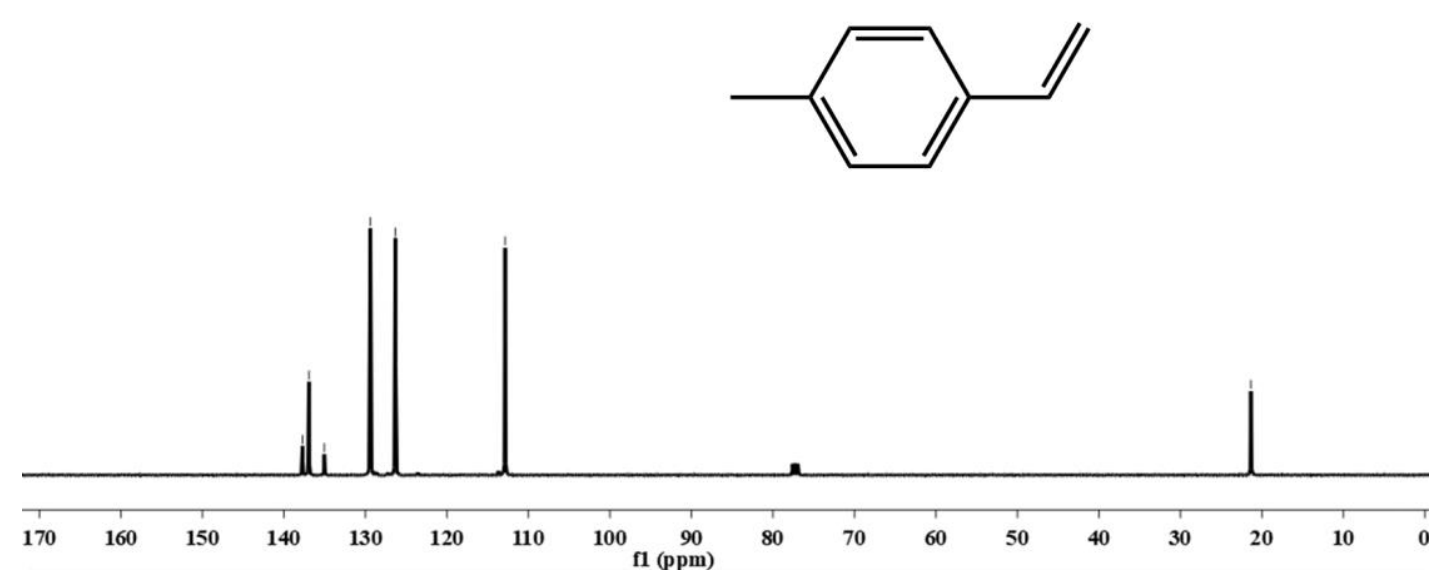

Figure $\mathrm{S} 38 .{ }^{13} \mathrm{C}$ NMR spectrum of the $4-\mathrm{CH}_{3}-\mathrm{Ph}-\mathrm{CH}=\mathrm{CH}_{2}$ (in $\mathrm{CDCl}_{3}, 101 \mathrm{MHz}$ ). 


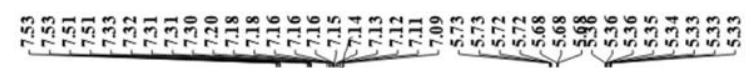

$\int 1$
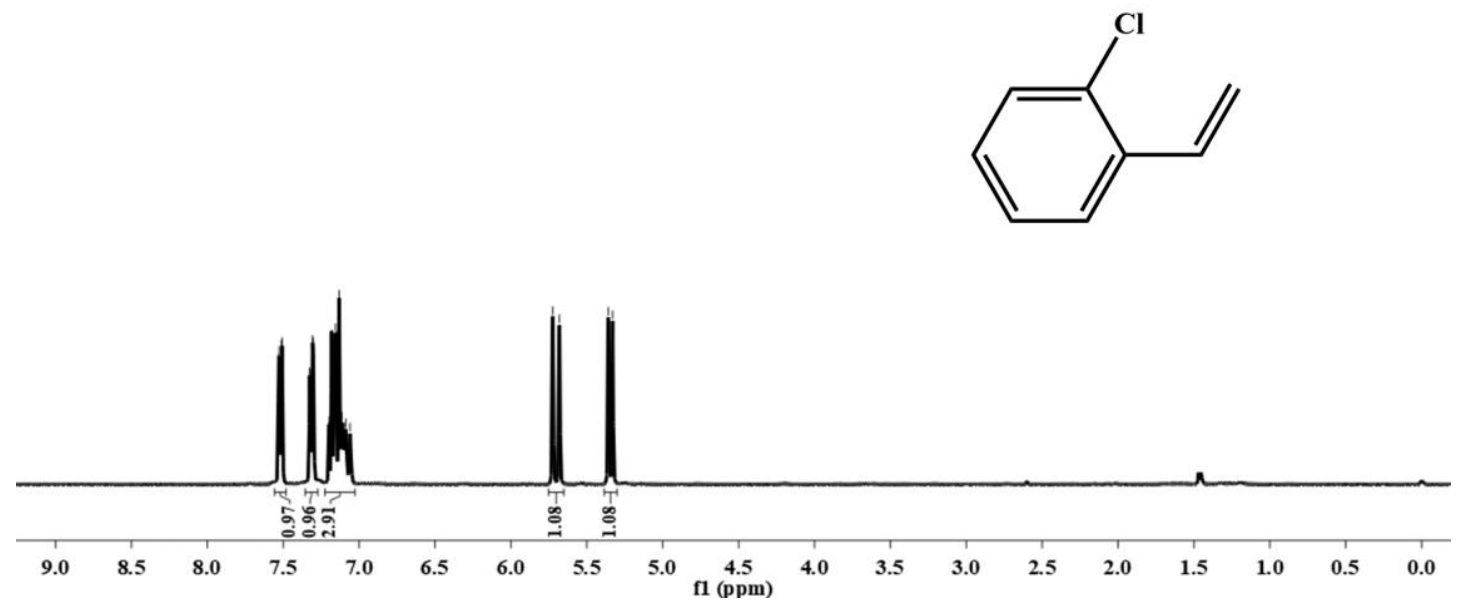

Figure $\mathrm{S} 39 .{ }^{1} \mathrm{H}$ NMR spectrum of the $2-\mathrm{Cl}-\mathrm{Ph}-\mathrm{CH}=\mathrm{CH}_{2}$ (in $\mathrm{CDCl}_{3}, 400 \mathrm{MHz}$ ).

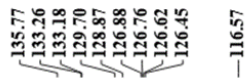
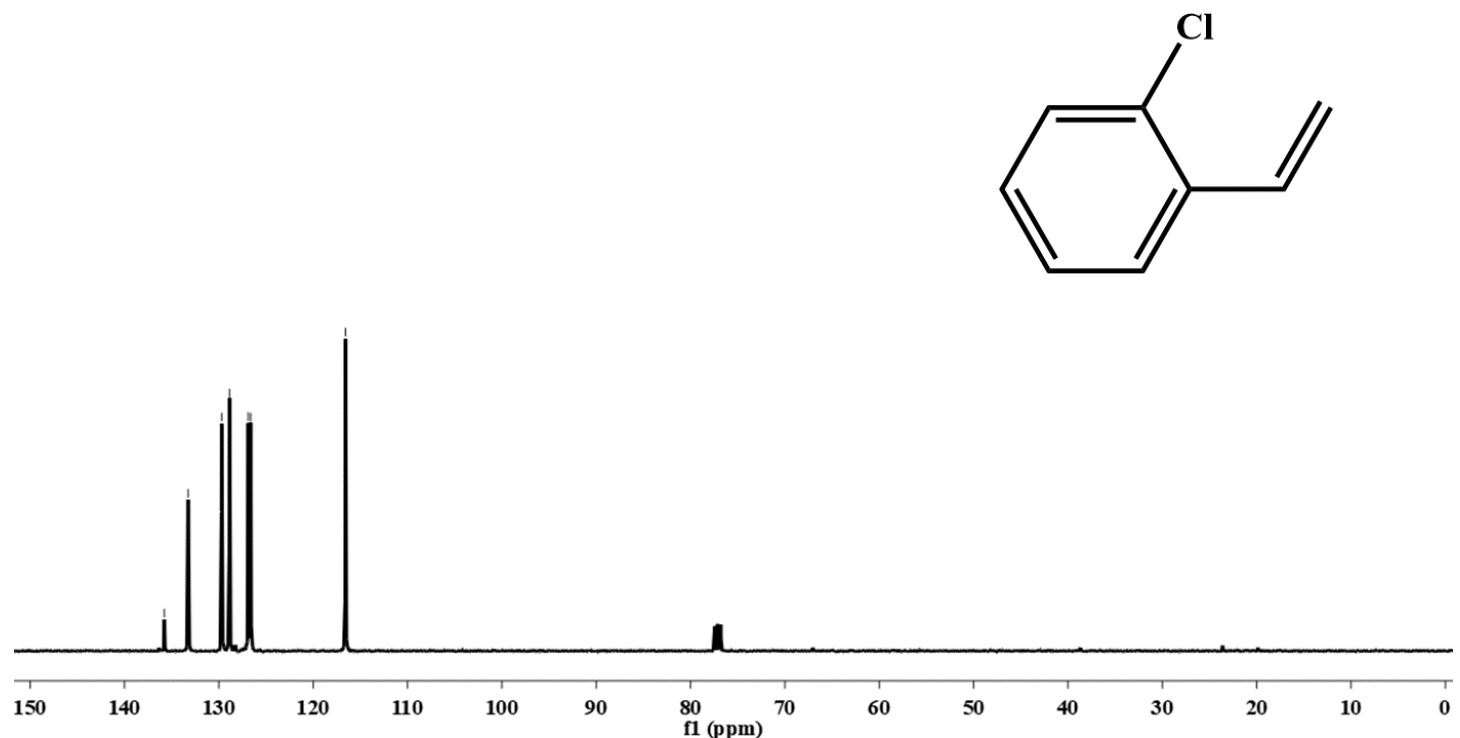

Figure $\mathrm{S} 40 .{ }^{13} \mathrm{C}$ NMR spectrum of the 2-Cl-Ph- $\mathrm{CH}=\mathrm{CH}_{2}$ (in $\mathrm{CDCl}_{3}, 101 \mathrm{MHz}$ ). 


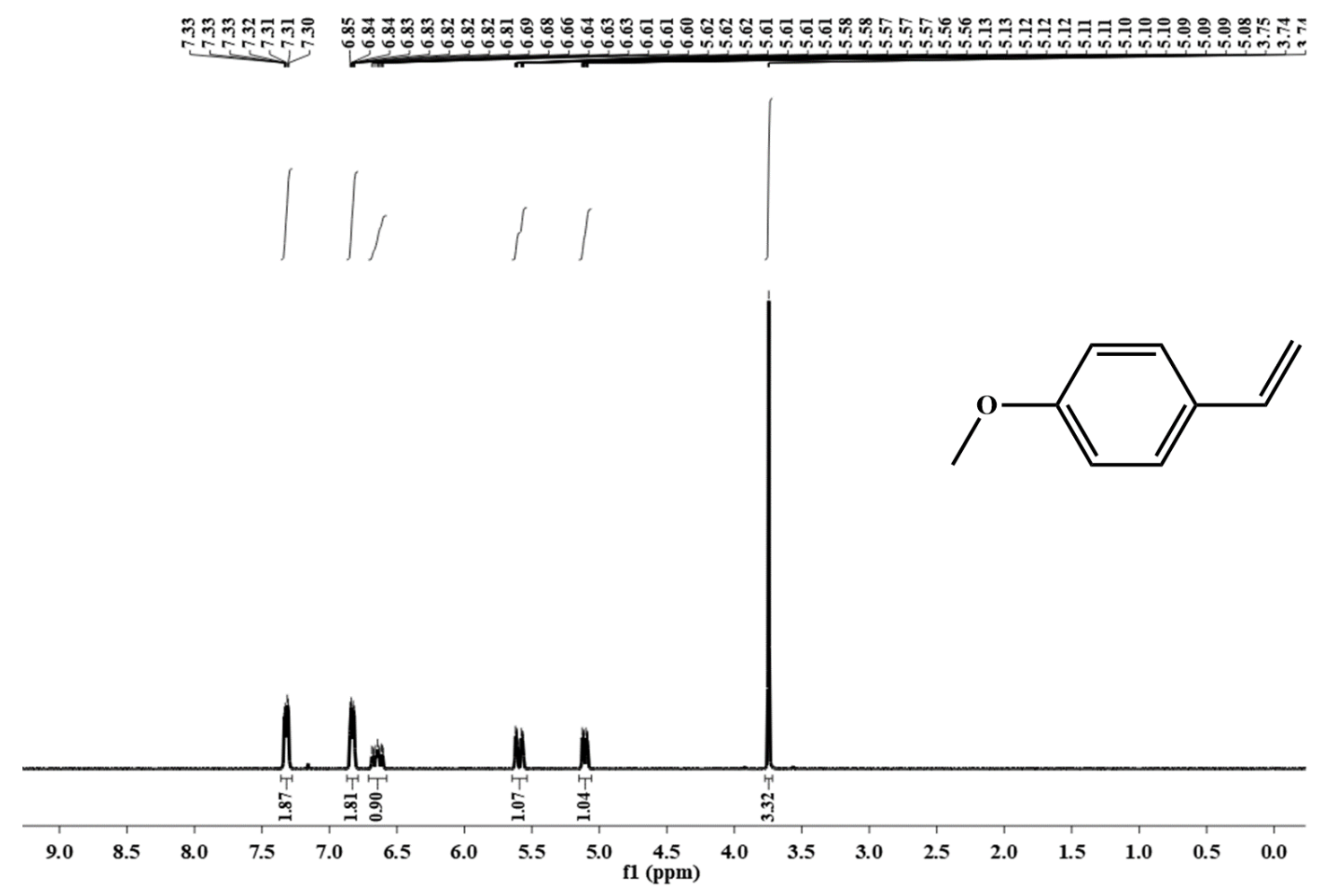

Figure S41. ${ }^{1} \mathrm{H}$ NMR spectrum of the $4-\mathrm{CH}_{3}-\mathrm{O}-\mathrm{Ph}-\mathrm{CH}=\mathrm{CH}_{2}\left(\right.$ in $\mathrm{CDCl}_{3}, 400 \mathrm{MHz}$ ).
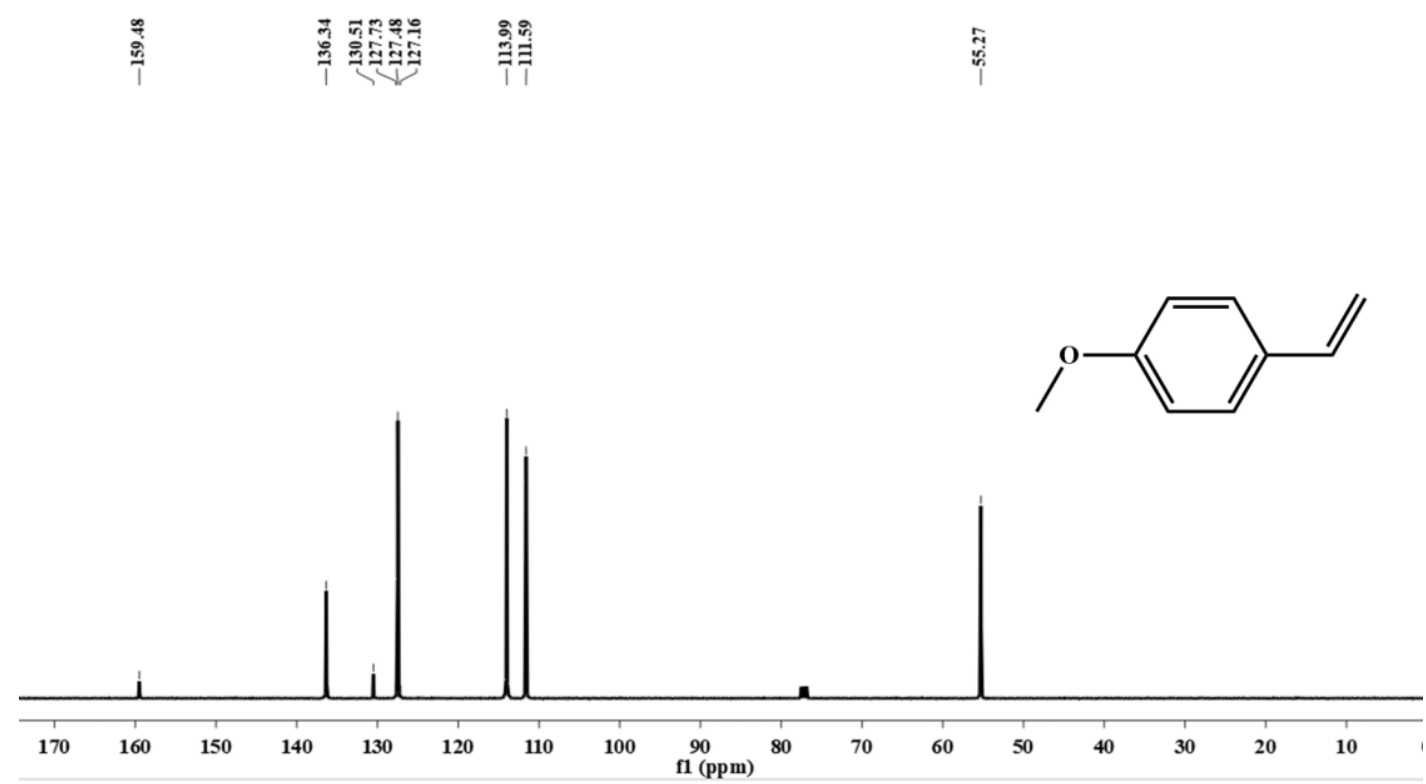

Figure $\mathrm{S} 42 .{ }^{13} \mathrm{C}$ NMR spectrum of the $4-\mathrm{CH}_{3}-\mathrm{O}-\mathrm{Ph}-\mathrm{CH}=\mathrm{CH}_{2}\left(\right.$ in $\left.\mathrm{CDCl}_{3}, 101 \mathrm{MHz}\right)$. 


\section{Original MS data}

1.
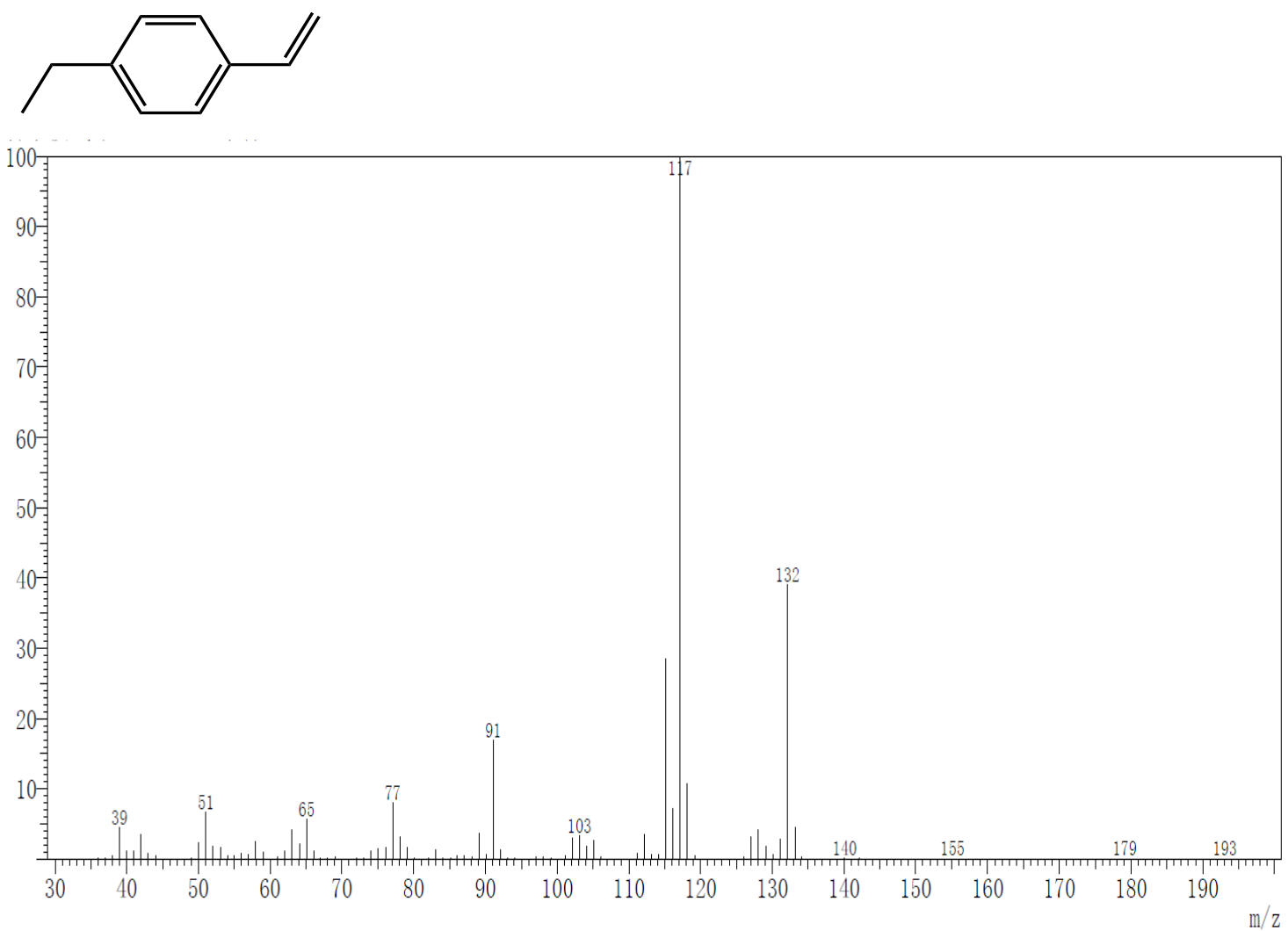

2.
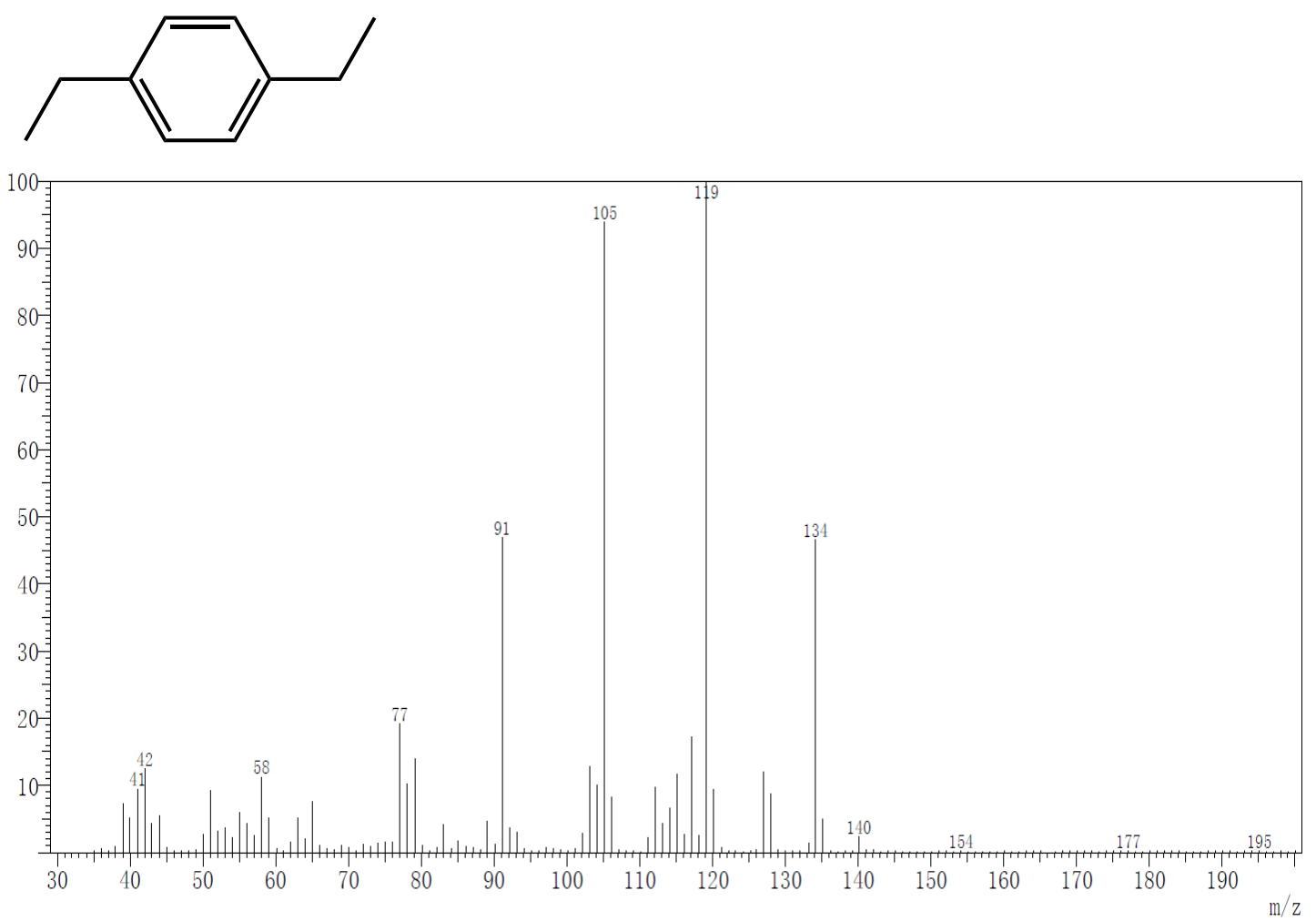
3.
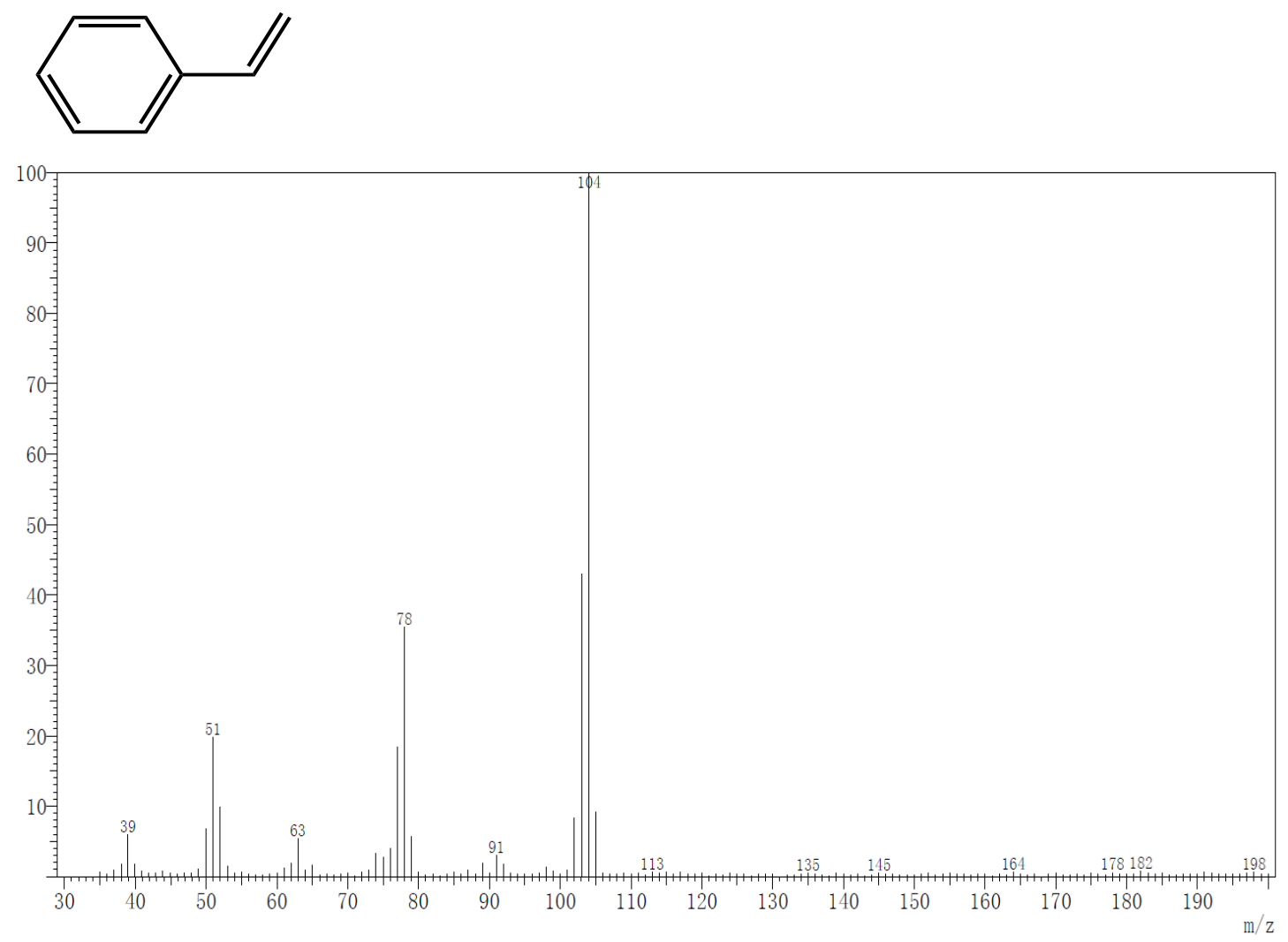

4.
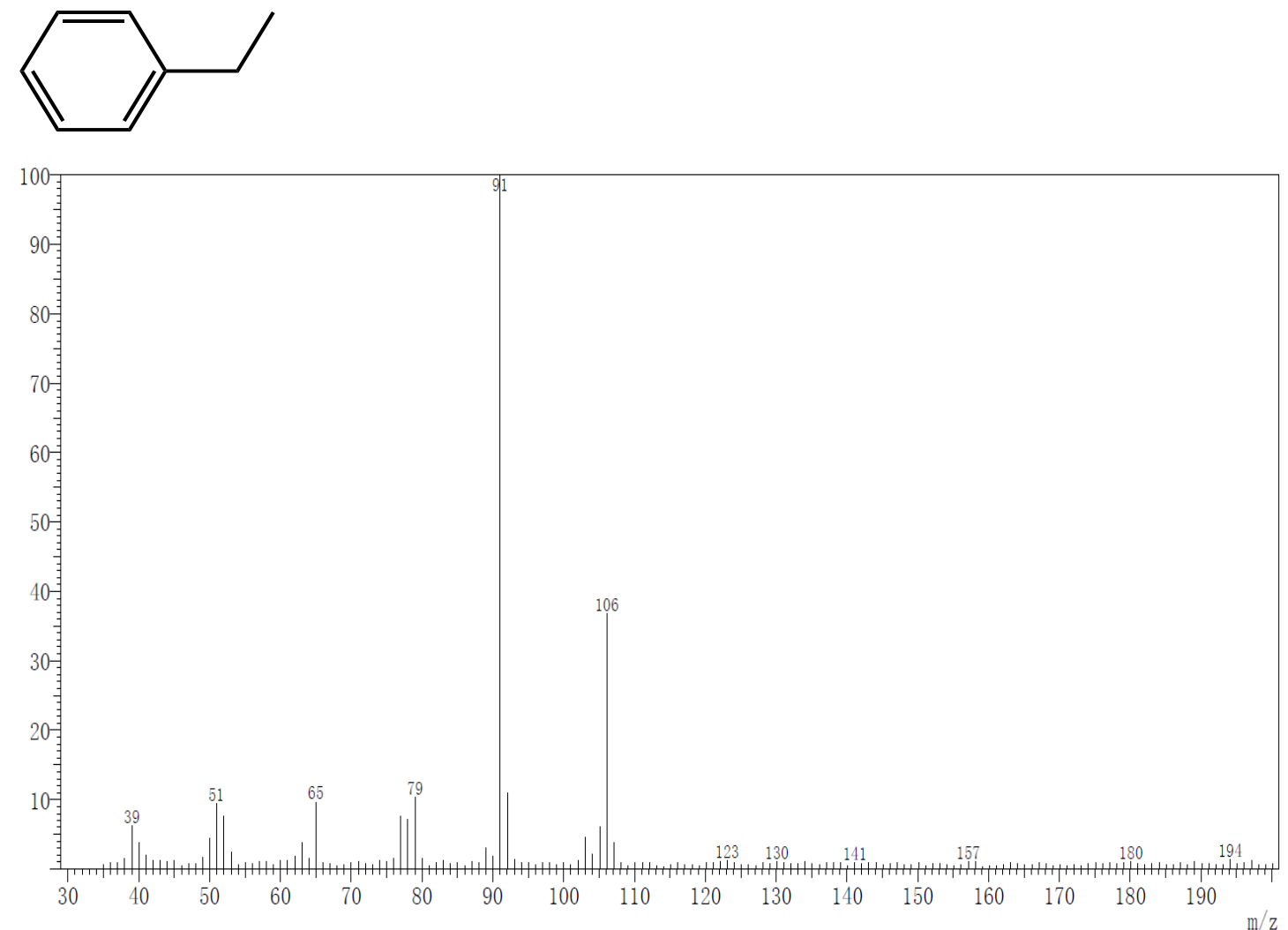
5.
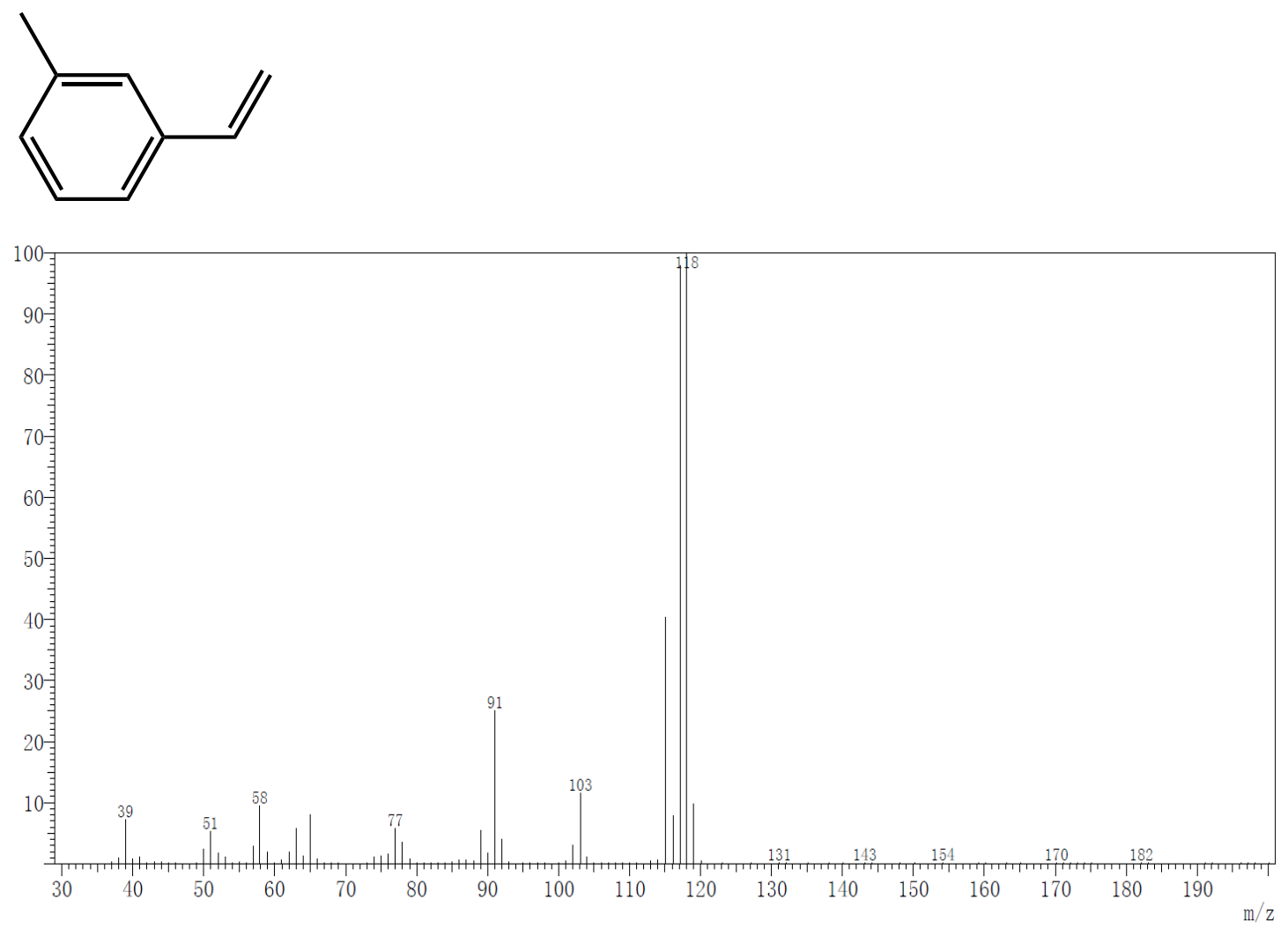

6.
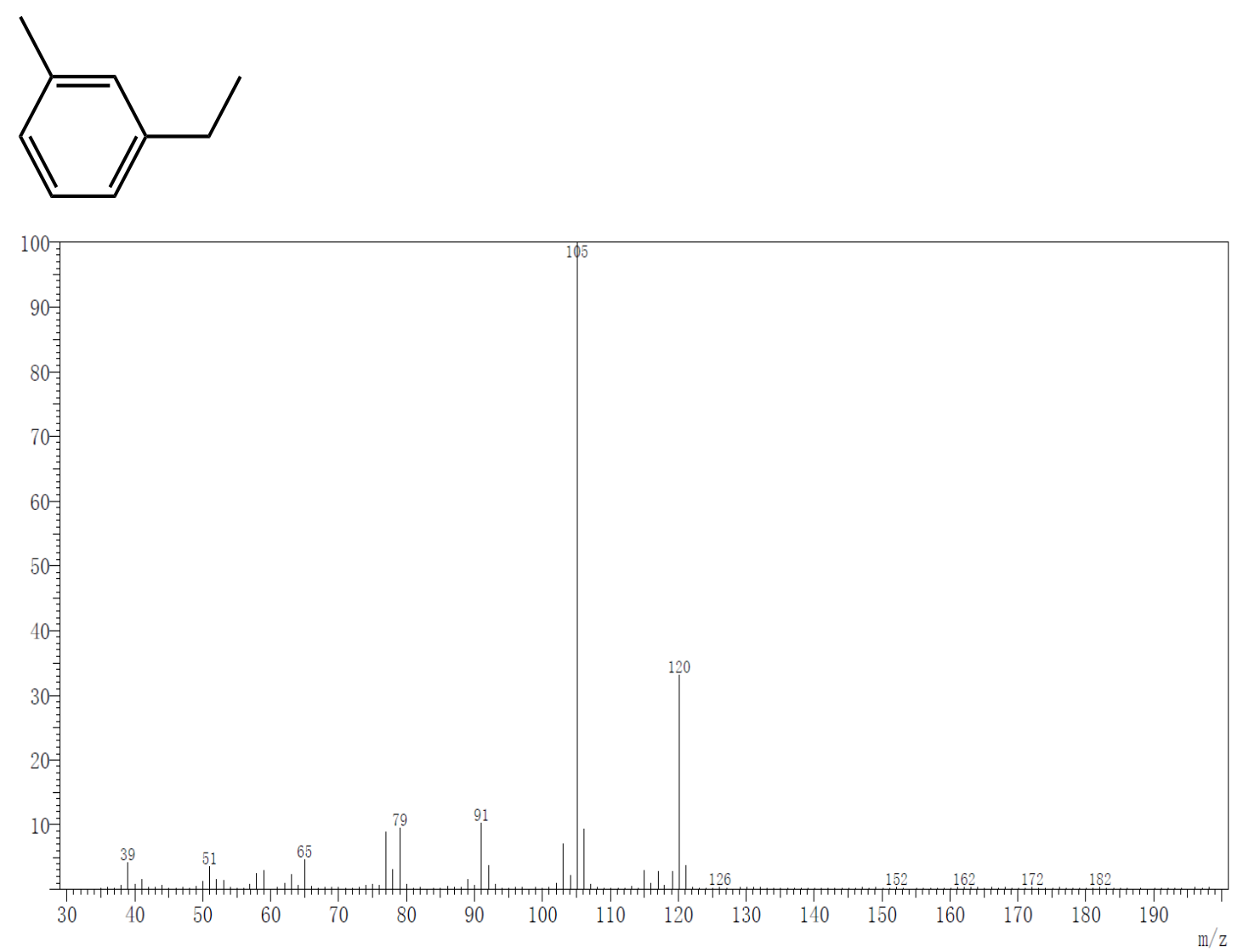
7.
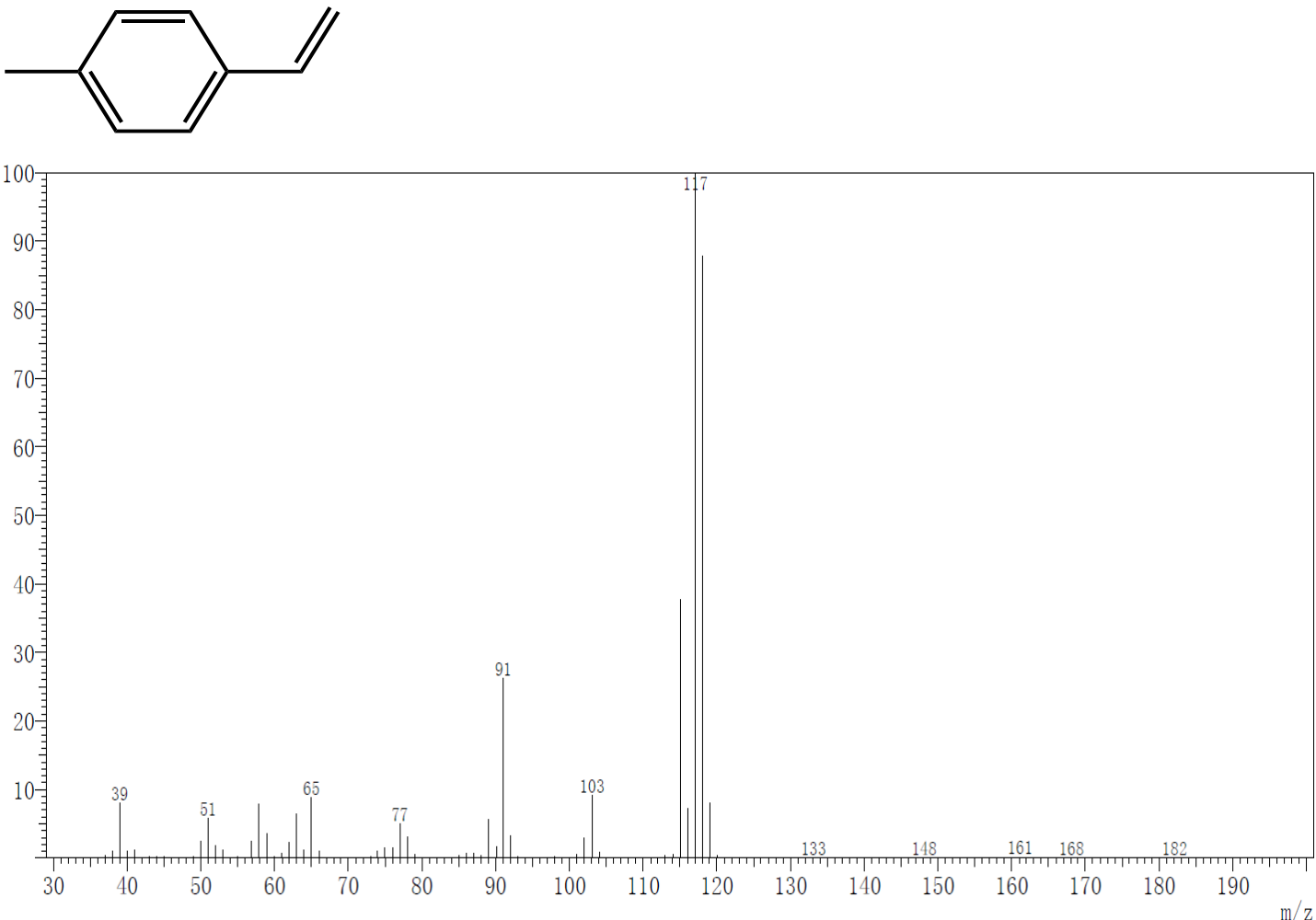

8.
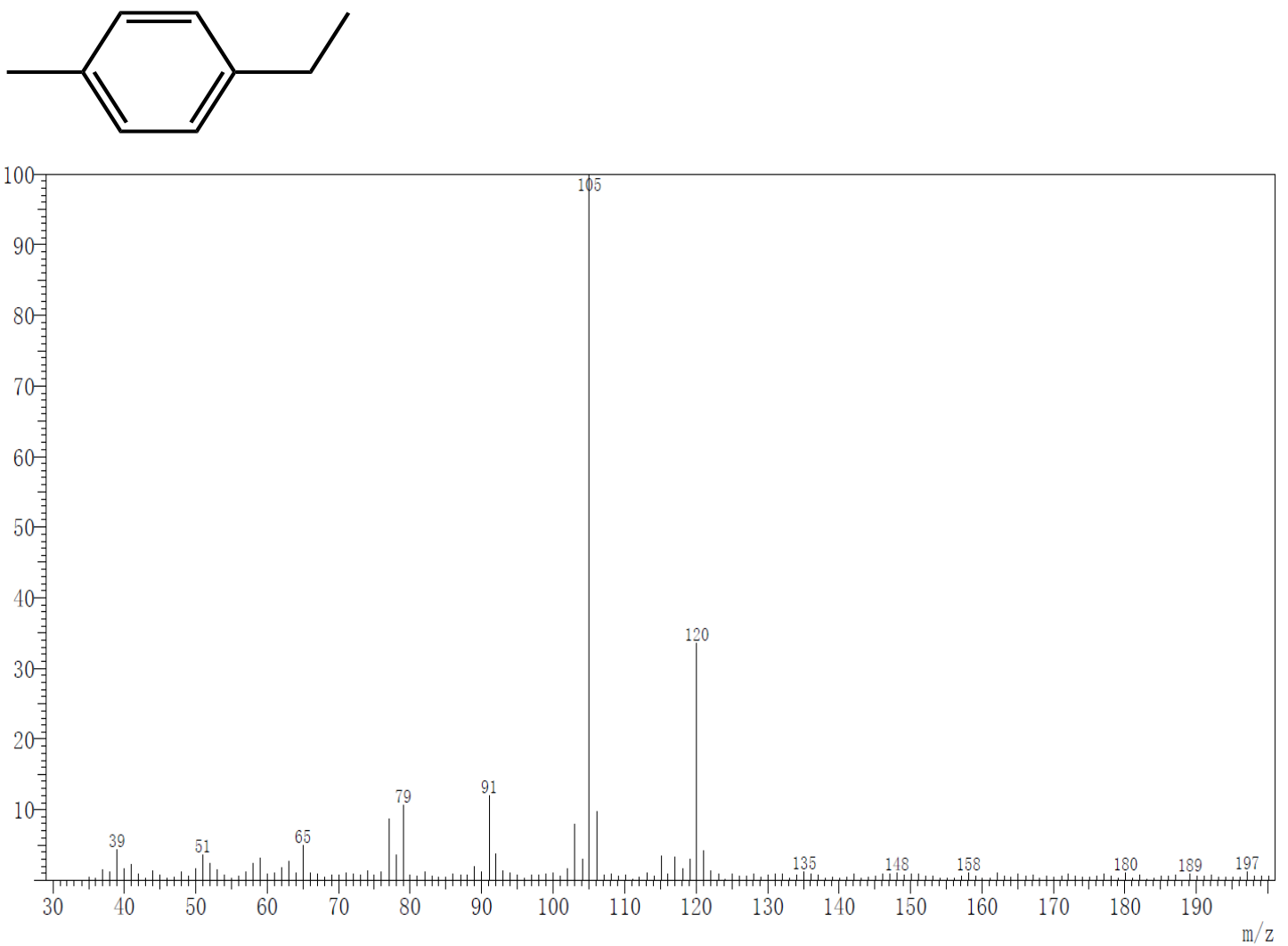
9.
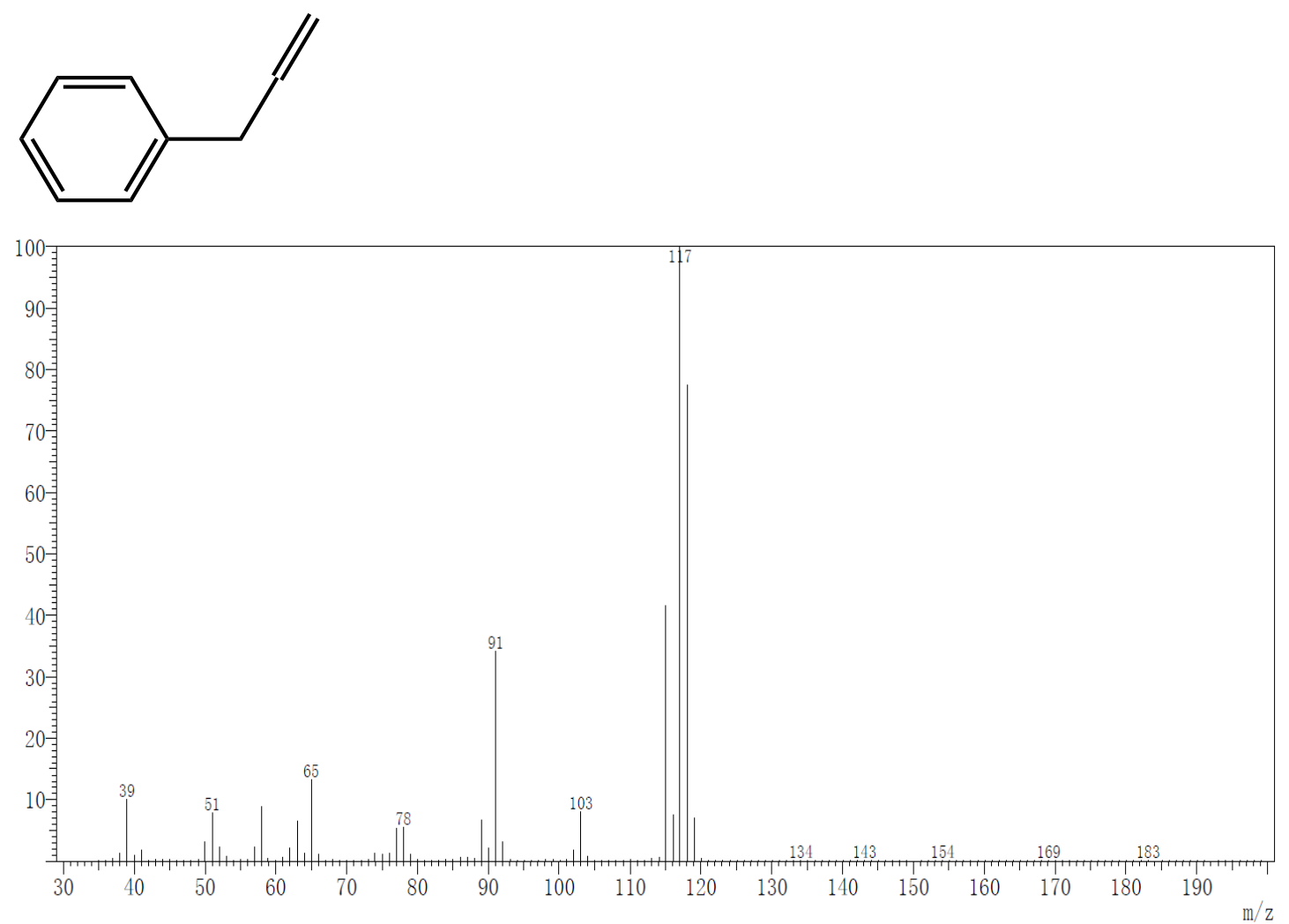

10.

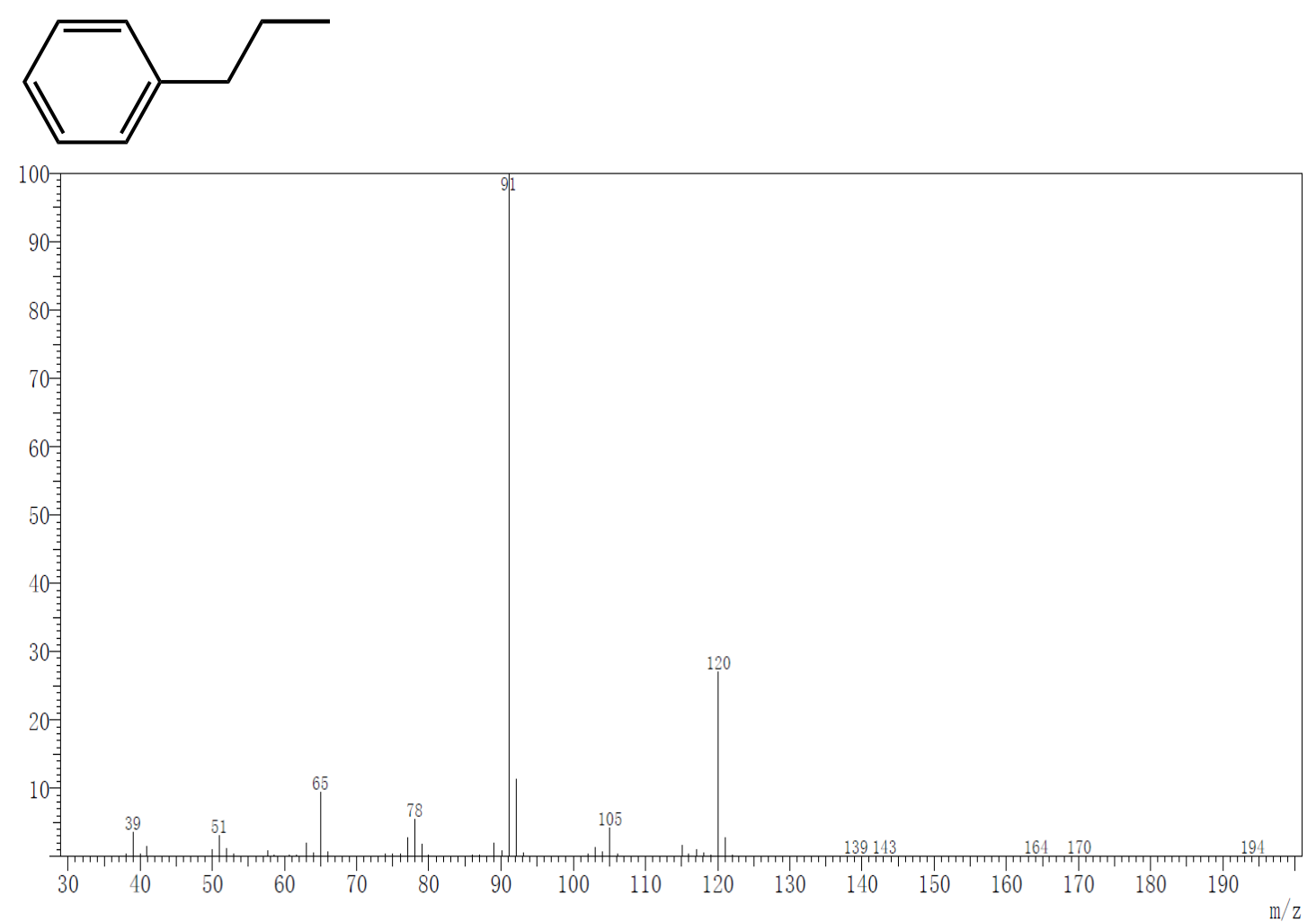


11.

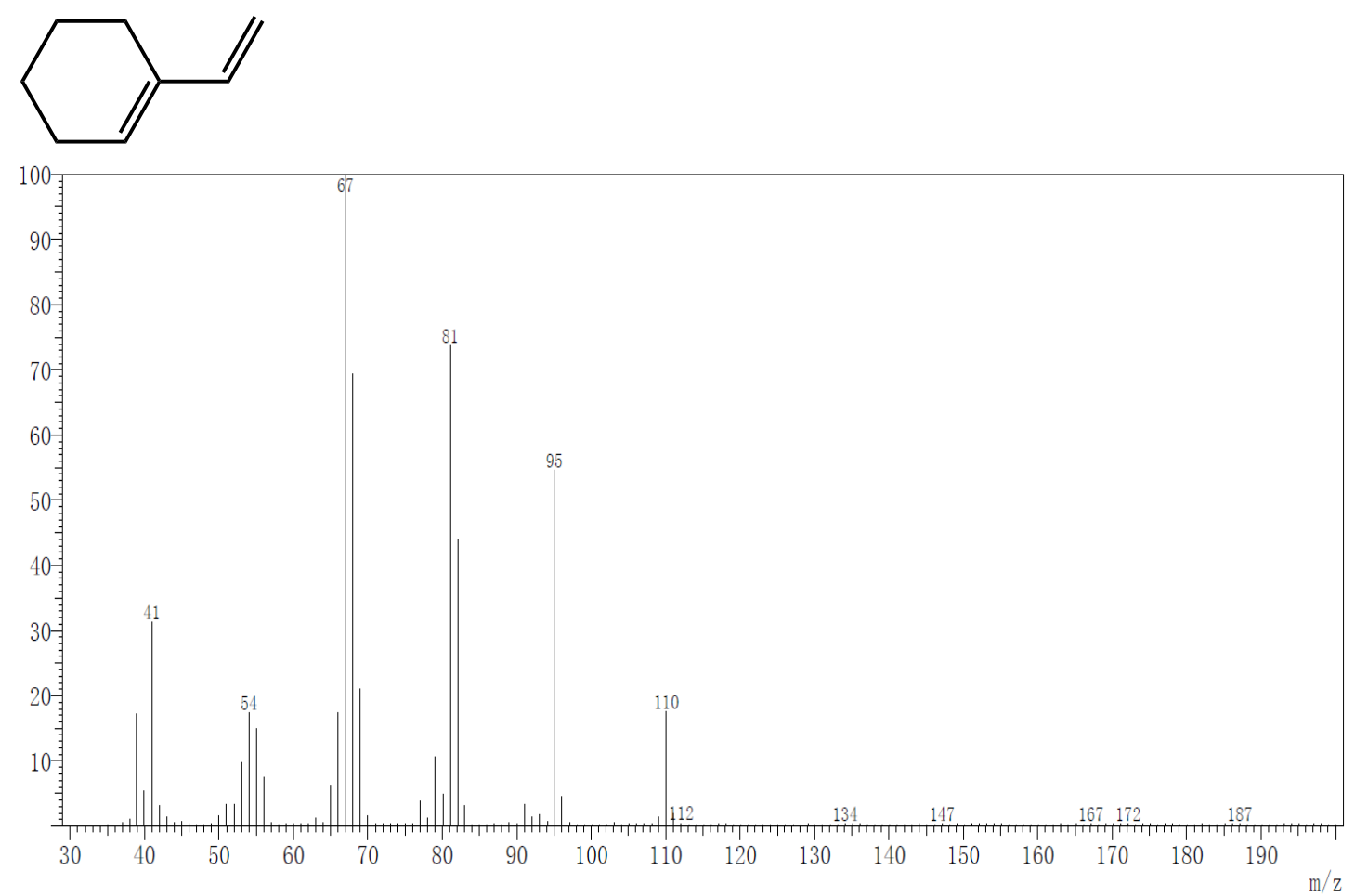

12.
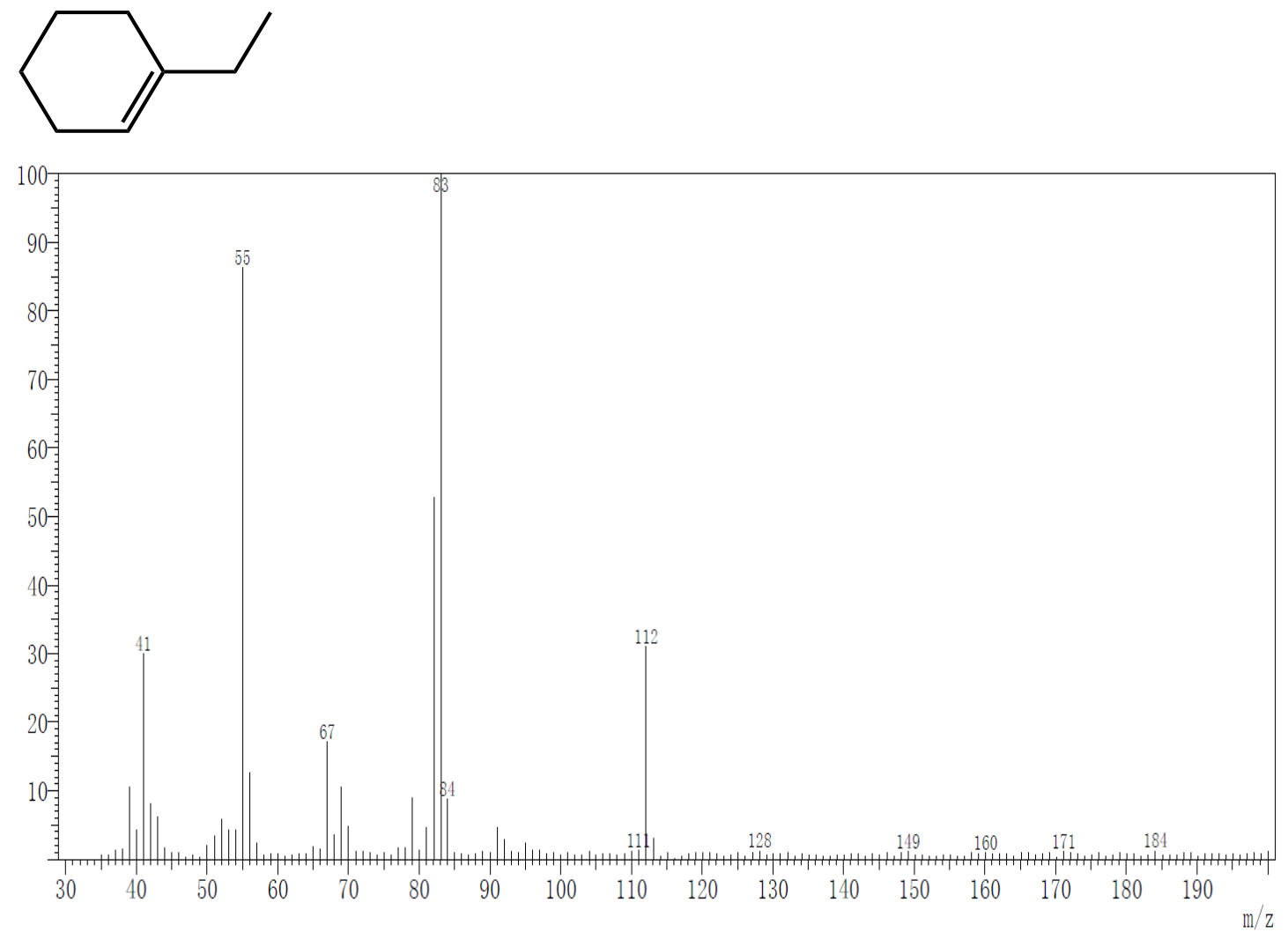
13.
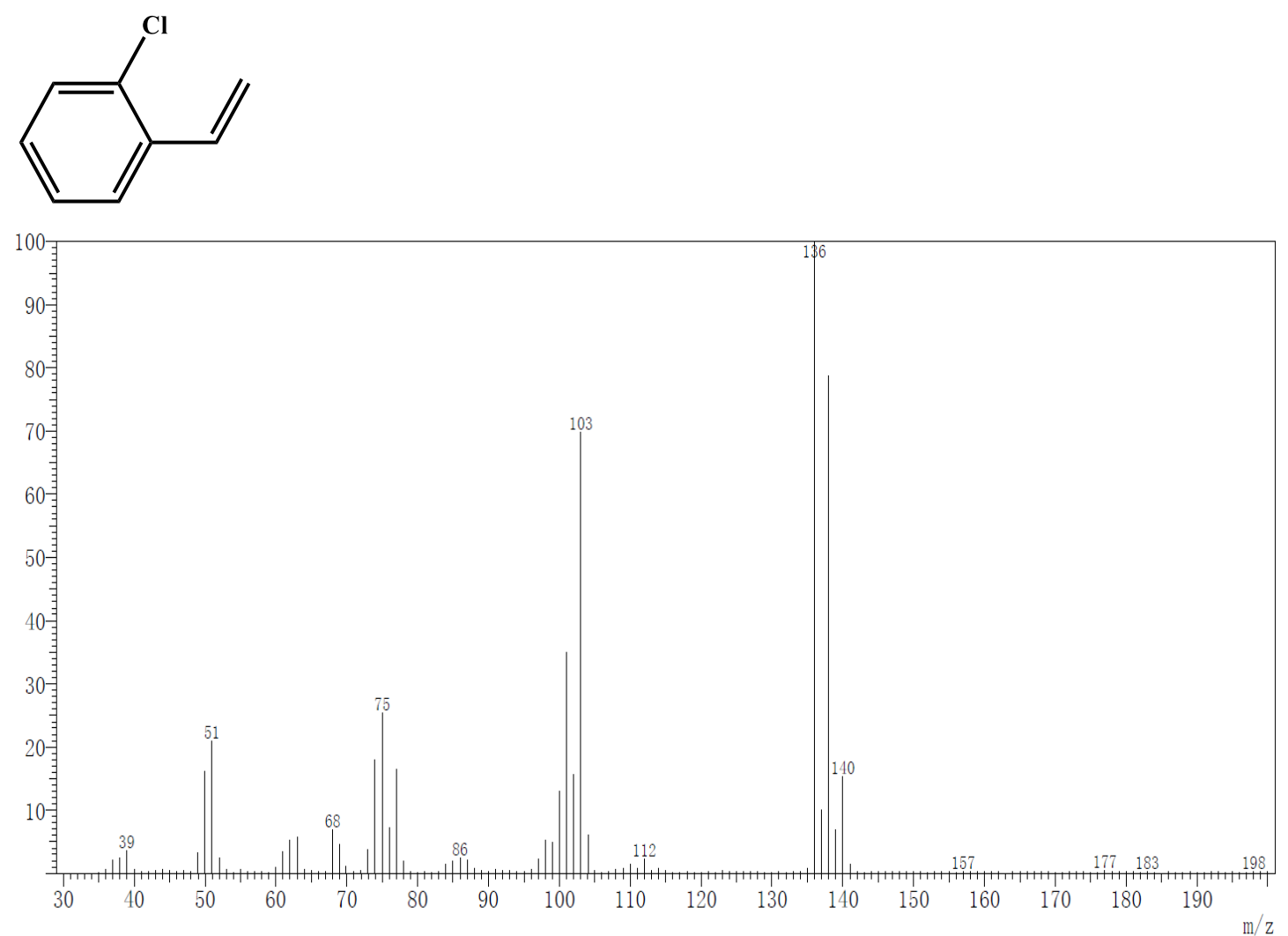

14.<smiles>CCc1ccccc1Cl</smiles> 


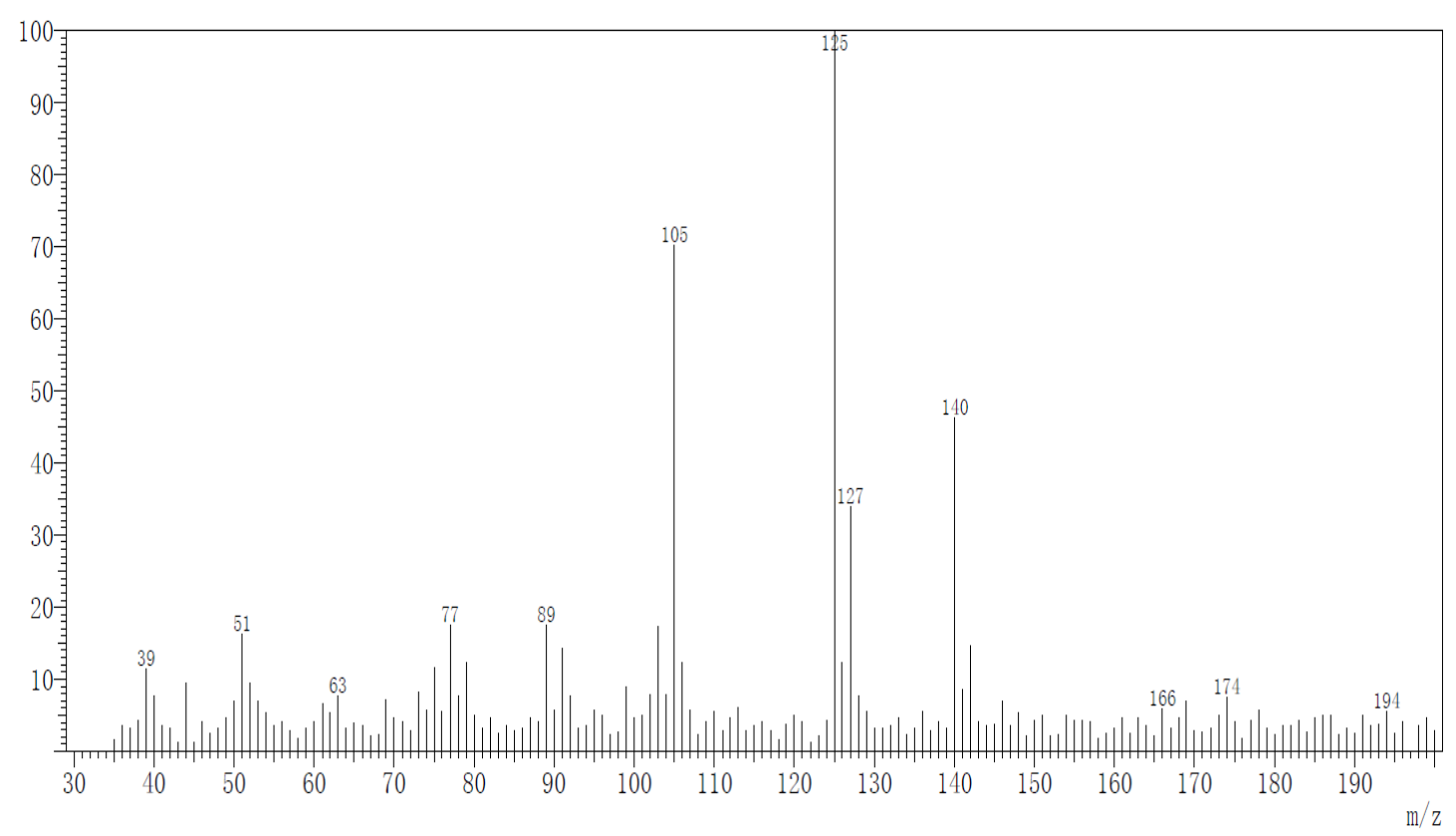

15.
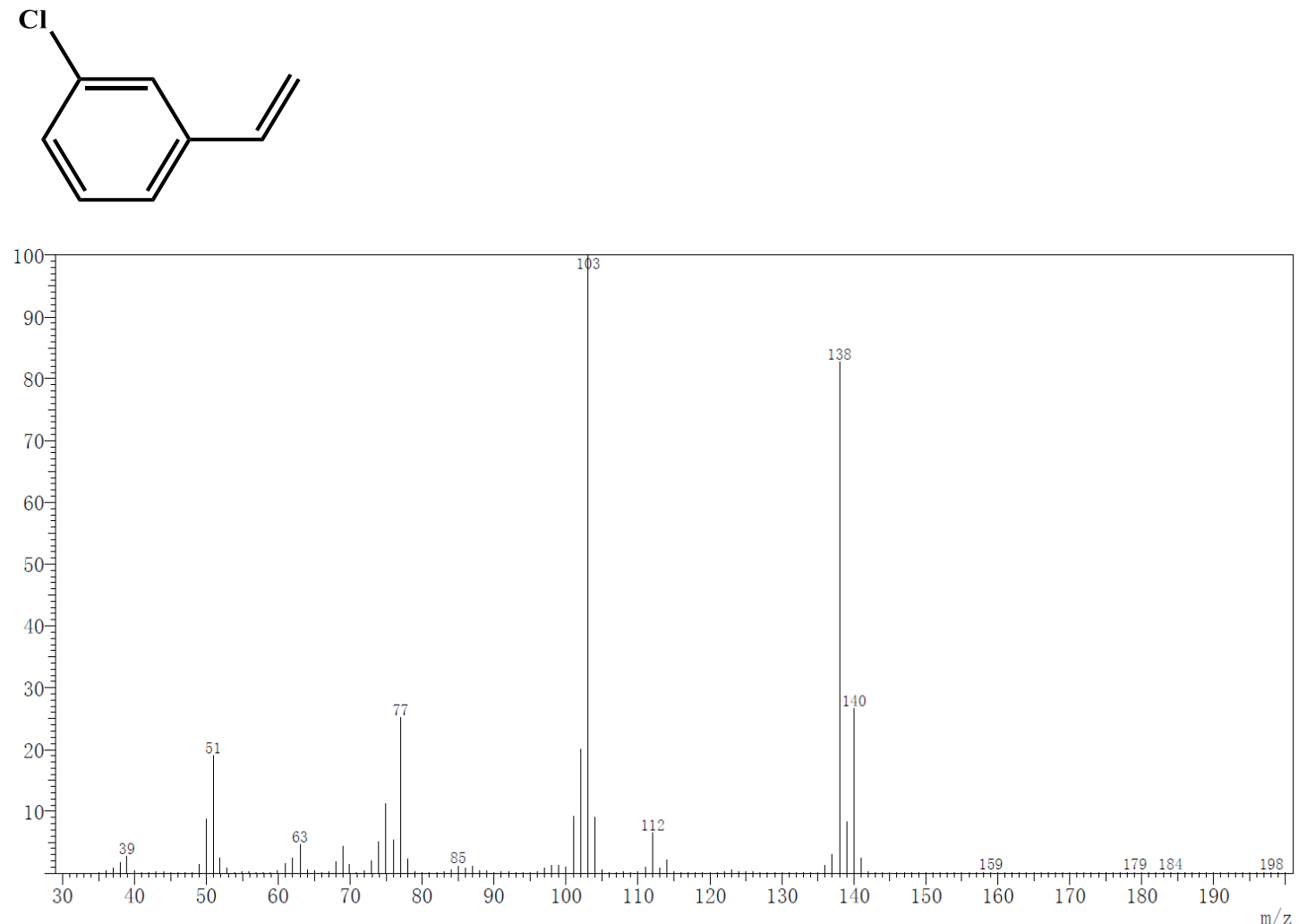

16. 


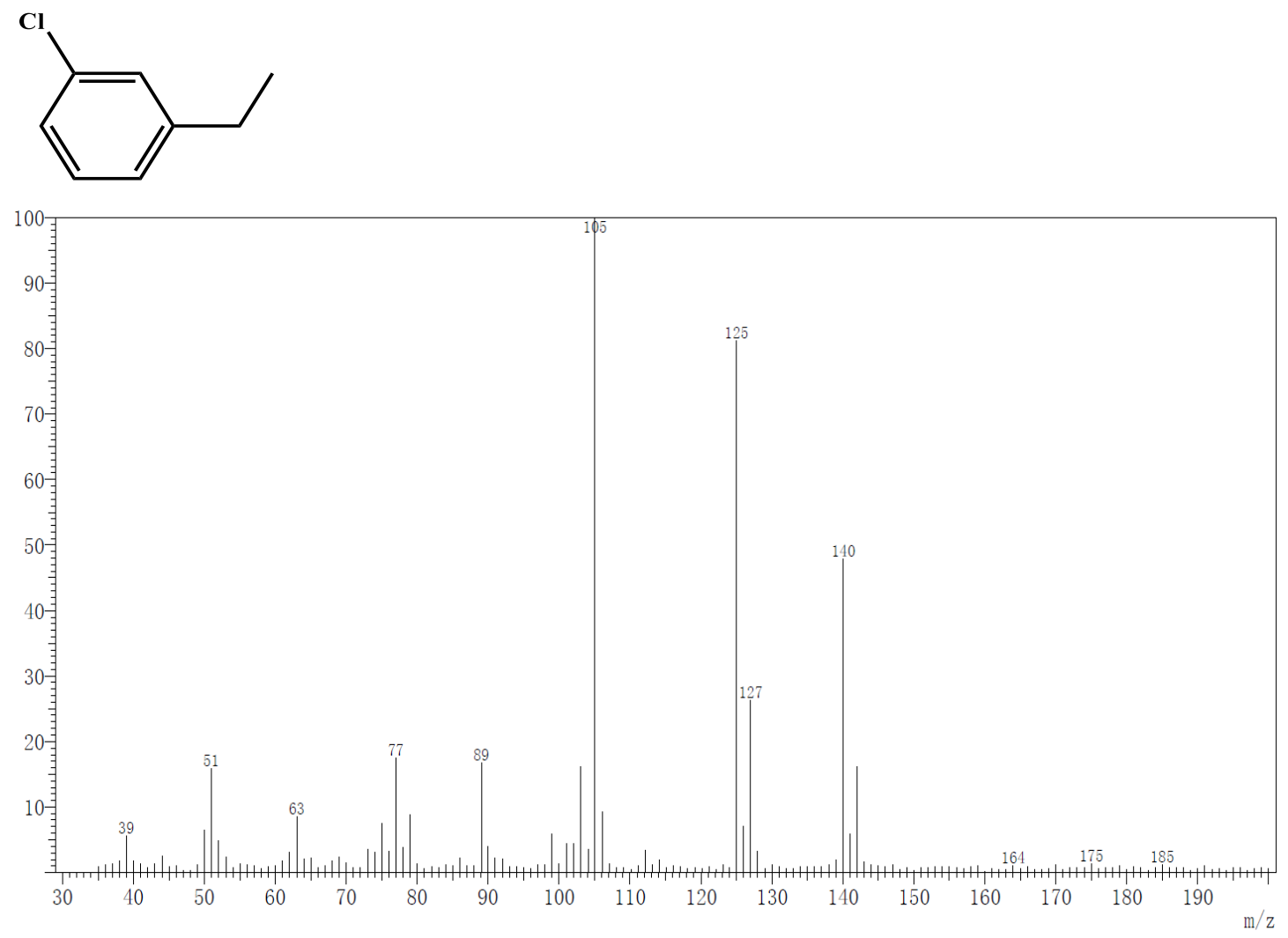

17.
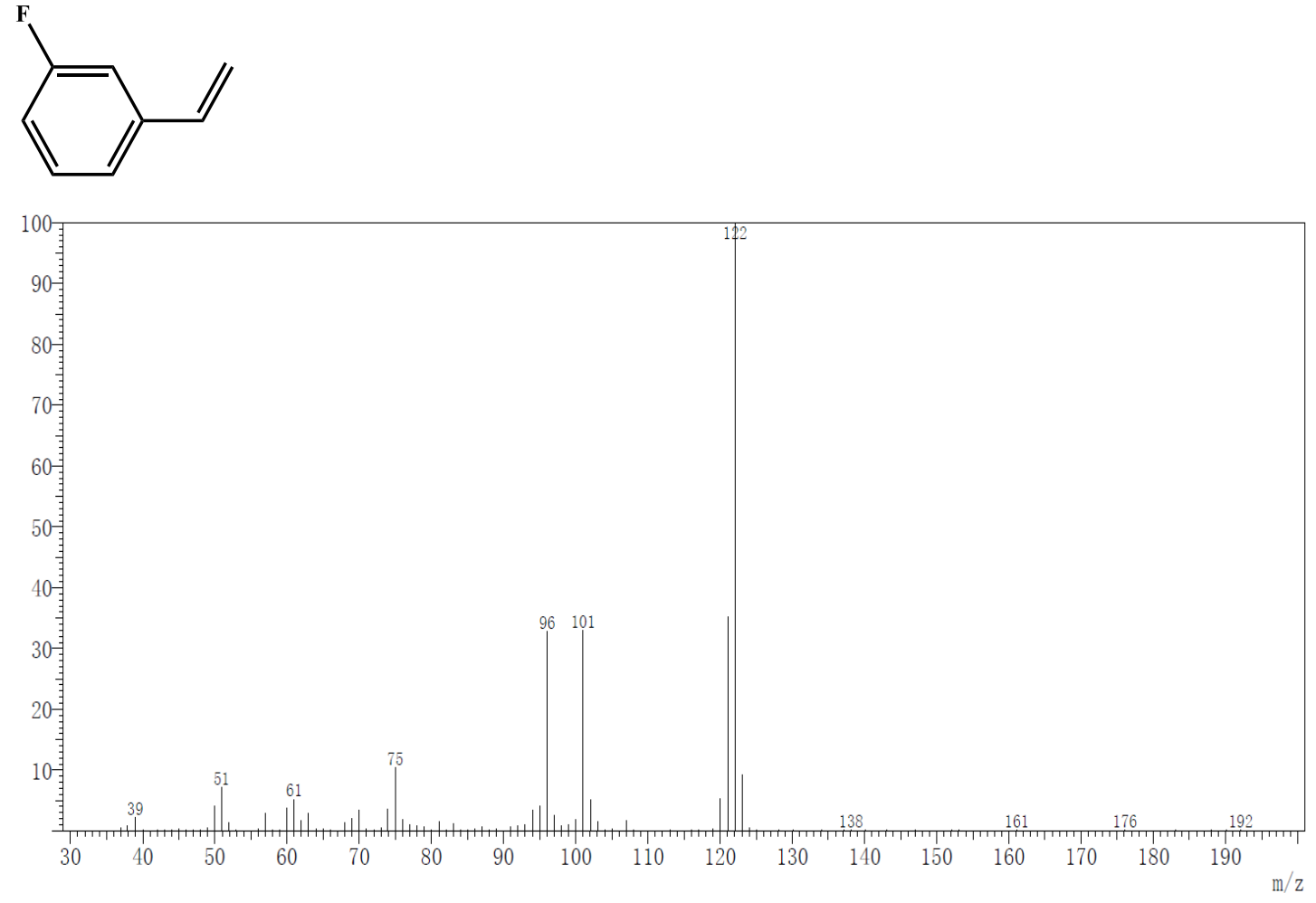

18. 


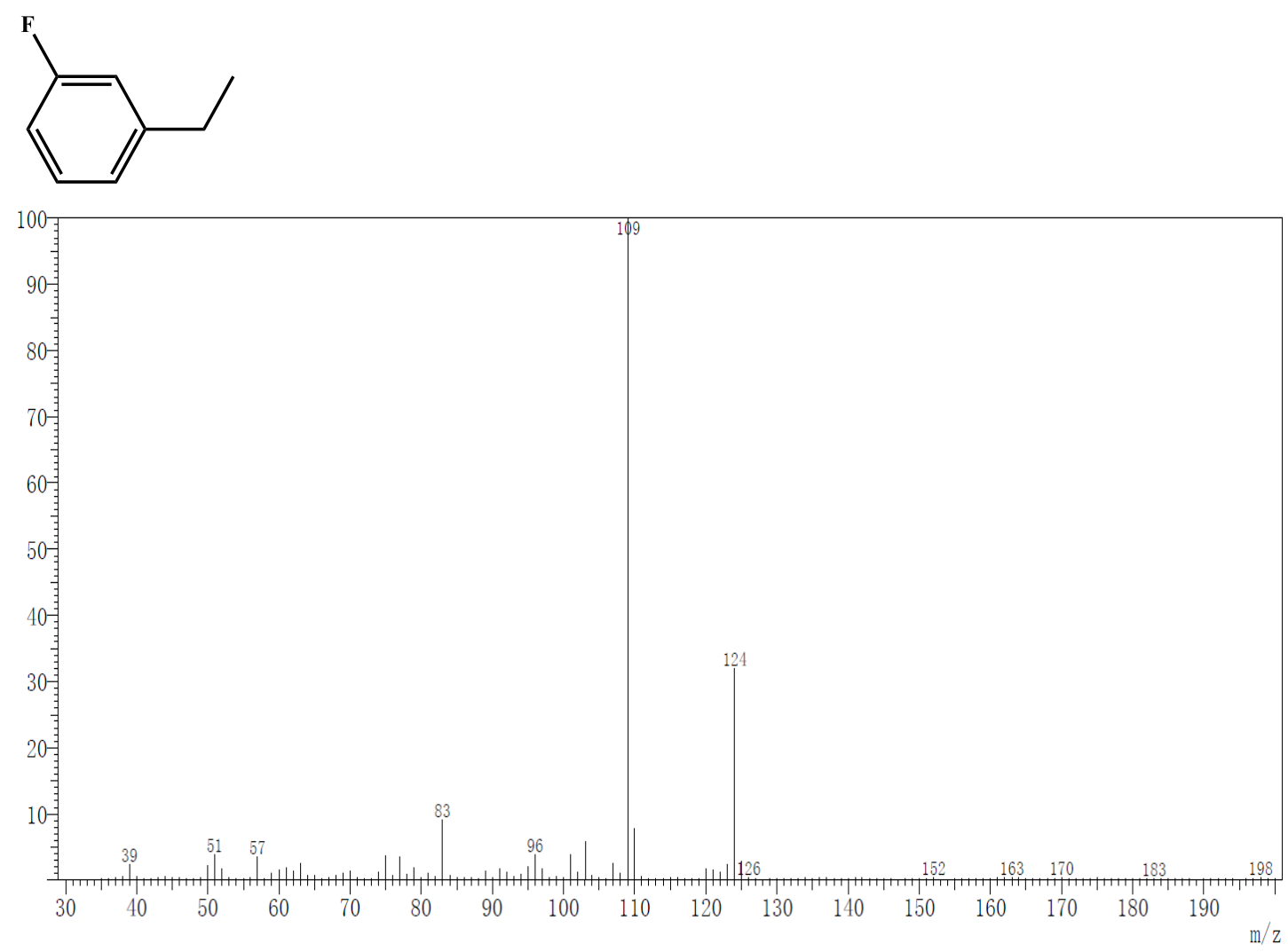

19.
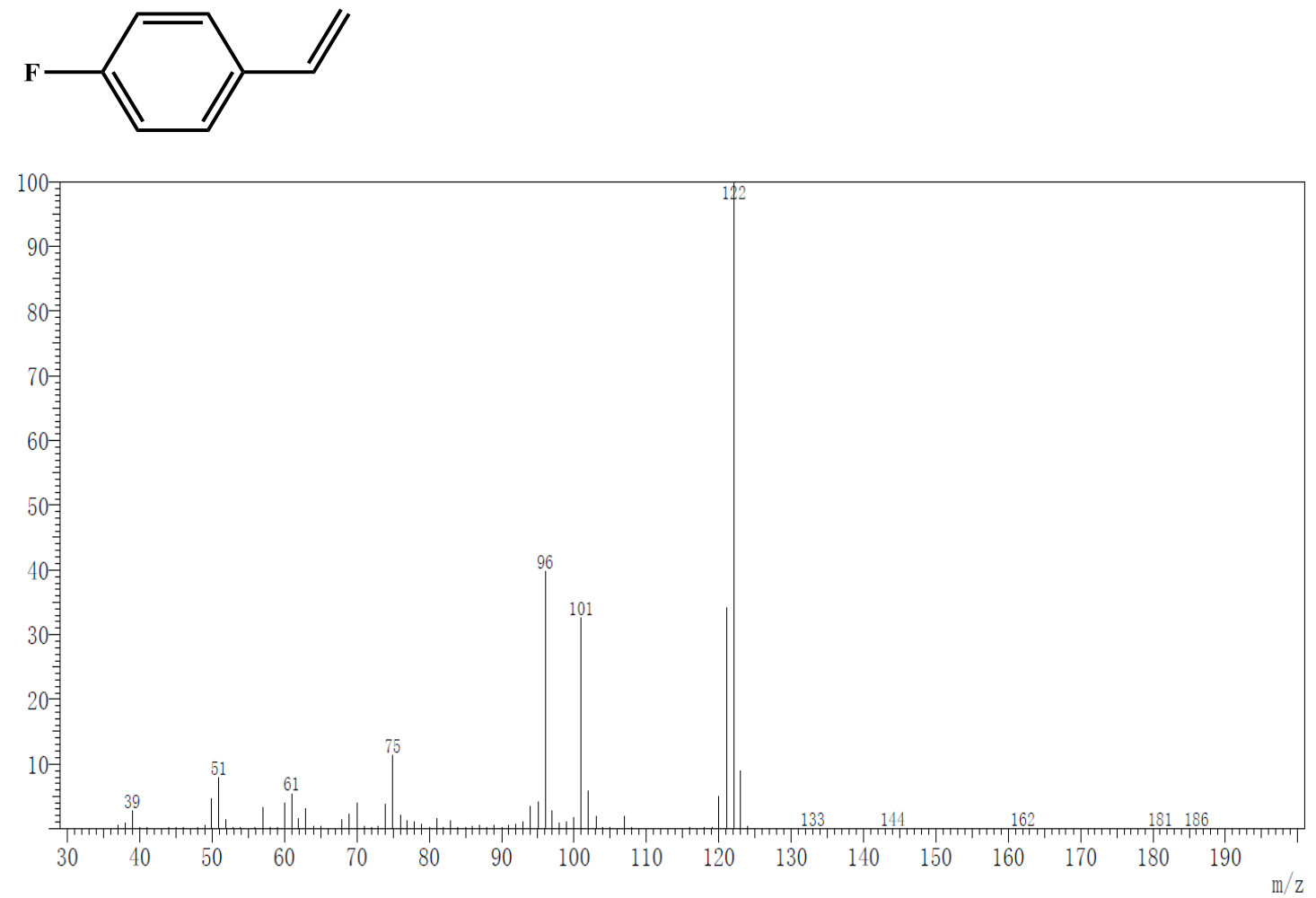

20. 

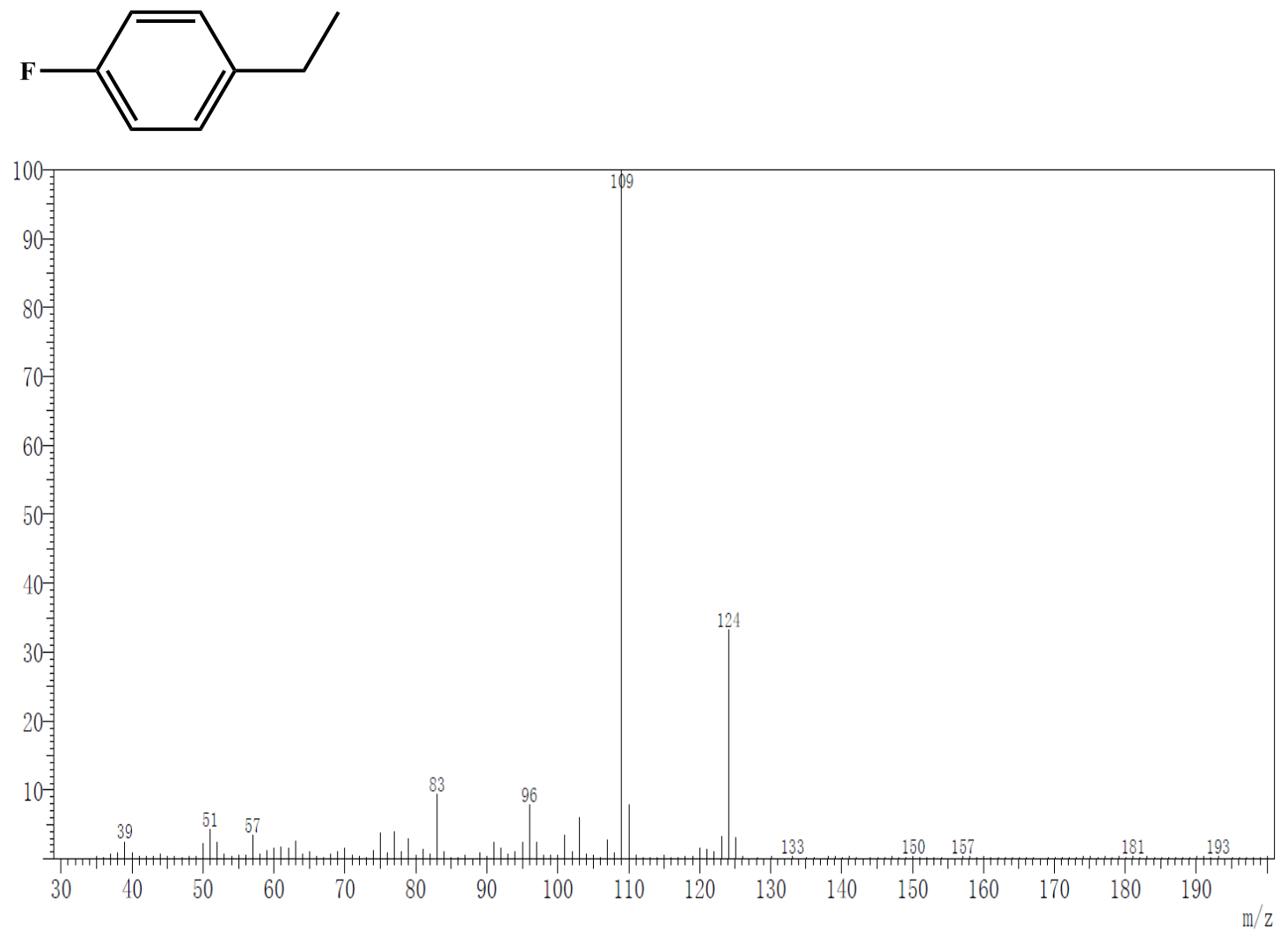

21.
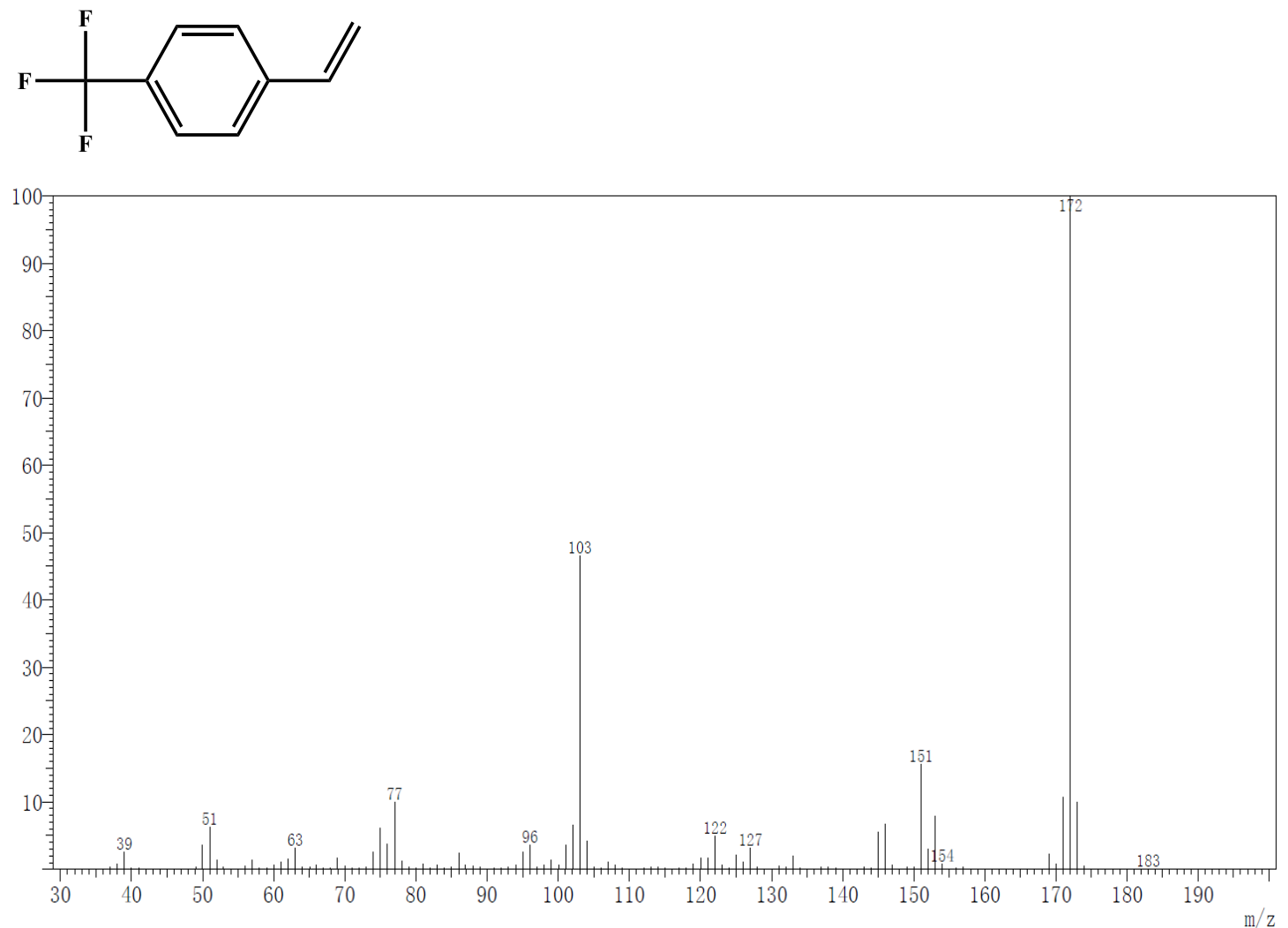
22.<smiles>CCc1ccc(C(F)(F)F)cc1</smiles>

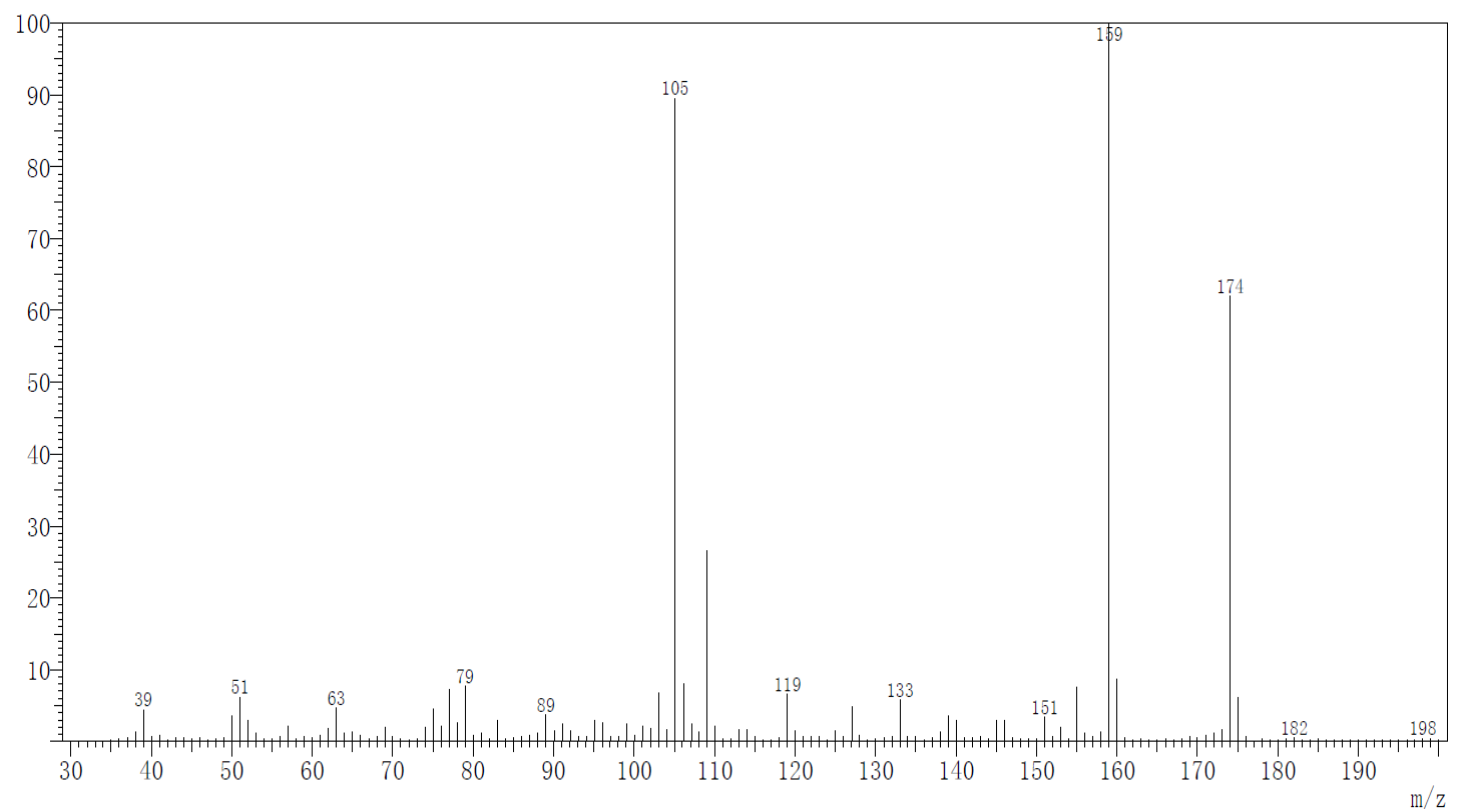

23.

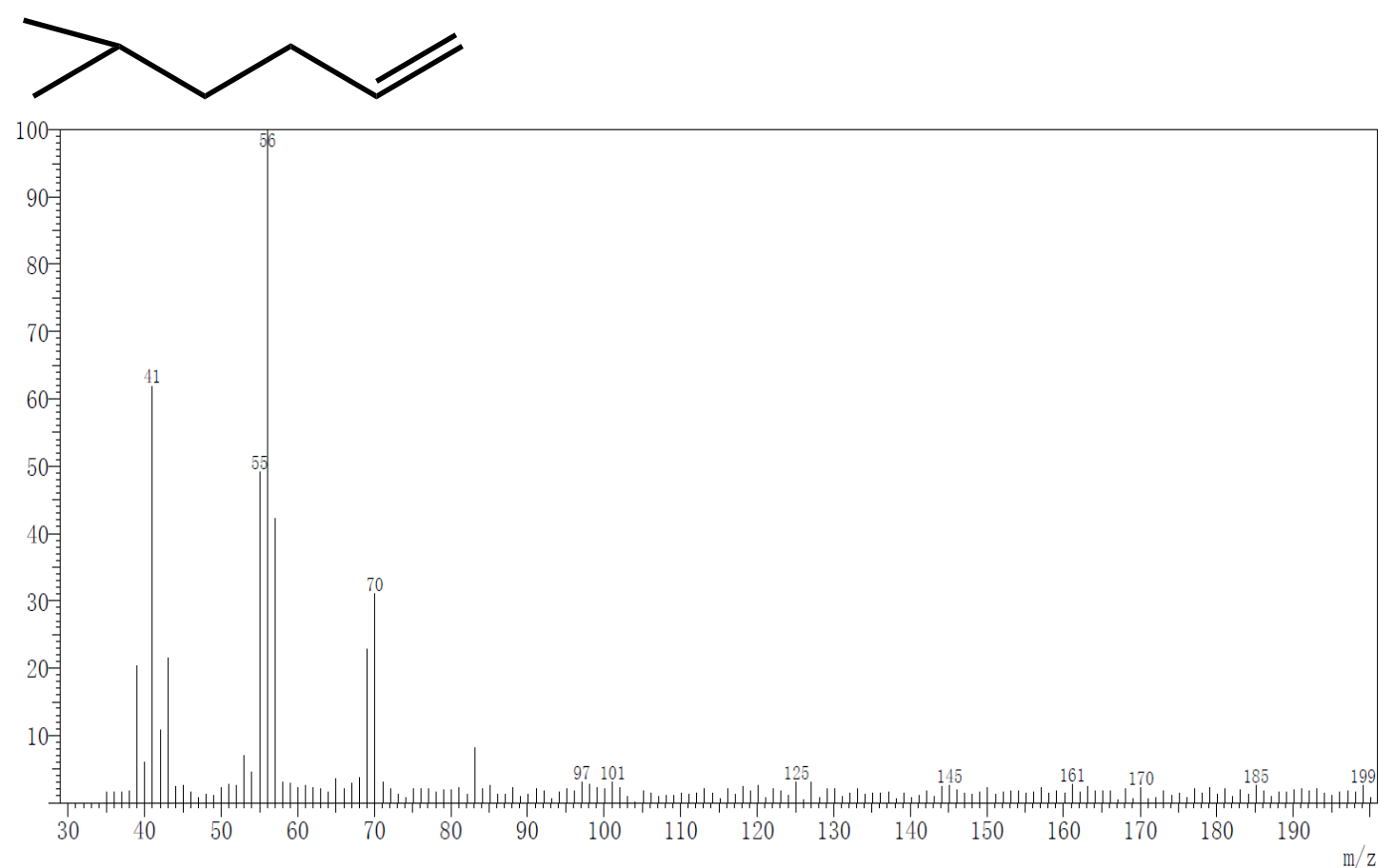

24.<smiles>CCCCC(C)C</smiles> 


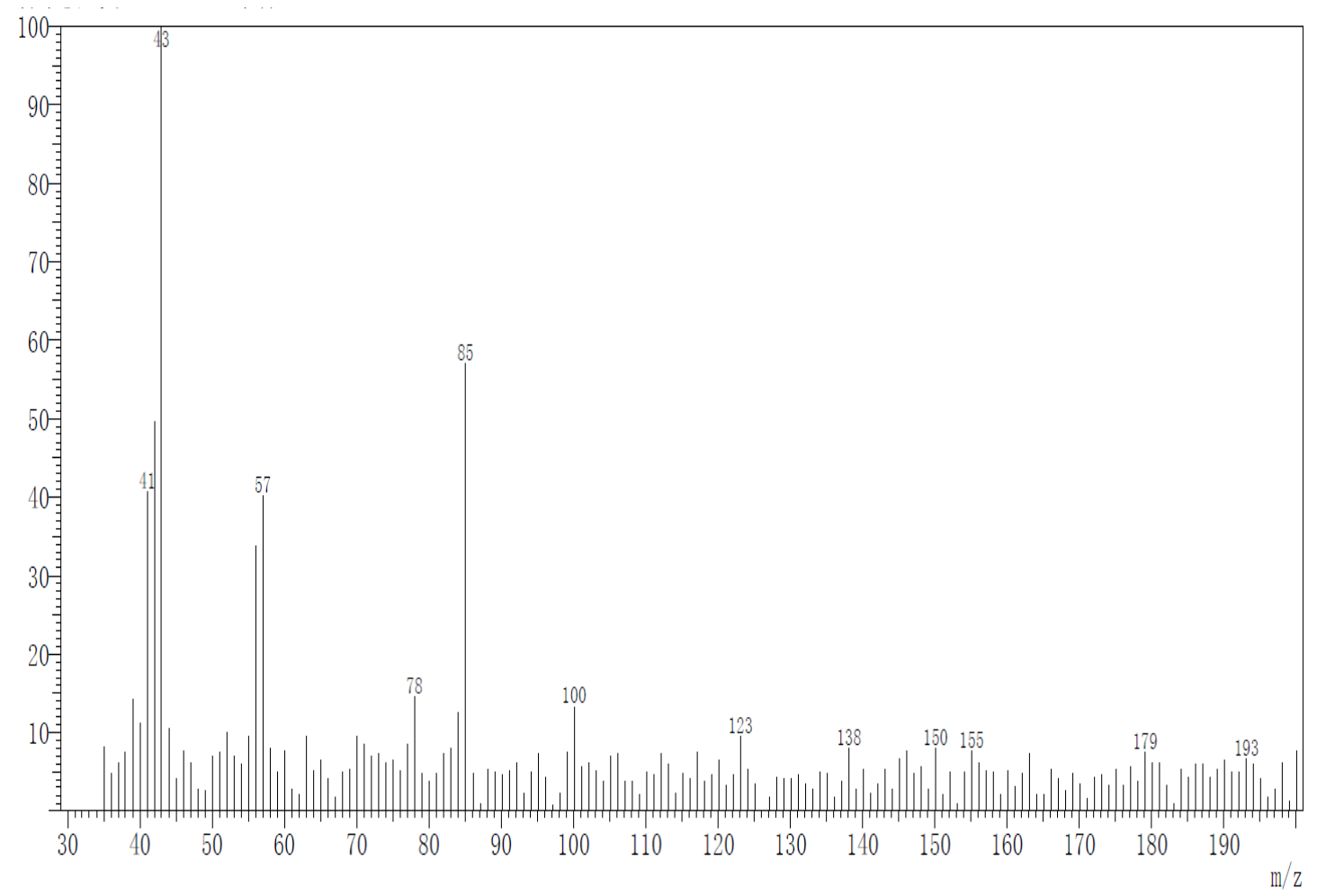

25.
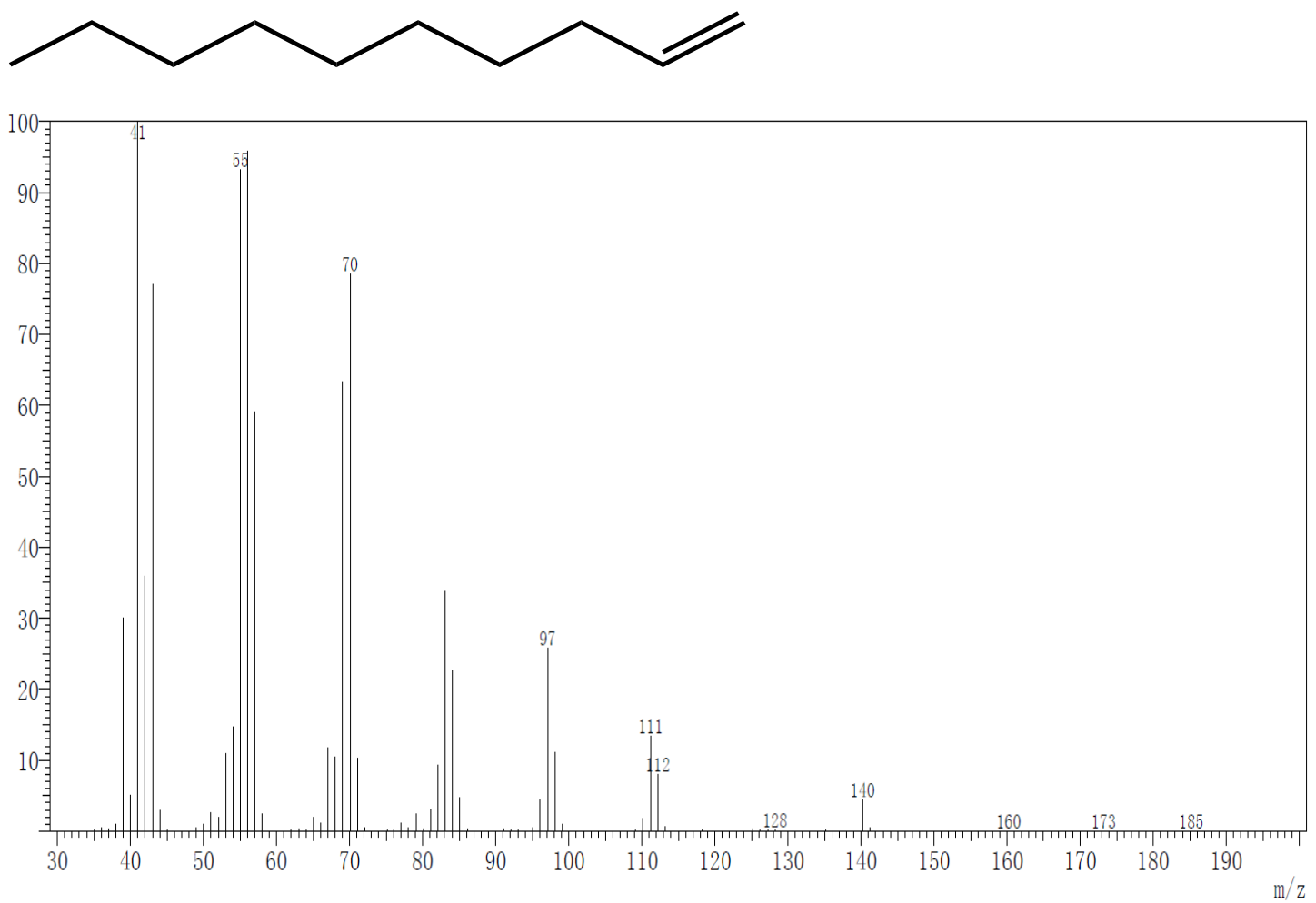

26. 


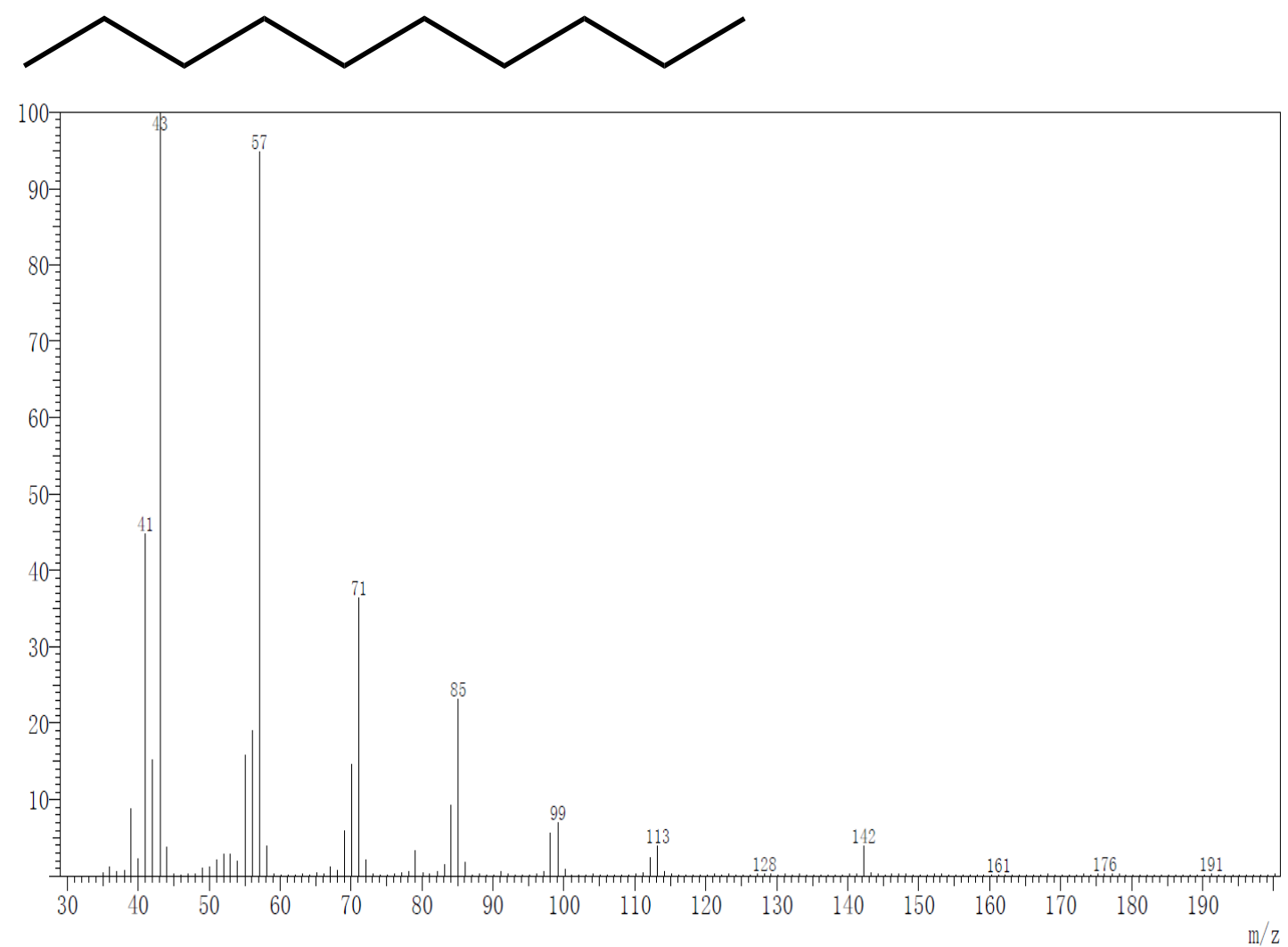

27.
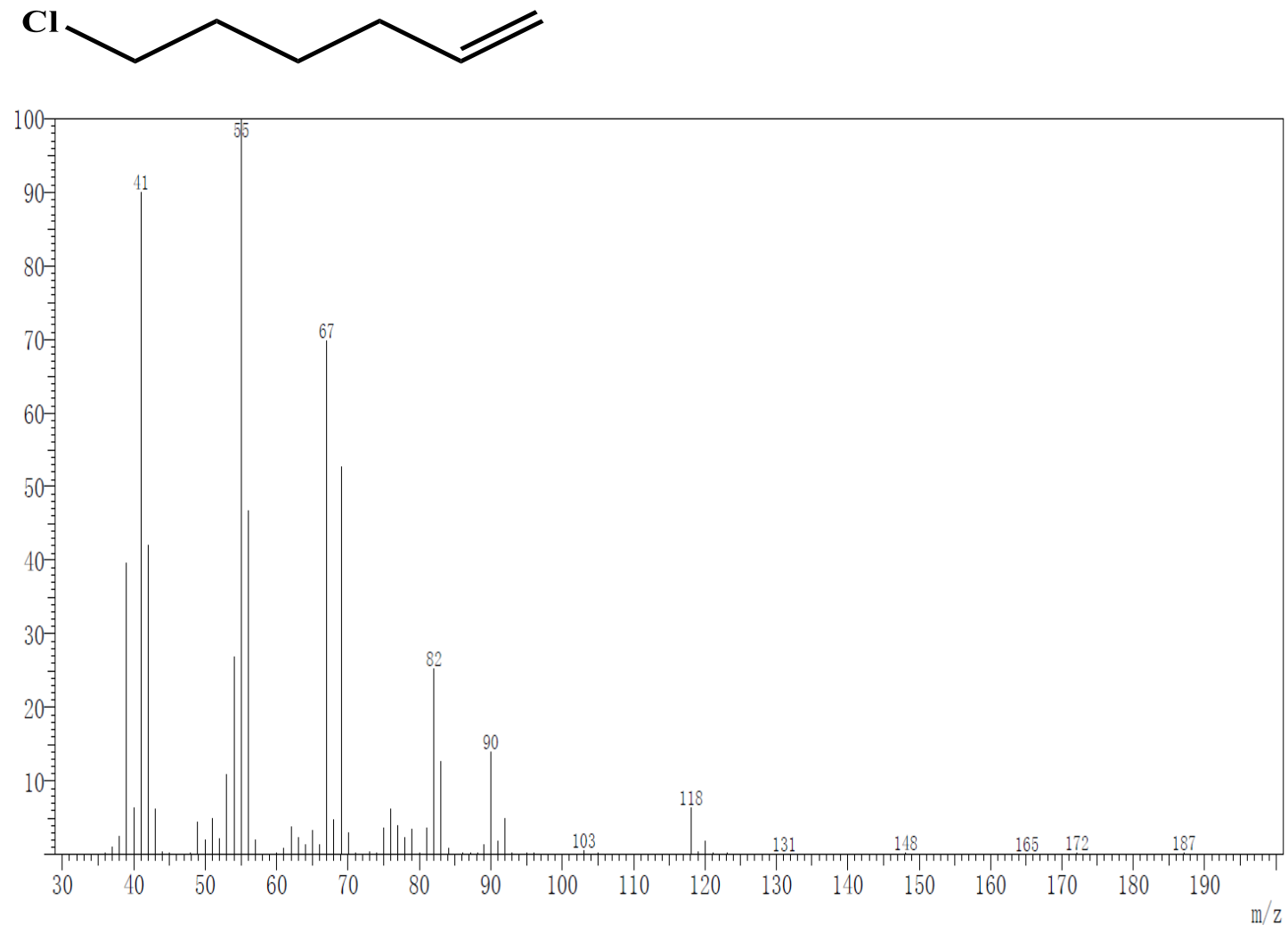

28. 

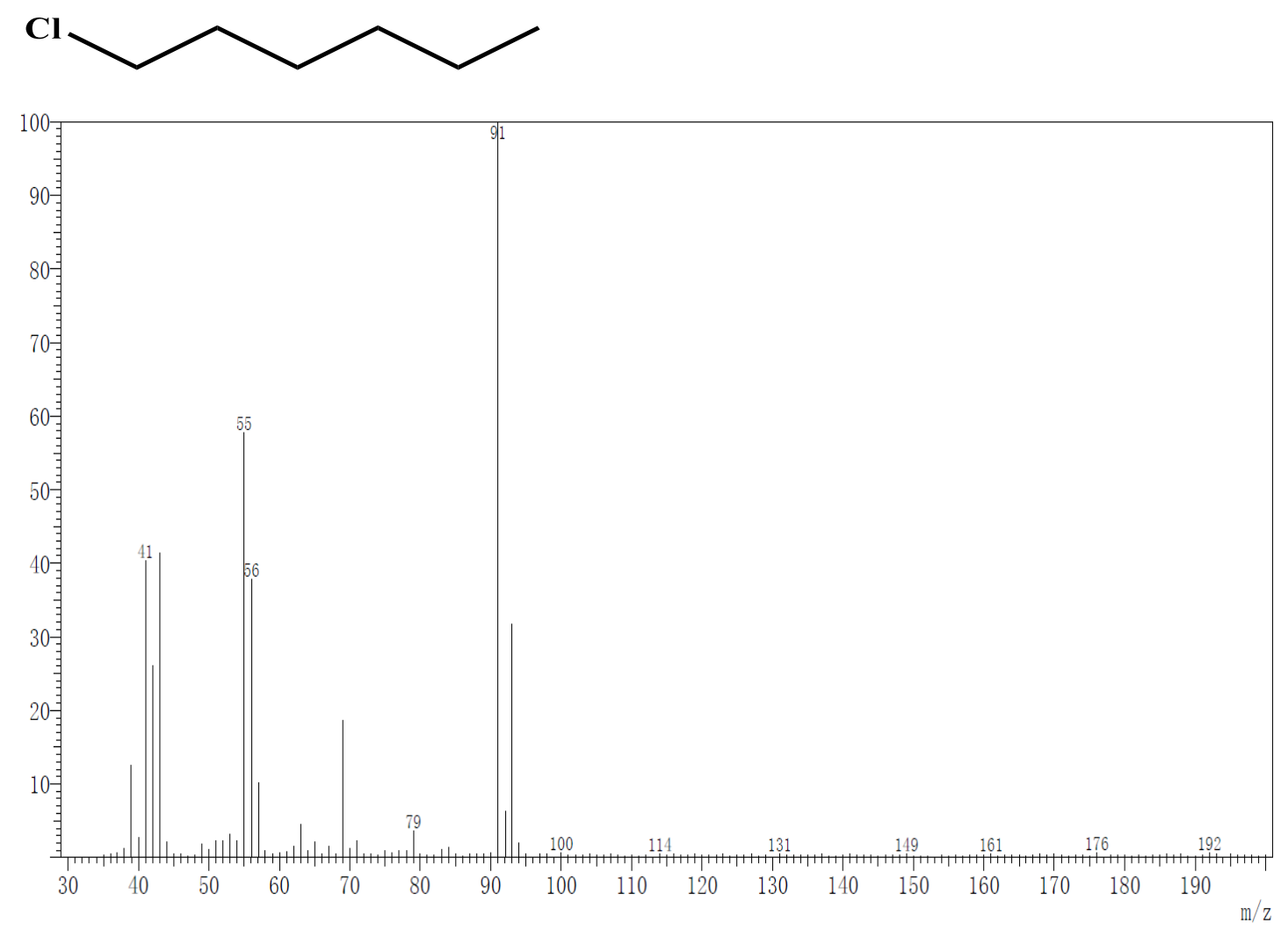

29.
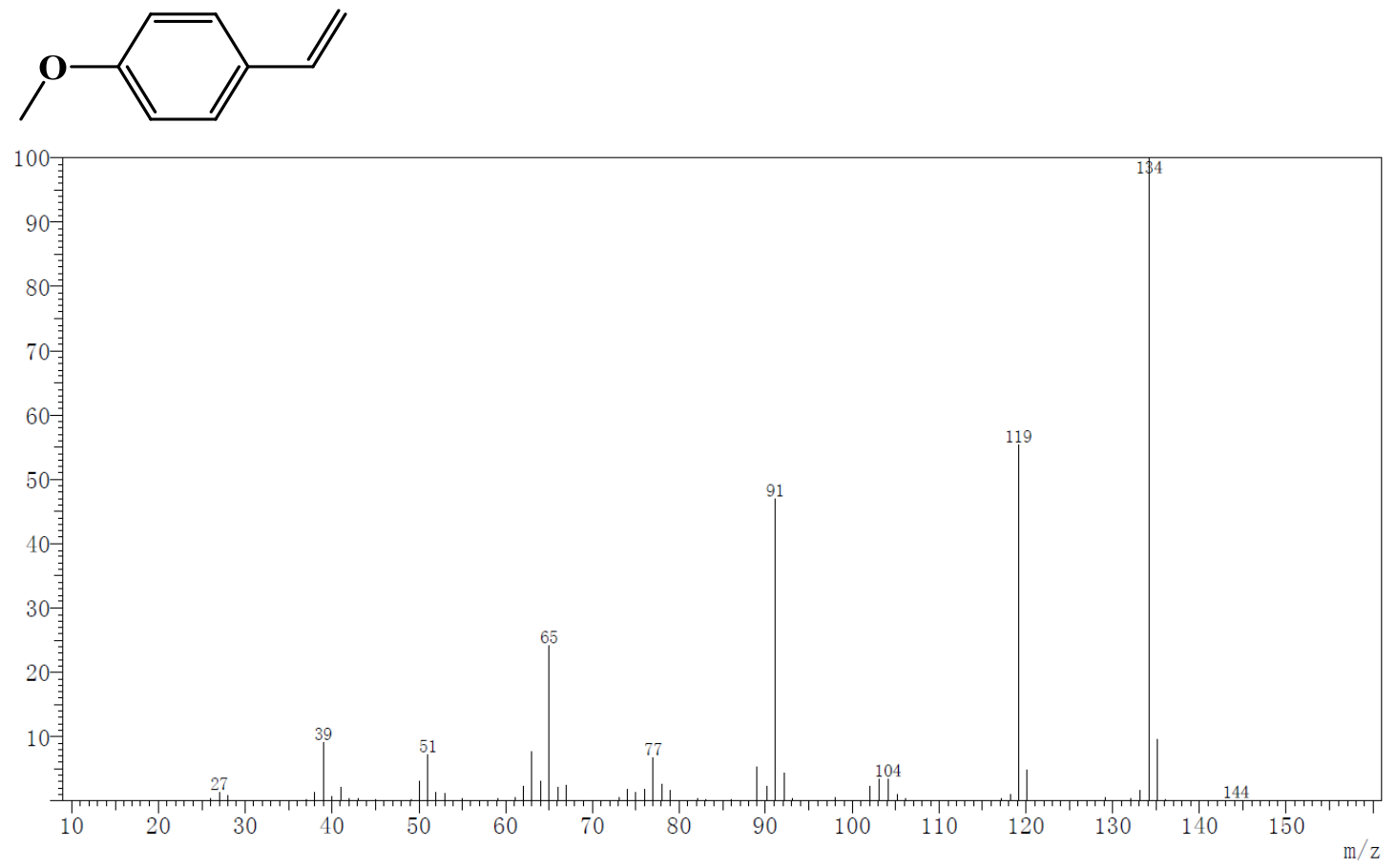

30. 

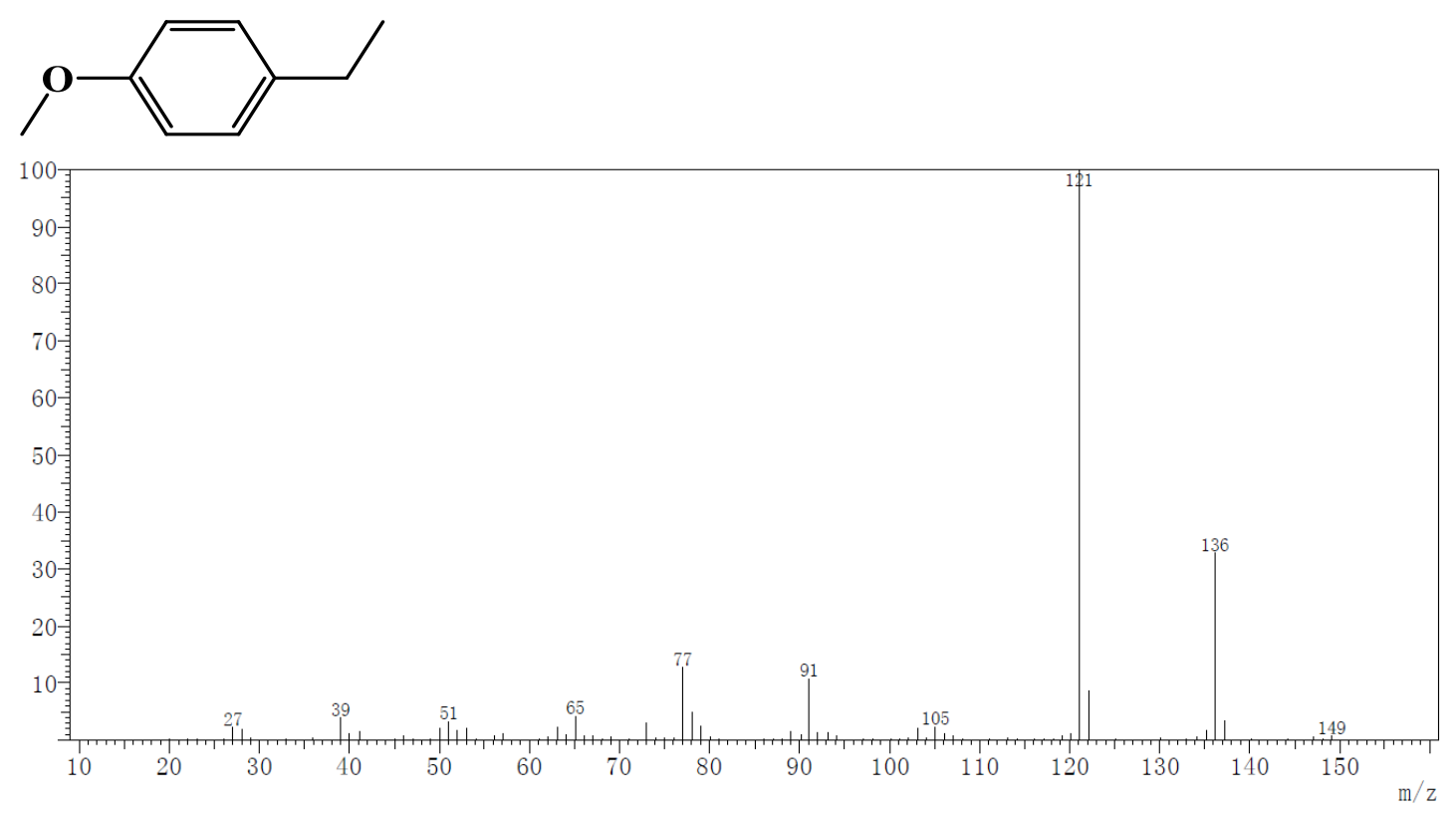

31.
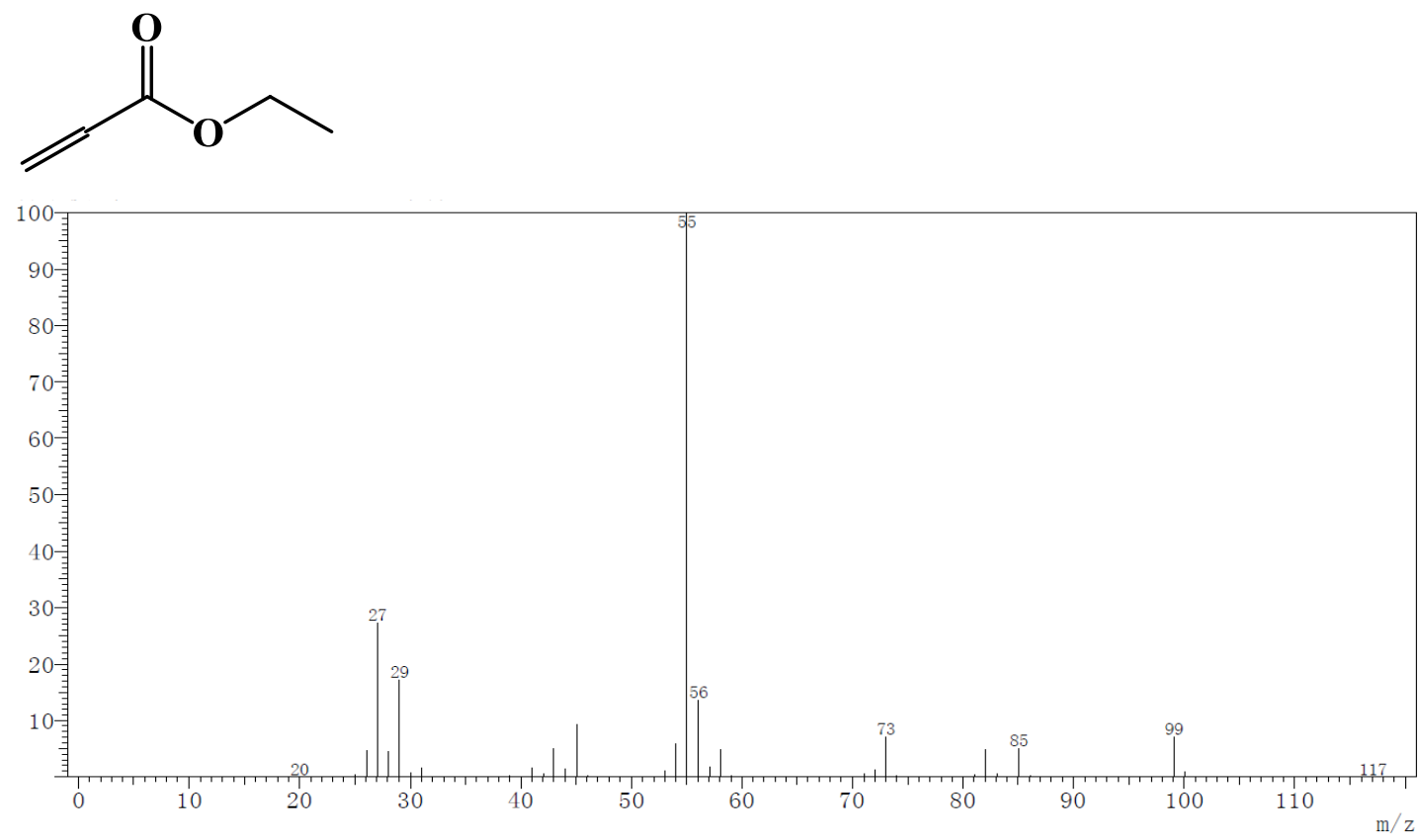

32. 

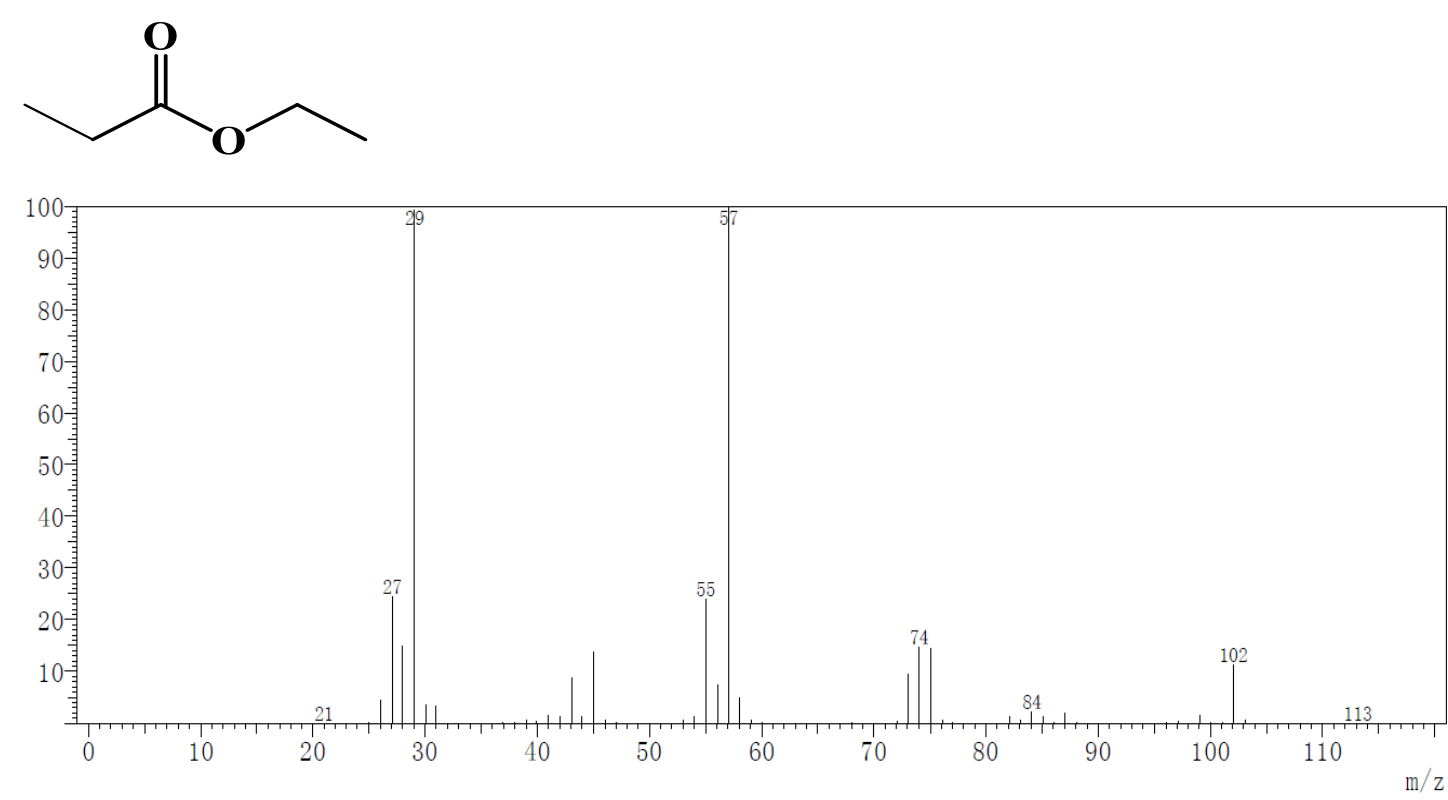

33.
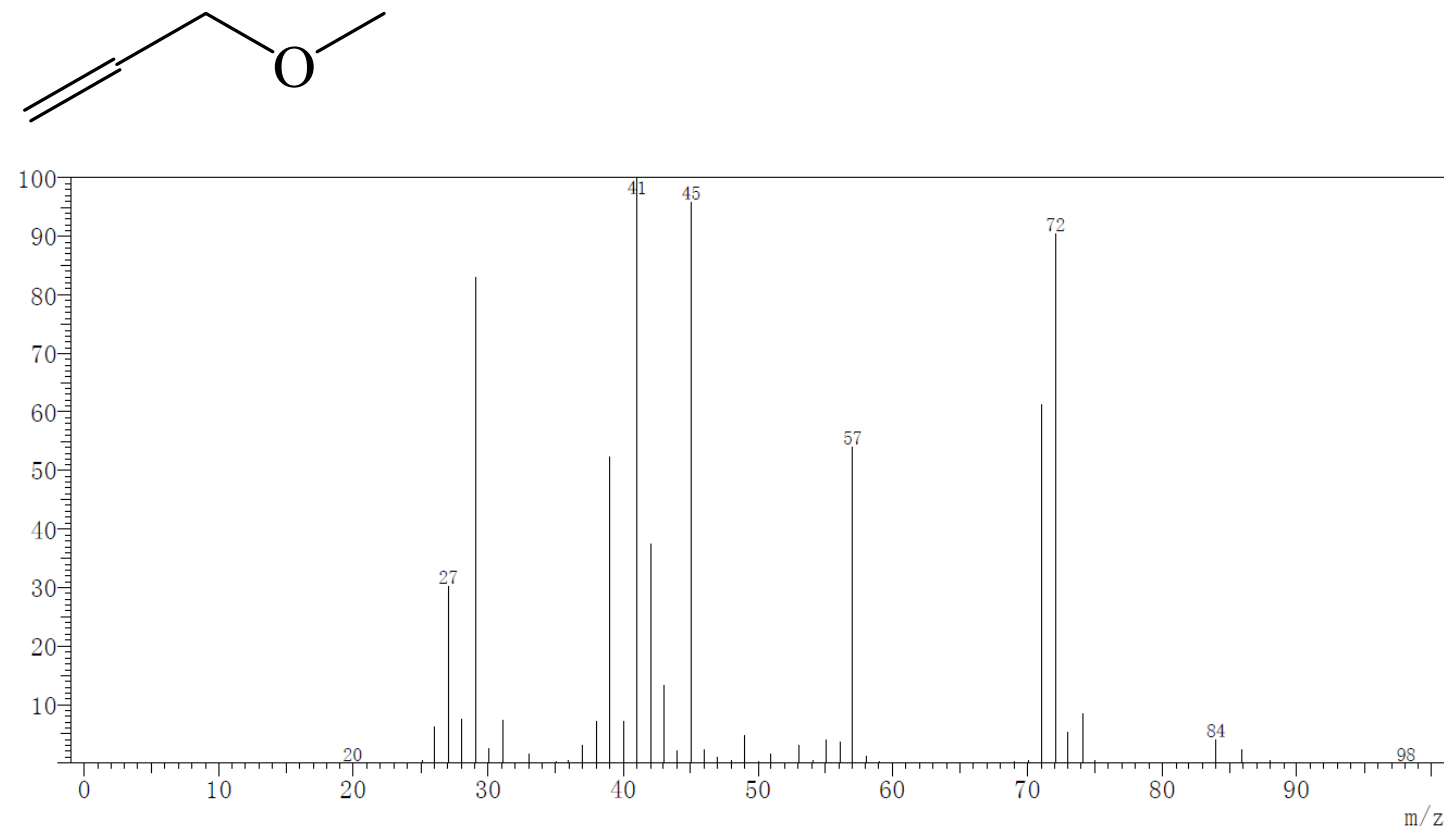

34. 


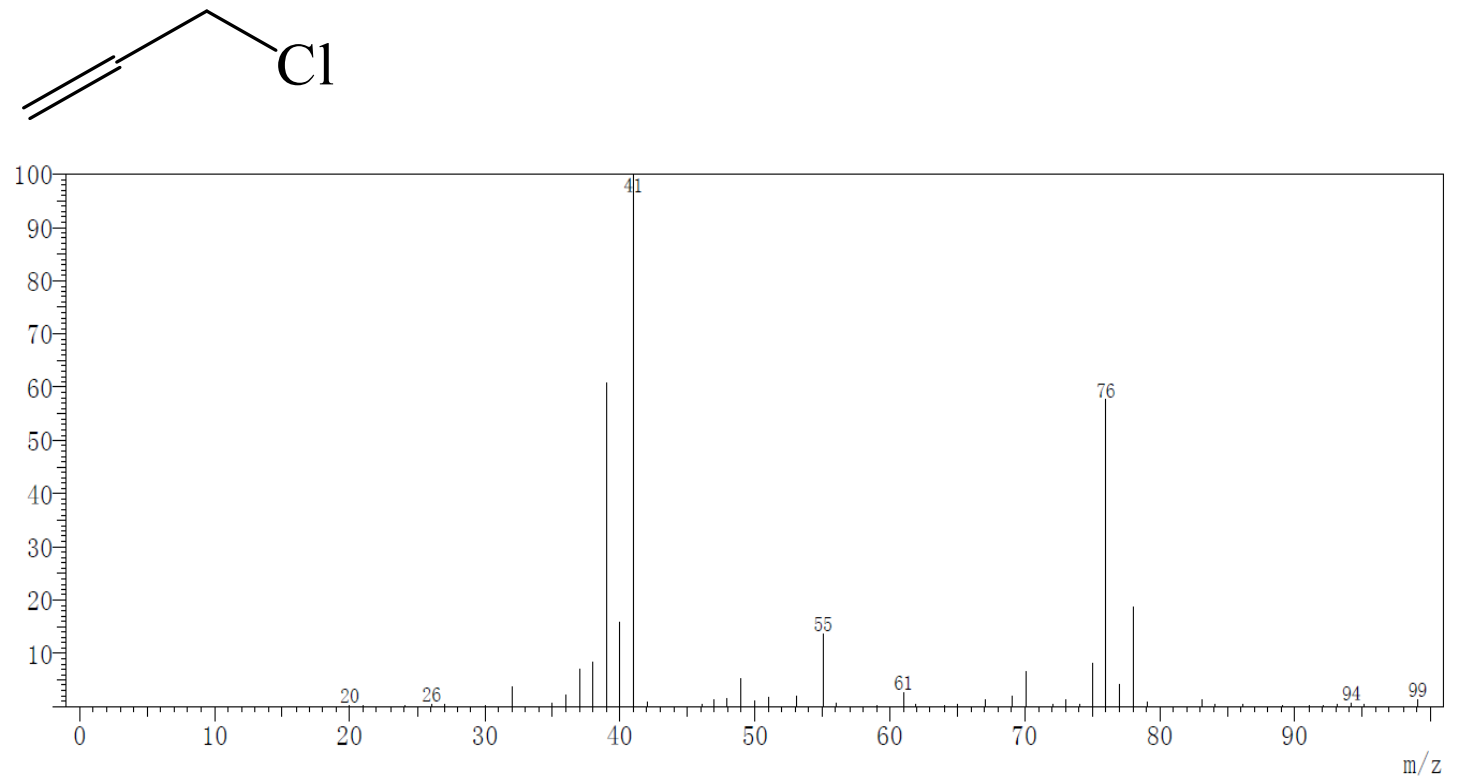

35.
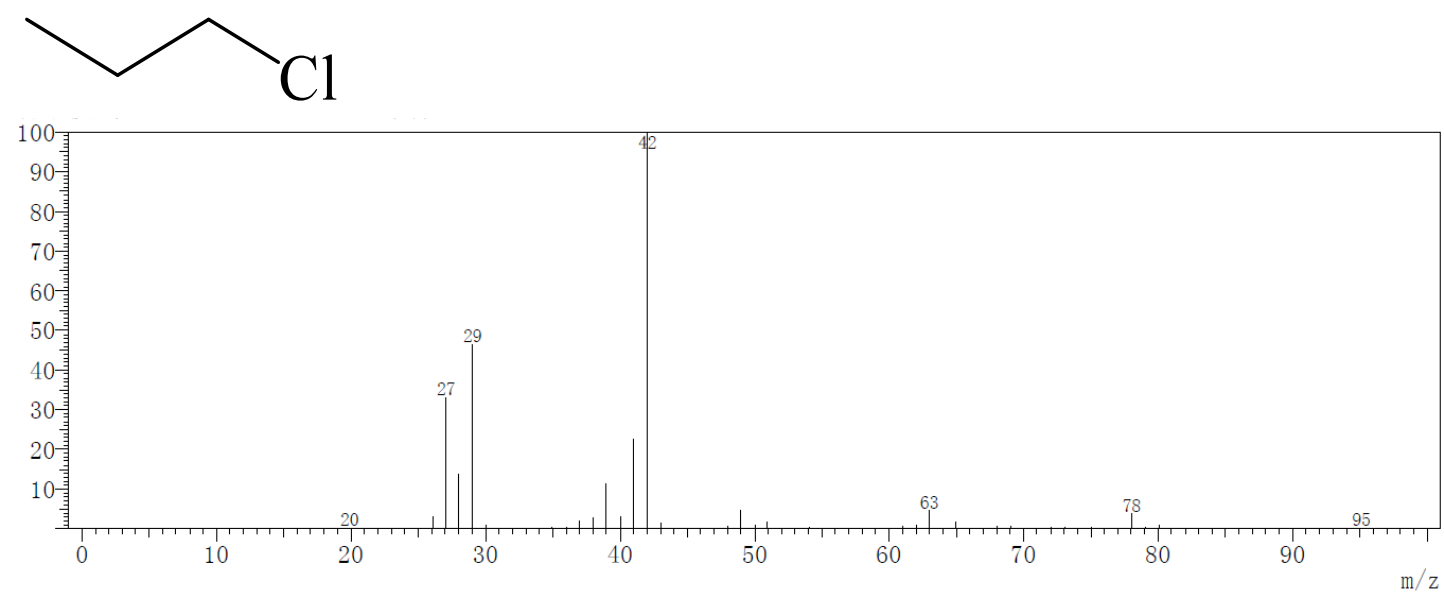


\section{Theoretical calculation method}

All the structures were fully optimized with DFT-D3 method including dispersion corrections (B3LYP-D3(BJ) method using EmpiricalDispersion=GD3BJ keyword) [5-8]. 6-311+G* basis set was used for all atoms (abbreviation as: B3LYP-D3(BJ)/6-311+G*). The influence of toluene solvent was investigated in condensed phase using the Polarizable Continuum Model (PCM) at B3LYP-D3(BJ)/6-311++G** method. Energy calculations as well as Zero-point energy (ZPE) correction have been done by using the same level of theory.

The computed stationary points have been characterized as minima or transition states by diagonalizing the Hessian matrix and analyzing the vibrational normal modes. In this way, the stationary points can be classified as minima if no imaginary frequencies are shown or as transition states if only one imaginary frequency is obtained. The particular nature of the transition states has been determined by analyzing the motion described by the eigenvector associated with the imaginary frequency. All calculations were performed with the Gaussian 09 suite of programs ${ }^{[9]}$.

\section{Cartesians coordinates of the optimized structures}

$\mathrm{TS}_{\mathrm{BPh} 3}$

$\begin{array}{ccrrr}6 & 0 & -4.979270 & -0.190316 & -1.636572 \\ 6 & 0 & -4.094400 & -0.558839 & -2.647631 \\ 6 & 0 & -2.731890 & -0.463331 & -2.401441 \\ 7 & 0 & -2.257641 & -0.029509 & -1.228806 \\ 6 & 0 & -3.097212 & 0.328414 & -0.247823 \\ 6 & 0 & -4.473872 & 0.258472 & -0.418792 \\ 1 & 0 & -6.049727 & -0.252925 & -1.796171 \\ 1 & 0 & -4.448948 & -0.914242 & -3.607096 \\ 1 & 0 & -1.989496 & -0.737128 & -3.143463 \\ 1 & 0 & -2.644729 & 0.669457 & 0.673380 \\ 1 & 0 & -5.130738 & 0.553795 & 0.389909 \\ 5 & 0 & 0.826999 & 0.016612 & -0.009793 \\ 6 & 0 & 0.930767 & -1.528077 & 0.417116 \\ 6 & 0 & -0.016699 & 0.971364 & 0.970630 \\ 6 & 0 & 2.165389 & 0.658469 & -0.621278 \\ 6 & 0 & 2.171447 & -2.145391 & 0.636391\end{array}$




\begin{tabular}{|c|c|c|c|c|}
\hline 6 & 0 & 2.272199 & -3.476285 & 1.045515 \\
\hline 6 & 0 & 1.122031 & -4.238162 & 1.238173 \\
\hline 6 & 0 & -0.126503 & -3.652580 & 1.023953 \\
\hline 6 & 0 & -0.212262 & -2.320008 & 0.627398 \\
\hline 6 & 0 & 2.744675 & 0.154032 & -1.798050 \\
\hline 6 & 0 & 3.935332 & 0.662277 & -2.310975 \\
\hline 6 & 0 & 4.594894 & 1.698155 & -1.647073 \\
\hline 6 & 0 & 4.047308 & 2.213502 & -0.474550 \\
\hline 6 & 0 & 2.847854 & 1.700359 & 0.023433 \\
\hline 6 & 0 & -0.431221 & 0.570543 & 2.248745 \\
\hline 6 & 0 & -1.206702 & 1.397969 & 3.064550 \\
\hline 6 & 0 & -1.592991 & 2.659348 & 2.615665 \\
\hline 6 & 0 & -1.180421 & 3.090934 & 1.353078 \\
\hline 6 & 0 & -0.400659 & 2.258523 & 0.554621 \\
\hline 1 & 0 & 3.080072 & -1.572519 & 0.482946 \\
\hline 1 & 0 & 3.250340 & -3.918569 & 1.210356 \\
\hline 1 & 0 & 1.195061 & -5.274852 & 1.551864 \\
\hline 1 & 0 & -1.031600 & -4.234976 & 1.171179 \\
\hline 1 & 0 & -1.197055 & -1.886151 & 0.481163 \\
\hline 1 & 0 & 2.251943 & -0.662079 & -2.321027 \\
\hline 1 & 0 & 4.352890 & 0.251305 & -3.225589 \\
\hline 1 & 0 & 5.524630 & 2.097083 & -2.040741 \\
\hline 1 & 0 & 4.552271 & 3.017446 & 0.053036 \\
\hline 1 & 0 & 2.435652 & 2.119560 & 0.935892 \\
\hline 1 & 0 & -0.153811 & -0.413891 & 2.610586 \\
\hline 1 & 0 & -1.511490 & 1.055293 & 4.048937 \\
\hline 1 & 0 & -2.200626 & 3.303415 & 3.243537 \\
\hline 1 & 0 & -1.468865 & 4.074571 & 0.994576 \\
\hline 1 & 0 & -0.091385 & 2.608981 & -0.426551 \\
\hline 1 & 0 & -0.863319 & -0.008629 & -1.116189 \\
\hline 1 & 0 & 0.080654 & -0.047669 & -1.210421 \\
\hline
\end{tabular}

$\begin{array}{lllll}\mathrm{TS}_{\mathrm{B}(\mathrm{DiMe}) \mathrm{Ph} 3} & & & & \\ 6 & 0 & 4.928679 & -0.111340 & -2.625134 \\ 6 & 0 & 3.894221 & -0.099074 & -3.558381 \\ 6 & 0 & 2.585877 & -0.088713 & -3.095142 \\ 7 & 0 & 2.303726 & -0.091877 & -1.788315 \\ 6 & 0 & 3.287884 & -0.104455 & -0.879319 \\ 6 & 0 & 4.621547 & -0.112168 & -1.266585 \\ 1 & 0 & 5.961776 & -0.119977 & -2.953716 \\ 1 & 0 & 4.093212 & -0.097192 & -4.622771 \\ 1 & 0 & 1.733821 & -0.077993 & -3.766524 \\ 1 & 0 & 2.983843 & -0.108880 & 0.158934 \\ 1 & 0 & 5.398862 & -0.123016 & -0.512677\end{array}$




\begin{tabular}{|c|c|c|c|c|}
\hline 1 & 0 & 0.960416 & -0.079937 & -1.458078 \\
\hline 5 & 0 & -0.551870 & -0.025262 & -0.102264 \\
\hline 6 & 0 & -0.751537 & 1.550557 & 0.128825 \\
\hline 6 & 0 & 0.525745 & -0.736807 & 0.855870 \\
\hline 6 & 0 & -1.894962 & -0.853264 & -0.395596 \\
\hline 6 & 0 & -1.958303 & 2.062856 & 0.612720 \\
\hline 6 & 0 & -2.137308 & 3.425626 & 0.889482 \\
\hline 6 & 0 & -1.076072 & 4.298077 & 0.658945 \\
\hline 6 & 0 & 0.151085 & 3.833292 & 0.166691 \\
\hline 6 & 0 & 0.291906 & 2.470177 & -0.082356 \\
\hline 6 & 0 & -2.713437 & -0.528581 & -1.492637 \\
\hline 6 & 0 & -3.917789 & -1.179249 & -1.745257 \\
\hline 6 & 0 & -4.327893 & -2.189632 & -0.863404 \\
\hline 6 & 0 & -3.554231 & -2.542856 & 0.239323 \\
\hline 6 & 0 & -2.343007 & -1.868571 & 0.453217 \\
\hline 6 & 0 & 1.094562 & -0.088612 & 1.956822 \\
\hline 6 & 0 & 2.091573 & -0.683488 & 2.742372 \\
\hline 6 & 0 & 2.533442 & -1.961900 & 2.402170 \\
\hline 6 & 0 & 1.979303 & -2.658501 & 1.319578 \\
\hline 6 & 0 & 0.981879 & -2.036054 & 0.572138 \\
\hline 6 & 0 & 2.663007 & 0.044426 & 3.934092 \\
\hline 6 & 0 & 2.453450 & -4.051144 & 0.985334 \\
\hline 6 & 0 & 1.285613 & 4.796641 & -0.083769 \\
\hline 6 & 0 & -3.455378 & 3.924887 & 1.428635 \\
\hline 6 & 0 & -3.998432 & -3.627832 & 1.189602 \\
\hline 6 & 0 & -4.769500 & -0.817195 & -2.937383 \\
\hline 1 & 0 & -2.789455 & 1.383451 & 0.780892 \\
\hline 1 & 0 & -1.201055 & 5.359426 & 0.862650 \\
\hline 1 & 0 & 1.249788 & 2.112233 & -0.451878 \\
\hline 1 & 0 & -2.400117 & 0.268474 & -2.163786 \\
\hline 1 & 0 & -5.269278 & -2.704421 & -1.043733 \\
\hline 1 & 0 & -1.738793 & -2.145576 & 1.312876 \\
\hline 1 & 0 & 0.770189 & 0.918594 & 2.200598 \\
\hline 1 & 0 & 3.318827 & -2.430612 & 2.991304 \\
\hline 1 & 0 & 0.558837 & -2.566587 & -0.277739 \\
\hline 1 & 0 & 2.792705 & 1.110261 & 3.728385 \\
\hline 1 & 0 & 1.996181 & -0.034263 & 4.799502 \\
\hline 1 & 0 & 3.631635 & -0.364832 & 4.231126 \\
\hline 1 & 0 & 2.094719 & -4.779173 & 1.720746 \\
\hline 1 & 0 & 2.091757 & -4.370730 & 0.005719 \\
\hline 1 & 0 & 3.545634 & -4.115609 & 0.979616 \\
\hline 1 & 0 & 1.022748 & 5.536056 & -0.847383 \\
\hline 1 & 0 & 1.547700 & 5.353193 & 0.821735 \\
\hline 1 & 0 & 2.183031 & 4.274702 & -0.424241 \\
\hline
\end{tabular}




$\begin{array}{llrrr}1 & 0 & -4.286478 & 3.638625 & 0.776891 \\ 1 & 0 & -3.665975 & 3.501671 & 2.416135 \\ 1 & 0 & -3.465071 & 5.013027 & 1.525200 \\ 1 & 0 & -4.966933 & -4.043055 & 0.901534 \\ 1 & 0 & -3.277992 & -4.451688 & 1.218161 \\ 1 & 0 & -4.088697 & -3.249490 & 2.212674 \\ 1 & 0 & -4.818651 & -1.639468 & -3.659222 \\ 1 & 0 & -5.798519 & -0.590481 & -2.641699 \\ 1 & 0 & -4.372347 & 0.056797 & -3.458291 \\ 1 & 0 & 0.005415 & -0.066709 & -1.398522\end{array}$

$\mathrm{TS}_{\mathrm{B}(\mathrm{C} 6 \mathrm{~F} 2 \mathrm{H} 3) 3}$

$\begin{array}{llrrr}6 & 0 & 5.254784 & -0.206594 & -1.263959 \\ 6 & 0 & 4.498386 & -1.175374 & -1.918376 \\ 6 & 0 & 3.124019 & -0.986844 & -2.020089 \\ 7 & 0 & 2.505204 & 0.085470 & -1.518520 \\ 6 & 0 & 3.231739 & 1.016071 & -0.890915 \\ 6 & 0 & 4.610137 & 0.911182 & -0.741089 \\ 1 & 0 & 6.328192 & -0.322621 & -1.161110 \\ 1 & 0 & 4.958762 & -2.061857 & -2.338390 \\ 1 & 0 & 2.490157 & -1.721893 & -2.505568 \\ 1 & 0 & 2.681367 & 1.857692 & -0.488628 \\ 1 & 0 & 5.159476 & 1.686086 & -0.219737 \\ 1 & 0 & 0.767360 & 0.039554 & -1.423556 \\ 5 & 0 & -0.715306 & 0.008781 & 0.053539 \\ 6 & 0 & -1.476204 & 1.389602 & -0.181145 \\ 6 & 0 & 0.521864 & -0.049520 & 1.049419 \\ 6 & 0 & -1.578878 & -1.312778 & -0.163962 \\ 6 & 0 & -2.824613 & 1.572703 & 0.131005 \\ 6 & 0 & -3.525734 & 2.753381 & -0.061625 \\ 6 & 0 & -2.855158 & 3.843098 & -0.606473 \\ 6 & 0 & -1.505208 & 3.738641 & -0.932832 \\ 6 & 0 & -0.868918 & 2.532787 & -0.700781 \\ 6 & 0 & -2.208018 & -1.610379 & -1.372779 \\ 6 & 0 & -2.996421 & -2.724592 & -1.604340 \\ 6 & 0 & -3.203395 & -3.613275 & -0.552719 \\ 6 & 0 & -2.624681 & -3.371474 & 0.689861 \\ 6 & 0 & -1.838804 & -2.241130 & 0.843875 \\ 6 & 0 & 0.848401 & 0.936218 & 1.982413 \\ 6 & 0 & 1.963306 & 0.902264 & 2.806948 \\ 6 & 0 & 2.826387 & -0.184620 & 2.715153 \\ 6 & 0 & 2.558122 & -1.215206 & 1.818625 \\ 6 & 0 & 1.425585 & -1.116893 & 1.031979 \\ 9 & 0 & 0.457684 & 2.467282 & -1.009256\end{array}$




$\begin{array}{ccrcc}9 & 0 & -3.512699 & 0.542637 & 0.692496 \\ 9 & 0 & -1.315214 & -2.022327 & 2.080306 \\ 9 & 0 & -2.031957 & -0.748726 & -2.414346 \\ 9 & 0 & 1.198873 & -2.131786 & 0.155503 \\ 9 & 0 & 0.030235 & 2.011992 & 2.121248 \\ 1 & 0 & -4.571053 & 2.805794 & 0.216840 \\ 1 & 0 & -3.381243 & 4.776385 & -0.770398 \\ 1 & 0 & -0.950281 & 4.569640 & -1.350484 \\ 1 & 0 & -3.437756 & -2.879479 & -2.581198 \\ 1 & 0 & -3.821908 & -4.491078 & -0.699876 \\ 1 & 0 & -2.778183 & -4.036170 & 1.531099 \\ 1 & 0 & 2.137180 & 1.713217 & 3.503492 \\ 1 & 0 & 3.706278 & -0.231598 & 3.346364 \\ 1 & 0 & 3.209126 & -2.074808 & 1.720275 \\ 1 & 0 & -0.039847 & -0.066326 & -1.399887\end{array}$

$\begin{array}{llrrr}\mathrm{TS} \mathrm{B}_{\mathrm{C} 6 \mathrm{~F} 3 \mathrm{H} 2) 3} & & & & \\ 6 & 0 & 5.135904 & -0.208370 & -1.892225 \\ 6 & 0 & 4.313423 & -1.178319 & -2.459407 \\ 6 & 0 & 2.938397 & -0.970036 & -2.451395 \\ 7 & 0 & 2.379779 & 0.124234 & -1.926098 \\ 6 & 0 & 3.170383 & 1.059590 & -1.387962 \\ 6 & 0 & 4.554157 & 0.933862 & -1.348714 \\ 1 & 0 & 6.211794 & -0.342070 & -1.871408 \\ 1 & 0 & 4.723798 & -2.082212 & -2.893624 \\ 1 & 0 & 2.255354 & -1.706494 & -2.861866 \\ 1 & 0 & 2.669898 & 1.922407 & -0.966517 \\ 1 & 0 & 5.156602 & 1.711203 & -0.894218 \\ 1 & 0 & 0.696740 & 0.072200 & -1.622349 \\ 5 & 0 & -0.598823 & 0.005525 & 0.069893 \\ 6 & 0 & -1.406124 & 1.374302 & -0.045410 \\ 6 & 0 & 0.763151 & -0.038777 & 0.885970 \\ 6 & 0 & -1.462375 & -1.327149 & -0.046834 \\ 6 & 0 & -2.710212 & 1.529851 & 0.428495 \\ 6 & 0 & -3.455417 & 2.696859 & 0.341163 \\ 6 & 0 & -2.852083 & 3.782495 & -0.266508 \\ 6 & 0 & -1.558980 & 3.734795 & -0.759965 \\ 6 & 0 & -0.885396 & 2.534527 & -0.618546 \\ 6 & 0 & -2.267976 & -1.603819 & -1.151853 \\ 6 & 0 & -3.065016 & -2.726950 & -1.300870 \\ 6 & 0 & -3.069195 & -3.628641 & -0.250564 \\ 6 & 0 & -2.322559 & -3.436906 & 0.898633 \\ 6 & -1.544489 & -2.291327 & 0.957851 \\ 6 & 0 & 1.213974 & 0.959257 & 1.751842\end{array}$




$\begin{array}{ccrrc}6 & 0 & 2.440902 & 0.955066 & 2.400506 \\ 6 & 0 & 3.271133 & -0.126352 & 2.168907 \\ 6 & 0 & 2.910020 & -1.179146 & 1.346301 \\ 6 & 0 & 1.667623 & -1.096426 & 0.744375 \\ 9 & 0 & 0.390231 & 2.501136 & -1.085310 \\ 9 & 0 & -3.546486 & 4.937418 & -0.376569 \\ 9 & 0 & -3.311311 & 0.486961 & 1.052353 \\ 9 & 0 & -0.837877 & -2.105751 & 2.100378 \\ 9 & 0 & -3.837867 & -4.737249 & -0.349390 \\ 9 & 0 & -2.274988 & -0.715370 & -2.178770 \\ 9 & 0 & 1.331009 & -2.122342 & -0.074972 \\ 9 & 0 & 0.418373 & 2.025234 & 2.006353 \\ 9 & 0 & 4.481946 & -0.157346 & 2.769640 \\ 1 & 0 & -4.460890 & 2.751352 & 0.736716 \\ 1 & 0 & -1.093845 & 4.593255 & -1.225792 \\ 1 & 0 & -3.659151 & -2.884742 & -2.191090 \\ 1 & 0 & -2.347218 & -4.143161 & 1.717815 \\ 1 & 0 & 2.728851 & 1.762836 & 3.060069 \\ 1 & 0 & 3.567646 & -2.019498 & 1.170221 \\ 1 & 0 & -0.106643 & -0.036874 & -1.460881\end{array}$

$\begin{array}{llrrc}\mathrm{TS}_{\mathrm{B}(\mathrm{C} 6 \mathrm{F5}) 3} & & & & \\ 6 & 0 & -5.201963 & -0.201212 & 2.092460 \\ 6 & 0 & -4.377894 & -1.186284 & 2.629364 \\ 6 & 0 & -3.005789 & -0.960756 & 2.660267 \\ 7 & 0 & -2.447016 & 0.163063 & 2.198434 \\ 6 & 0 & -3.242731 & 1.115073 & 1.696179 \\ 6 & 0 & -4.624198 & 0.974926 & 1.621249 \\ 1 & 0 & -6.274754 & -0.348673 & 2.039190 \\ 1 & 0 & -4.784066 & -2.117374 & 3.005696 \\ 1 & 0 & -2.324252 & -1.710422 & 3.048757 \\ 1 & 0 & -2.750246 & 2.008999 & 1.333704 \\ 1 & 0 & -5.227686 & 1.768781 & 1.197479 \\ 1 & 0 & -0.693212 & 0.097572 & 1.837768 \\ 5 & 0 & 0.475664 & 0.003454 & -0.025060 \\ 6 & 0 & 1.255235 & 1.388946 & 0.007324 \\ 6 & 0 & -0.958054 & -0.092849 & -0.690542 \\ 6 & 0 & 1.374358 & -1.303277 & 0.068053 \\ 6 & 0 & 2.509892 & 1.534646 & -0.585093 \\ 6 & 0 & 3.219298 & 2.728575 & -0.574882 \\ 6 & 0 & 2.677184 & 3.839456 & 0.054410 \\ 6 & 0 & 1.428175 & 3.743046 & 0.654278 \\ 6 & 0 & 0.746280 & 2.538131 & 0.609564 \\ 6 & 0 & 2.275450 & -1.498833 & 1.113485\end{array}$




$\begin{array}{rrrrr}6 & 0 & 3.106262 & -2.605192 & 1.203710 \\ 6 & 0 & 3.069763 & -3.564199 & 0.200292 \\ 6 & 0 & 2.202924 & -3.401555 & -0.871687 \\ 6 & 0 & 1.377232 & -2.287704 & -0.918390 \\ 6 & 0 & -1.512275 & 0.899373 & -1.499304 \\ 6 & 0 & -2.803457 & 0.828456 & -2.006256 \\ 6 & 0 & -3.596179 & -0.270449 & -1.709717 \\ 6 & 0 & -3.082708 & -1.292736 & -0.923230 \\ 6 & 0 & -1.789926 & -1.187564 & -0.439803 \\ 9 & 0 & -0.469885 & 2.509297 & 1.188166 \\ 9 & 0 & 0.893852 & 4.811804 & 1.256878 \\ 9 & 0 & 3.345263 & 4.993399 & 0.077337 \\ 9 & 0 & 4.414644 & 2.817050 & -1.168973 \\ 9 & 0 & 3.084779 & 0.504249 & -1.234217 \\ 9 & 0 & 0.577330 & -2.174229 & -1.995623 \\ 9 & 0 & 2.174853 & -4.315903 & -1.848348 \\ 9 & 0 & 3.866431 & -4.632313 & 0.263755 \\ 9 & 0 & 3.941609 & -2.754395 & 2.238502 \\ 9 & 0 & 2.358702 & -0.590030 & 2.104703 \\ 9 & 0 & -1.356437 & -2.193469 & 0.341100 \\ 9 & 0 & -0.803273 & 1.991356 & -1.836127 \\ 9 & 0 & -3.843117 & -2.353827 & -0.630126 \\ 9 & 0 & -4.843081 & -0.344612 & -2.176074 \\ 9 & 0 & -3.292057 & 1.812875 & -2.770187 \\ 1 & 0 & 0.077203 & -0.016981 & 1.626403\end{array}$

$\mathrm{BPh}_{3} / \mathrm{Py}$

$\begin{array}{rrrrr}6 & 0 & 1.391814 & -0.564978 & 4.069007 \\ 6 & 0 & 1.832258 & -1.378673 & 3.028063 \\ 6 & 0 & 1.369544 & -1.138662 & 1.746571 \\ 7 & 0 & 0.499650 & -0.146184 & 1.472182 \\ 6 & 0 & 0.070676 & 0.638499 & 2.474062 \\ 6 & 0 & 0.496747 & 0.459264 & 3.782160 \\ 5 & 0 & -0.023755 & 0.016088 & -0.095309 \\ 6 & 0 & -0.807674 & 1.438420 & -0.224789 \\ 6 & 0 & -1.046458 & -1.213397 & -0.381126 \\ 6 & 0 & 1.339871 & -0.046839 & -0.982060 \\ 6 & 0 & -0.218163 & 2.596512 & -0.752359 \\ 6 & 0 & -0.910164 & 3.806369 & -0.838112 \\ 6 & 0 & -2.226985 & 3.894057 & -0.392808 \\ 6 & 0 & -2.845482 & 2.756816 & 0.127097 \\ 6 & 0 & -2.144535 & 1.554756 & 0.199637 \\ 6 & 0 & 2.466308 & 0.714936 & -0.618759 \\ 6 & 0 & 3.643557 & 0.705896 & -1.363338\end{array}$




\begin{tabular}{|c|c|c|c|c|}
\hline 6 & 0 & 3.734298 & -0.078412 & -2.513436 \\
\hline 6 & 0 & 2.639055 & -0.849183 & -2.894967 \\
\hline 6 & 0 & 1.466826 & -0.832316 & -2.136054 \\
\hline 6 & 0 & -1.753046 & -1.213730 & -1.598654 \\
\hline 6 & 0 & -2.645495 & -2.225619 & -1.939578 \\
\hline 6 & 0 & -2.877398 & -3.282132 & -1.057086 \\
\hline 6 & 0 & -2.208952 & -3.300756 & 0.162765 \\
\hline 6 & 0 & -1.310454 & -2.280394 & 0.487899 \\
\hline 1 & 0 & 1.742553 & -0.725682 & 5.081932 \\
\hline 1 & 0 & 2.529489 & -2.189039 & 3.198948 \\
\hline 1 & 0 & 1.687608 & -1.729374 & 0.899807 \\
\hline 1 & 0 & -0.621572 & 1.419751 & 2.197100 \\
\hline 1 & 0 & 0.127737 & 1.121350 & 4.555161 \\
\hline 1 & 0 & 0.800478 & 2.555011 & -1.120803 \\
\hline 1 & 0 & -0.420617 & 4.679363 & -1.259860 \\
\hline 1 & 0 & -2.769200 & 4.832084 & -0.460018 \\
\hline 1 & 0 & -3.876458 & 2.804900 & 0.465308 \\
\hline 1 & 0 & -2.652982 & 0.676788 & 0.587263 \\
\hline 1 & 0 & 2.427634 & 1.331476 & 0.275866 \\
\hline 1 & 0 & 4.489499 & 1.310051 & -1.048493 \\
\hline 1 & 0 & 4.647788 & -0.090748 & -3.099634 \\
\hline 1 & 0 & 2.696860 & -1.472002 & -3.782873 \\
\hline 1 & 0 & 0.636585 & -1.454484 & -2.450818 \\
\hline 1 & 0 & -1.608085 & -0.389711 & -2.290816 \\
\hline 1 & 0 & -3.167549 & -2.188164 & -2.891165 \\
\hline 1 & 0 & -3.575792 & -4.071890 & -1.315204 \\
\hline 1 & 0 & -2.387173 & -4.107132 & 0.868334 \\
\hline 1 & 0 & -0.822460 & -2.332307 & 1.456443 \\
\hline \multicolumn{5}{|c|}{$\mathrm{B}(\mathrm{DiMe}) \mathrm{Ph}_{3} / \mathrm{Py}$} \\
\hline 6 & 0 & 0.391649 & -0.362522 & 4.631066 \\
\hline 6 & 0 & 0.579619 & -1.459325 & 3.793729 \\
\hline 6 & 0 & 0.470132 & -1.285901 & 2.425333 \\
\hline 7 & 0 & 0.180070 & -0.090411 & 1.874916 \\
\hline 6 & 0 & -0.002510 & 0.969154 & 2.679278 \\
\hline 6 & 0 & 0.097010 & 0.870000 & 4.059611 \\
\hline 1 & 0 & 0.476875 & -0.467517 & 5.706562 \\
\hline 1 & 0 & 0.812923 & -2.439800 & 4.189165 \\
\hline 1 & 0 & 0.620079 & -2.096898 & 1.727493 \\
\hline 1 & 0 & -0.225072 & 1.902916 & 2.184065 \\
\hline 1 & 0 & -0.052740 & 1.753884 & 4.666690 \\
\hline 5 & 0 & 0.028599 & -0.014664 & 0.222559 \\
\hline 6 & 0 & -0.009994 & 1.553810 & -0.212787 \\
\hline 6 & 0 & -1.376473 & -0.734602 & -0.158331 \\
\hline
\end{tabular}




\begin{tabular}{|c|c|c|c|c|}
\hline 6 & 0 & 1.337194 & -0.804512 & -0.334809 \\
\hline 6 & 0 & 1.091834 & 2.230035 & -0.742336 \\
\hline 6 & 0 & 1.040764 & 3.583984 & -1.105561 \\
\hline 6 & 0 & -0.152055 & 4.279476 & -0.925882 \\
\hline 6 & 0 & -1.289231 & 3.644476 & -0.408787 \\
\hline 6 & 0 & -1.198578 & 2.296380 & -0.069470 \\
\hline 6 & 0 & 2.616041 & -0.513807 & 0.179226 \\
\hline 6 & 0 & 3.771929 & -1.143765 & -0.275444 \\
\hline 6 & 0 & 3.651843 & -2.107985 & -1.285288 \\
\hline 6 & 0 & 2.409245 & -2.434992 & -1.821763 \\
\hline 6 & 0 & 1.269834 & -1.779355 & -1.332210 \\
\hline 6 & 0 & -1.815890 & -0.639103 & -1.493095 \\
\hline 6 & 0 & -2.995029 & -1.226468 & -1.940727 \\
\hline 6 & 0 & -3.784307 & -1.930682 & -1.020171 \\
\hline 6 & 0 & -3.402503 & -2.040612 & 0.312801 \\
\hline 6 & 0 & -2.201866 & -1.438203 & 0.721016 \\
\hline 6 & 0 & 2.277665 & -3.472526 & -2.909771 \\
\hline 6 & 0 & 5.127089 & -0.796776 & 0.290218 \\
\hline 6 & 0 & -3.424515 & -1.113749 & -3.382632 \\
\hline 6 & 0 & -4.252171 & -2.791479 & 1.308901 \\
\hline 6 & 0 & -2.579361 & 4.408823 & -0.240466 \\
\hline 6 & 0 & 2.256654 & 4.258097 & -1.692918 \\
\hline 1 & 0 & 2.021924 & 1.692554 & -0.896431 \\
\hline 1 & 0 & -0.207417 & 5.329824 & -1.203870 \\
\hline 1 & 0 & -2.087423 & 1.797025 & 0.307425 \\
\hline 1 & 0 & 2.715904 & 0.229968 & 0.966752 \\
\hline 1 & 0 & 4.543819 & -2.611723 & -1.651384 \\
\hline 1 & 0 & 0.303166 & -2.050639 & -1.744622 \\
\hline 1 & 0 & -1.218330 & -0.071779 & -2.201246 \\
\hline 1 & 0 & -4.713403 & -2.388616 & -1.352270 \\
\hline 1 & 0 & -1.935135 & -1.527600 & 1.771071 \\
\hline 1 & 0 & 1.547844 & -4.242152 & -2.640982 \\
\hline 1 & 0 & 1.933945 & -3.022740 & -3.846987 \\
\hline 1 & 0 & 3.229780 & -3.968929 & -3.110736 \\
\hline 1 & 0 & 5.653350 & -1.686968 & 0.648625 \\
\hline 1 & 0 & 5.767610 & -0.330984 & -0.466021 \\
\hline 1 & 0 & 5.043260 & -0.098973 & 1.126453 \\
\hline 1 & 0 & -3.407632 & -2.088747 & -3.881291 \\
\hline 1 & 0 & -4.445565 & -0.729314 & -3.468271 \\
\hline 1 & 0 & -2.767355 & -0.444845 & -3.942175 \\
\hline 1 & 0 & -3.739653 & -3.687069 & 1.675983 \\
\hline 1 & 0 & -4.483037 & -2.175098 & 2.183394 \\
\hline 1 & 0 & -5.198982 & -3.111710 & 0.868438 \\
\hline 1 & 0 & -2.455939 & 5.261637 & 0.435133 \\
\hline
\end{tabular}




$\begin{array}{rrrrr}1 & 0 & -2.934585 & 4.808306 & -1.195719 \\ 1 & 0 & -3.368320 & 3.772339 & 0.165813 \\ 1 & 0 & 3.127440 & 4.154323 & -1.038270 \\ 1 & 0 & 2.528708 & 3.813688 & -2.655725 \\ 1 & 0 & 2.086356 & 5.324600 & -1.856644\end{array}$

$\mathrm{B}\left(\mathrm{C}_{6} \mathrm{~F}_{2} \mathrm{H}_{3}\right)_{3} / \mathrm{Py}$

$\begin{array}{llrrr}6 & 0 & -1.762366 & -3.037568 & -2.772216 \\ 6 & 0 & -1.693753 & -3.256930 & -1.397729 \\ 6 & 0 & -1.106195 & -2.298685 & -0.597144 \\ 7 & 0 & -0.589571 & -1.160818 & -1.103063 \\ 6 & 0 & -0.667846 & -0.937848 & -2.423491 \\ 6 & 0 & -1.243935 & -1.856543 & -3.287356 \\ 1 & 0 & -2.217881 & -3.772378 & -3.425816 \\ 1 & 0 & -2.089126 & -4.157788 & -0.946602 \\ 1 & 0 & -1.033492 & -2.414658 & 0.474780 \\ 1 & 0 & -0.274396 & 0.002785 & -2.774841 \\ 1 & 0 & -1.283184 & -1.634307 & -4.345898 \\ 5 & 0 & -0.040063 & -0.045726 & -0.032772 \\ 6 & 0 & 0.715485 & 1.178021 & -0.814098 \\ 6 & 0 & 1.122071 & -0.684344 & 0.926098 \\ 6 & 0 & -1.445525 & 0.344571 & 0.713883 \\ 6 & 0 & 0.512622 & 2.544393 & -0.602942 \\ 6 & 0 & 1.263866 & 3.557539 & -1.183270 \\ 6 & 0 & 2.309464 & 3.218338 & -2.034001 \\ 6 & 0 & 2.589019 & 1.877221 & -2.279801 \\ 6 & 0 & 1.799627 & 0.923643 & -1.659846 \\ 6 & 0 & -2.458910 & 0.998653 & 0.008564 \\ 6 & 0 & -3.707223 & 1.329140 & 0.503089 \\ 6 & 0 & -4.009792 & 0.969485 & 1.814286 \\ 6 & 0 & -3.070800 & 0.280691 & 2.572307 \\ 6 & 0 & -1.840781 & -0.018501 & 2.000408 \\ 6 & 0 & 1.593364 & 0.082119 & 1.996979 \\ 6 & 0.635264 & -0.260718 & 2.838772 \\ 6 & 0 & 3.297458 & -1.465081 & 2.612447 \\ 6 & 0 & 2.903894 & -2.275580 & 1.555251 \\ 9 & 0 & 1.849825 & -1.860120 & 0.752044 \\ 6 & 0 & -2.211866 & 1.338148 & -1.292841 \\ 9 & 0.992204 & -0.749612 & 2.778910 \\ 9 & 0 & 0.534626 & -2.701310 & -0.281097 \\ 9 & 0 & 1.275751 & 2.235495 \\ 9 & 0 & 0.382135 & -1.911052 \\ 6 & 0 & 0.236336 \\ 6 & 0 & 0.952816 & 0.589364 & -0.956358\end{array}$




$\begin{array}{llrcc}1 & 0 & 2.908853 & 3.993844 & -2.496750 \\ 1 & 0 & 3.402841 & 1.566738 & -2.923660 \\ 1 & 0 & -4.414934 & 1.854472 & -0.126559 \\ 1 & 0 & -4.976499 & 1.216795 & 2.237557 \\ 1 & 0 & -3.274582 & -0.032692 & 3.589020 \\ 1 & 0 & 2.914560 & 0.405760 & 3.645672 \\ 1 & 0 & 4.118856 & -1.764734 & 3.253035 \\ 1 & 0 & 3.400605 & -3.213149 & 1.336545\end{array}$

$\mathrm{B}\left(\mathrm{C}_{6} \mathrm{~F}_{3} \mathrm{H}_{2}\right)_{3} / \mathrm{Py}$

\begin{tabular}{|c|c|c|c|c|}
\hline 6 & 0 & 1.457173 & -0.284196 & 4.416493 \\
\hline 6 & 0 & 1.541632 & -1.373340 & 3.551149 \\
\hline 6 & 0 & 1.064484 & -1.241418 & 2.263140 \\
\hline 7 & 0 & 0.512101 & -0.094899 & 1.817231 \\
\hline 6 & 0 & 0.444701 & 0.961484 & 2.641767 \\
\hline 6 & 0 & 0.903646 & 0.900537 & 3.948268 \\
\hline 1 & 0 & 1.823442 & -0.358613 & 5.433726 \\
\hline 1 & 0 & 1.971024 & -2.315609 & 3.865870 \\
\hline 1 & 0 & 1.111958 & -2.052048 & 1.550220 \\
\hline 1 & 0 & 0.032193 & 1.867344 & 2.226731 \\
\hline 1 & 0 & 0.827275 & 1.778170 & 4.576983 \\
\hline 5 & 0 & 0.097141 & -0.026841 & 0.232311 \\
\hline 6 & 0 & -0.695717 & 1.367933 & -0.093406 \\
\hline 6 & 0 & -0.982077 & -1.200358 & -0.137819 \\
\hline 6 & 0 & 1.571129 & -0.178636 & -0.465999 \\
\hline 6 & 0 & -0.426287 & 2.250307 & -1.143008 \\
\hline 6 & 0 & -1.200199 & 3.353237 & -1.481348 \\
\hline 6 & 0 & -2.332929 & 3.590634 & -0.726801 \\
\hline 6 & 0 & -2.704745 & 2.768112 & 0.321686 \\
\hline 6 & 0 & -1.876929 & 1.688068 & 0.582534 \\
\hline 6 & 0 & 2.535052 & 0.817053 & -0.287746 \\
\hline 6 & 0 & 3.830564 & 0.796975 & -0.773405 \\
\hline 6 & 0 & 4.204915 & -0.327808 & -1.488676 \\
\hline 6 & 0 & 3.344734 & -1.388299 & -1.695158 \\
\hline 6 & 0 & 2.064356 & -1.279305 & -1.164405 \\
\hline 6 & 0 & -1.346807 & -1.360937 & -1.478368 \\
\hline 6 & 0 & -2.308286 & -2.230076 & -1.962927 \\
\hline 6 & 0 & -2.977717 & -2.999675 & -1.026870 \\
\hline 6 & 0 & -2.714247 & -2.905070 & 0.325036 \\
\hline 6 & 0 & -1.732985 & -2.002213 & 0.718181 \\
\hline 9 & 0 & 2.188344 & 1.918210 & 0.436493 \\
\hline 9 & 0 & 1.272786 & -2.369598 & -1.345095 \\
\hline 9 & 0 & 5.461406 & -0.394919 & -1.989132 \\
\hline 9 & 0 & -1.526617 & -1.931165 & 2.064897 \\
\hline
\end{tabular}




$\begin{array}{llrrr}9 & 0 & -0.711077 & -0.595567 & -2.402480 \\ 9 & 0 & -3.927755 & -3.867614 & -1.451387 \\ 9 & 0 & -2.266926 & 0.875006 & 1.603925 \\ 9 & 0 & 0.654521 & 2.046053 & -1.931853 \\ 9 & 0 & -3.108914 & 4.658588 & -1.026519 \\ 1 & 0 & -0.924706 & 3.992108 & -2.309992 \\ 1 & 0 & -3.600545 & 2.946156 & 0.901624 \\ 1 & 0 & 4.511207 & 1.620698 & -0.603948 \\ 1 & 0 & 3.649921 & -2.271991 & -2.239767 \\ 1 & 0 & -2.523421 & -2.299248 & -3.020974 \\ 1 & 0 & -3.251451 & -3.497468 & 1.053816\end{array}$

\begin{tabular}{|c|c|c|c|c|}
\hline \multicolumn{5}{|c|}{$\mathrm{B}\left(\mathrm{C}_{6} \mathrm{~F}_{5}\right)_{3} / \mathrm{Py}$} \\
\hline 6 & 0 & 1.116827 & -0.258254 & 4.714331 \\
\hline 6 & 0 & 1.217918 & -1.372167 & 3.882946 \\
\hline 6 & 0 & 0.859164 & -1.250898 & 2.556602 \\
\hline 7 & 0 & 0.405210 & -0.088924 & 2.040174 \\
\hline 6 & 0 & 0.322896 & 0.991432 & 2.834718 \\
\hline 6 & 0 & 0.665798 & 0.940227 & 4.175832 \\
\hline 1 & 0 & 1.391320 & -0.324717 & 5.760384 \\
\hline 1 & 0 & 1.569367 & -2.326219 & 4.253467 \\
\hline 1 & 0 & 0.925759 & -2.083623 & 1.870873 \\
\hline 1 & 0 & -0.007387 & 1.906992 & 2.370287 \\
\hline 1 & 0 & 0.580845 & 1.835882 & 4.777069 \\
\hline 5 & 0 & 0.129488 & -0.038817 & 0.434363 \\
\hline 6 & 0 & -0.592575 & 1.371499 & 0.008444 \\
\hline 6 & 0 & -0.956636 & -1.180344 & -0.018618 \\
\hline 6 & 0 & 1.650171 & -0.250456 & -0.142989 \\
\hline 6 & 0 & -0.202419 & 2.197334 & -1.045390 \\
\hline 6 & 0 & -0.931822 & 3.308544 & -1.454896 \\
\hline 6 & 0 & -2.115519 & 3.634293 & -0.811466 \\
\hline 6 & 0 & -2.558680 & 2.833645 & 0.231289 \\
\hline 6 & 0 & -1.804476 & 1.731000 & 0.601971 \\
\hline 6 & 0 & 2.607703 & 0.737738 & 0.085488 \\
\hline 6 & 0 & 3.934122 & 0.639886 & -0.299673 \\
\hline 6 & 0 & 4.369095 & -0.513521 & -0.938798 \\
\hline 6 & 0 & 3.467622 & -1.541543 & -1.160907 \\
\hline 6 & 0 & 2.144663 & -1.398728 & -0.753907 \\
\hline 6 & 0 & -1.178511 & -1.351346 & -1.386527 \\
\hline 6 & 0 & -2.137860 & -2.196239 & -1.918036 \\
\hline 6 & 0 & -2.954243 & -2.921040 & -1.059455 \\
\hline 6 & 0 & -2.790650 & -2.773602 & 0.307305 \\
\hline 6 & 0 & -1.814712 & -1.910952 & 0.797245 \\
\hline 9 & 0 & -2.303064 & 0.975451 & 1.607590 \\
\hline
\end{tabular}




$\begin{array}{llrrr}9 & 0 & -3.705692 & 3.125306 & 0.859533 \\ 9 & 0 & -2.822617 & 4.701577 & -1.192389 \\ 9 & 0 & -0.500832 & 4.066436 & -2.471247 \\ 9 & 0 & 0.915309 & 1.950006 & -1.751630 \\ 9 & 0 & 1.354751 & -2.473888 & -0.963864 \\ 9 & 0 & 3.879640 & -2.671721 & -1.751251 \\ 9 & 0 & 5.644380 & -0.635833 & -1.318320 \\ 9 & 0 & 4.796798 & 1.636915 & -0.060185 \\ 9 & 0 & 2.250941 & 1.875868 & 0.724688 \\ 9 & 0 & -1.753055 & -1.817009 & 2.145664 \\ 9 & 0 & -0.428295 & -0.658785 & -2.268987 \\ 9 & 0 & -3.579244 & -3.455027 & 1.151085 \\ 9 & 0 & -3.888606 & -3.743231 & -1.547058 \\ 9 & 0 & -2.288312 & -2.319487 & -3.243424\end{array}$

\begin{tabular}{|c|c|c|c|c|}
\hline \multicolumn{5}{|c|}{$\mathrm{BPh}_{3}+\mathrm{Ph}-\mathrm{C} \equiv \mathrm{CH}+\mathrm{Py}$} \\
\hline 6 & 0 & -3.812951 & 3.949160 & -0.963873 \\
\hline 6 & 0 & -2.730106 & 4.124504 & -0.100725 \\
\hline 6 & 0 & -1.867622 & 3.062095 & 0.162548 \\
\hline 6 & 0 & -2.045410 & 1.796454 & -0.419059 \\
\hline 6 & 0 & -3.137777 & 1.649382 & -1.285922 \\
\hline 6 & 0 & -4.012827 & 2.703706 & -1.556065 \\
\hline 5 & 0 & -1.068642 & 0.549634 & -0.022535 \\
\hline 6 & 0 & -1.542475 & -0.035546 & 1.431687 \\
\hline 6 & 0 & -1.076351 & -0.599733 & -1.204414 \\
\hline 6 & 0 & -2.834642 & -0.567096 & 1.594478 \\
\hline 6 & 0 & -3.274767 & -1.096155 & 2.805242 \\
\hline 6 & 0 & -2.432793 & -1.098685 & 3.919627 \\
\hline 6 & 0 & -1.159299 & -0.547844 & 3.802385 \\
\hline 6 & 0 & -0.731641 & -0.026456 & 2.577340 \\
\hline 6 & 0 & -0.550321 & -0.278499 & -2.469577 \\
\hline 6 & 0 & -0.487089 & -1.204061 & -3.508690 \\
\hline 6 & 0 & -0.956609 & -2.505194 & -3.316562 \\
\hline 6 & 0 & -1.488804 & -2.852478 & -2.077567 \\
\hline 6 & 0 & -1.544569 & -1.911273 & -1.046040 \\
\hline 6 & 0 & 0.440384 & 1.055976 & 0.082024 \\
\hline 6 & 0 & 1.622427 & 1.347330 & 0.150540 \\
\hline 6 & 0 & 3.008183 & 1.682004 & 0.190446 \\
\hline 6 & 0 & 3.833486 & 1.215677 & 1.229994 \\
\hline 6 & 0 & 3.584446 & 2.472582 & -0.820675 \\
\hline 6 & 0 & 5.189428 & 1.525161 & 1.252722 \\
\hline 6 & 0 & 4.939904 & 2.781608 & -0.790084 \\
\hline 6 & 0 & 5.749122 & 2.308483 & 0.243494 \\
\hline 1 & 0 & -4.488713 & 4.772951 & -1.173145 \\
\hline
\end{tabular}




\begin{tabular}{|c|c|c|c|c|}
\hline 1 & 0 & -2.559480 & 5.090820 & 0.366111 \\
\hline 1 & 0 & -1.030726 & 3.217008 & 0.838580 \\
\hline 1 & 0 & -3.307366 & 0.691863 & -1.769706 \\
\hline 1 & 0 & -4.849447 & 2.552992 & -2.233037 \\
\hline 1 & 0 & -3.518335 & -0.555177 & 0.750734 \\
\hline 1 & 0 & -4.280636 & -1.498563 & 2.886039 \\
\hline 1 & 0 & -2.774472 & -1.503331 & 4.867258 \\
\hline 1 & 0 & -0.501159 & -0.510264 & 4.666509 \\
\hline 1 & 0 & 0.256833 & 0.423276 & 2.522893 \\
\hline 1 & 0 & -0.178629 & 0.728204 & -2.639006 \\
\hline 1 & 0 & -0.076553 & -0.911859 & -4.471334 \\
\hline 1 & 0 & -0.913296 & -3.231376 & -4.122588 \\
\hline 1 & 0 & -1.860645 & -3.859595 & -1.909277 \\
\hline 1 & 0 & -1.954609 & -2.217618 & -0.089784 \\
\hline 1 & 0 & 3.398662 & 0.617464 & 2.023689 \\
\hline 1 & 0 & 2.955009 & 2.841481 & -1.622415 \\
\hline 1 & 0 & 5.810047 & 1.159324 & 2.064099 \\
\hline 1 & 0 & 5.366893 & 3.396018 & -1.575818 \\
\hline 1 & 0 & 6.805768 & 2.552414 & 0.264689 \\
\hline 7 & 0 & 1.292533 & -1.782210 & 0.402793 \\
\hline 6 & 0 & 0.826125 & -2.711971 & 1.250204 \\
\hline 6 & 0 & 1.778972 & -2.070107 & -0.814781 \\
\hline 6 & 0 & 1.835086 & -3.385445 & -1.230793 \\
\hline 6 & 0 & 0.870734 & -4.043701 & 0.883113 \\
\hline 6 & 0 & 1.378017 & -4.381631 & -0.370165 \\
\hline 1 & 0 & 1.187537 & -0.777323 & 0.621657 \\
\hline 1 & 0 & 0.405338 & -2.343873 & 2.175791 \\
\hline 1 & 0 & 2.074827 & -1.223153 & -1.416042 \\
\hline 1 & 0 & 2.210895 & -3.617877 & -2.217367 \\
\hline 1 & 0 & 0.493645 & -4.796967 & 1.561640 \\
\hline 1 & 0 & 1.402521 & -5.419026 & -0.682142 \\
\hline
\end{tabular}

$\begin{array}{lcrrr}\mathrm{B}(\mathrm{DiMe}) \mathrm{Ph}_{3}+\mathrm{Ph}-\mathrm{C} \equiv \mathrm{CH}+\mathrm{Py} \\ 6 & 0 & -4.049819 & 3.108612 & -1.283799 \\ 6 & 0 & -3.060276 & 3.579163 & -0.409227 \\ 6 & 0 & -2.012623 & 2.726313 & -0.069402 \\ 6 & 0 & -1.910887 & 1.418274 & -0.573106 \\ 6 & 0 & -2.915634 & 0.994908 & -1.446416 \\ 6 & 0 & -3.990627 & 1.819445 & -1.808268 \\ 5 & 0 & -0.717234 & 0.426692 & -0.067928 \\ 6 & 0 & -1.101634 & -0.108176 & 1.432903 \\ 6 & 0 & -0.473780 & -0.798546 & -1.144654 \\ 6 & 0 & -2.266849 & -0.869960 & 1.633321 \\ 6 & 0 & -2.624307 & -1.388817 & 2.876176\end{array}$




\begin{tabular}{|c|c|c|c|c|}
\hline 6 & 0 & -1.797382 & -1.127304 & 3.977920 \\
\hline 6 & 0 & -0.656880 & -0.338759 & 3.843299 \\
\hline 6 & 0 & -0.330033 & 0.154880 & 2.571412 \\
\hline 6 & 0 & 0.079382 & -0.493095 & -2.400668 \\
\hline 6 & 0 & 0.376251 & -1.465877 & -3.355729 \\
\hline 6 & 0 & 0.115434 & -2.805945 & -3.048068 \\
\hline 6 & 0 & -0.448082 & -3.159841 & -1.822115 \\
\hline 6 & 0 & -0.734101 & -2.150364 & -0.894751 \\
\hline 6 & 0 & 0.667598 & 1.215297 & 0.001119 \\
\hline 6 & 0 & 1.780711 & 1.709503 & 0.055868 \\
\hline 6 & 0 & 3.094916 & 2.262606 & 0.077724 \\
\hline 6 & 0 & 3.769938 & 2.478218 & 1.293118 \\
\hline 6 & 0 & 3.755400 & 2.584577 & -1.122525 \\
\hline 6 & 0 & 5.061972 & 2.993353 & 1.304939 \\
\hline 6 & 0 & 5.046418 & 3.101269 & -1.104085 \\
\hline 6 & 0 & 5.706708 & 3.305830 & 0.107965 \\
\hline 6 & 0 & 0.191834 & 0.011004 & 5.041831 \\
\hline 6 & 0 & -3.882872 & -2.203821 & 3.047628 \\
\hline 6 & 0 & -3.137427 & 4.982327 & 0.142273 \\
\hline 6 & 0 & -5.061608 & 1.307642 & -2.741173 \\
\hline 6 & 0 & 0.951089 & -1.085490 & -4.698553 \\
\hline 6 & 0 & -0.752561 & -4.602374 & -1.501797 \\
\hline 1 & 0 & -4.875023 & 3.762648 & -1.558434 \\
\hline 1 & 0 & -1.244951 & 3.086706 & 0.611678 \\
\hline 1 & 0 & -2.865720 & -0.005987 & -1.868083 \\
\hline 1 & 0 & -2.922109 & -1.056345 & 0.786931 \\
\hline 1 & 0 & -2.064417 & -1.525478 & 4.954664 \\
\hline 1 & 0 & 0.551883 & 0.785734 & 2.478888 \\
\hline 1 & 0 & 0.298585 & 0.546238 & -2.632541 \\
\hline 1 & 0 & 0.354816 & -3.580210 & -3.774383 \\
\hline 1 & 0 & -1.148011 & -2.443785 & 0.064478 \\
\hline 1 & 0 & 3.265834 & 2.245084 & 2.224656 \\
\hline 1 & 0 & 3.239351 & 2.430557 & -2.063601 \\
\hline 1 & 0 & 5.566076 & 3.156330 & 2.251898 \\
\hline 1 & 0 & 5.538618 & 3.348774 & -2.038912 \\
\hline 1 & 0 & 6.713285 & 3.709835 & 0.119663 \\
\hline 1 & 0 & 1.255724 & 0.045946 & 4.789011 \\
\hline 1 & 0 & -0.072827 & 0.998104 & 5.436263 \\
\hline 1 & 0 & 0.061151 & -0.708094 & 5.854366 \\
\hline 1 & 0 & -3.677795 & -3.168356 & 3.523212 \\
\hline 1 & 0 & -4.608925 & -1.684109 & 3.681429 \\
\hline 1 & 0 & -4.364696 & -2.398915 & 2.087310 \\
\hline 1 & 0 & -3.088773 & 5.731022 & -0.655653 \\
\hline 1 & 0 & -4.075317 & 5.151371 & 0.681531 \\
\hline
\end{tabular}




$\begin{array}{ccrrr}1 & 0 & -2.316064 & 5.182763 & 0.833929 \\ 1 & 0 & -5.762663 & 2.097543 & -3.021740 \\ 1 & 0 & -4.629866 & 0.900994 & -3.660974 \\ 1 & 0 & -5.641031 & 0.501422 & -2.278391 \\ 1 & 0 & 1.698232 & -1.808130 & -5.040021 \\ 1 & 0 & 0.170670 & -1.046518 & -5.466277 \\ 1 & 0 & 1.421551 & -0.099933 & -4.667650 \\ 1 & 0 & -0.770773 & -4.776443 & -0.422931 \\ 1 & 0 & -1.733517 & -4.896780 & -1.890305 \\ 1 & 0 & -0.017406 & -5.281067 & -1.944073 \\ 7 & 0 & 1.934881 & -1.414895 & 0.664636 \\ 6 & 0 & 1.567696 & -2.367172 & 1.535763 \\ 6 & 0 & 2.512696 & -1.678286 & -0.518034 \\ 6 & 0 & 2.776439 & -2.988019 & -0.868345 \\ 6 & 0 & 1.822308 & -3.691731 & 1.234842 \\ 6 & 0 & 2.429653 & -4.003592 & 0.020115 \\ 1 & 0 & 1.664232 & -0.433274 & 0.826786 \\ 1 & 0 & 1.051364 & -2.025108 & 2.422071 \\ 1 & 0 & 2.708937 & -0.822439 & -1.145967 \\ 1 & 0 & 3.225507 & -3.203870 & -1.827404 \\ 1 & 0 & 1.526486 & -4.463289 & 1.932799 \\ 1 & 0 & 2.615202 & -5.038426 & -0.242037\end{array}$

$\begin{array}{lcrrr}\mathrm{B}\left(\mathrm{C}_{6} \mathrm{~F}_{2} \mathrm{H}_{3}\right)_{3}+\mathrm{Ph}-\mathrm{C} \equiv \mathrm{CH}+\mathrm{Py} & & \\ 6 & 0 & 3.837880 & -3.530177 & -1.094471 \\ 6 & 0 & 3.085132 & -3.579201 & 0.074996 \\ 6 & 0 & 2.215456 & -2.532626 & 0.340455 \\ 6 & 0 & 2.012133 & -1.418082 & -0.475650 \\ 6 & 0 & 2.817485 & -1.430616 & -1.612599 \\ 6 & 0 & 3.708485 & -2.440385 & -1.949289 \\ 5 & 0 & 0.943323 & -0.253141 & -0.012375 \\ 6 & 0 & 1.588136 & 0.467692 & 1.320289 \\ 6 & 0 & 0.553876 & 0.827588 & -1.204412 \\ 6 & 0 & 2.907499 & 0.930089 & 1.309510 \\ 6 & 0 & 3.582755 & 1.473038 & 2.389981 \\ 6 & 0 & 2.907842 & 1.595079 & 3.601669 \\ 6 & 0 & 1.580863 & 1.188805 & 3.688218 \\ 6 & 0 & 0.980392 & 0.655803 & 2.556386 \\ 6 & 0 & 0.027015 & 0.384932 & -2.423134 \\ 6 & 0 & -0.417518 & 1.195371 & -3.455090 \\ 6 & 0 & -0.345855 & 2.577153 & -3.292768 \\ 6 & 0 & 0.153369 & 3.098443 & -2.106296 \\ 6 & 0 & 0.573514 & 2.218448 & -1.115464 \\ 6 & 0 & -0.435793 & -0.992100 & 0.281267\end{array}$




\begin{tabular}{|c|c|c|c|c|}
\hline 6 & 0 & -1.524348 & -1.524915 & 0.372156 \\
\hline 6 & 0 & -2.824081 & -2.103870 & 0.449628 \\
\hline 6 & 0 & -3.546275 & -2.102631 & 1.656563 \\
\hline 6 & 0 & -3.424152 & -2.659221 & -0.695667 \\
\hline 6 & 0 & -4.830617 & -2.634396 & 1.711681 \\
\hline 6 & 0 & -4.707652 & -3.191045 & -0.632361 \\
\hline 6 & 0 & -5.417330 & -3.178816 & 0.569050 \\
\hline 9 & 0 & 1.519876 & -2.610255 & 1.512961 \\
\hline 9 & 0 & 2.763756 & -0.376835 & -2.477533 \\
\hline 9 & 0 & -0.069708 & -0.956018 & -2.633088 \\
\hline 9 & 0 & 1.003280 & 2.813980 & 0.039881 \\
\hline 9 & 0 & -0.353999 & 0.331348 & 2.704755 \\
\hline 9 & 0 & 3.594786 & 0.876071 & 0.135434 \\
\hline 1 & 0 & 4.527239 & -4.332070 & -1.333757 \\
\hline 1 & 0 & 3.165069 & -4.402357 & 0.775061 \\
\hline 1 & 0 & 4.288246 & -2.357483 & -2.860948 \\
\hline 1 & 0 & 4.610469 & 1.795208 & 2.272411 \\
\hline 1 & 0 & 3.409815 & 2.010105 & 4.468129 \\
\hline 1 & 0 & 1.014605 & 1.273670 & 4.608214 \\
\hline 1 & 0 & -0.794070 & 0.744330 & -4.365532 \\
\hline 1 & 0 & -0.673307 & 3.238669 & -4.086798 \\
\hline 1 & 0 & 0.224477 & 4.165802 & -1.934336 \\
\hline 1 & 0 & -3.084321 & -1.690265 & 2.546680 \\
\hline 1 & 0 & -2.867142 & -2.673024 & -1.625836 \\
\hline 1 & 0 & -5.373457 & -2.629775 & 2.651151 \\
\hline 1 & 0 & -5.154764 & -3.620587 & -1.522827 \\
\hline 1 & 0 & -6.417585 & -3.595859 & 0.615627 \\
\hline 7 & 0 & -2.036738 & 1.507274 & 0.580673 \\
\hline 6 & 0 & -1.842265 & 2.629377 & 1.289891 \\
\hline 6 & 0 & -2.693916 & 1.480412 & -0.591121 \\
\hline 6 & 0 & -3.215902 & 2.649906 & -1.105067 \\
\hline 6 & 0 & -2.346002 & 3.826335 & 0.816160 \\
\hline 6 & 0 & -3.037601 & 3.835498 & -0.393270 \\
\hline 1 & 0 & -1.611632 & 0.616207 & 0.887582 \\
\hline 1 & 0 & -1.275629 & 2.524707 & 2.202745 \\
\hline 1 & 0 & -2.754682 & 0.515473 & -1.072783 \\
\hline 1 & 0 & -3.736292 & 2.631554 & -2.052589 \\
\hline 1 & 0 & -2.184028 & 4.734110 & 1.381456 \\
\hline 1 & 0 & -3.429527 & 4.766416 & -0.785622 \\
\hline
\end{tabular}

$\begin{array}{lcrrr}\mathrm{B}\left(\mathrm{C}_{6} \mathrm{~F}_{3} \mathrm{H}_{2}\right)_{3}+\mathrm{Ph}-\mathrm{C} \equiv \mathrm{CH}+\mathrm{Py} \\ 6 & 0 & -4.236721 & 2.614400 & -1.421264 \\ 6 & 0 & -3.654273 & 2.840240 & -0.187964 \\ 6 & 0 & -2.596970 & 2.011669 & 0.162691\end{array}$




\begin{tabular}{|c|c|c|c|c|}
\hline 6 & 0 & -2.067419 & 0.985439 & -0.620613 \\
\hline 6 & 0 & -2.743579 & 0.828200 & -1.828297 \\
\hline 6 & 0 & -3.806417 & 1.608623 & -2.265672 \\
\hline 5 & 0 & -0.807016 & 0.087899 & -0.055874 \\
\hline 6 & 0 & -1.375491 & -0.807523 & 1.204346 \\
\hline 6 & 0 & -0.066393 & -0.833887 & -1.214073 \\
\hline 6 & 0 & -2.572449 & -1.521310 & 1.096586 \\
\hline 6 & 0 & -3.185458 & -2.243290 & 2.109611 \\
\hline 6 & 0 & -2.542017 & -2.273141 & 3.333432 \\
\hline 6 & 0 & -1.334180 & -1.635027 & 3.541500 \\
\hline 6 & 0 & -0.801693 & -0.939744 & 2.463488 \\
\hline 6 & 0 & 0.452252 & -0.241609 & -2.370421 \\
\hline 6 & 0 & 1.190203 & -0.881461 & -3.355289 \\
\hline 6 & 0 & 1.433659 & -2.231649 & -3.174512 \\
\hline 6 & 0 & 0.969885 & -2.917197 & -2.070924 \\
\hline 6 & 0 & 0.241321 & -2.189862 & -1.134077 \\
\hline 6 & 0 & 0.324747 & 1.114537 & 0.388596 \\
\hline 6 & 0 & 1.234237 & 1.885984 & 0.621445 \\
\hline 6 & 0 & 2.330724 & 2.754542 & 0.895321 \\
\hline 6 & 0 & 2.900475 & 2.808783 & 2.180253 \\
\hline 6 & 0 & 2.882893 & 3.552482 & -0.123173 \\
\hline 6 & 0 & 3.992484 & 3.632109 & 2.433774 \\
\hline 6 & 0 & 3.973431 & 4.375030 & 0.138415 \\
\hline 6 & 0 & 4.534202 & 4.416762 & 1.415367 \\
\hline 9 & 0 & -2.060817 & 2.230736 & 1.393875 \\
\hline 9 & 0 & -2.376759 & -0.173377 & -2.672620 \\
\hline 9 & 0 & -5.273841 & 3.400639 & -1.811677 \\
\hline 9 & 0 & 0.240688 & 1.083427 & -2.567187 \\
\hline 9 & 0 & -0.145851 & -2.908279 & -0.041010 \\
\hline 9 & 0 & 2.167161 & -2.898167 & -4.103379 \\
\hline 9 & 0 & 0.436129 & -0.385609 & 2.702250 \\
\hline 9 & 0 & -3.196831 & -1.554695 & -0.108282 \\
\hline 9 & 0 & -3.104260 & -2.964359 & 4.356972 \\
\hline 1 & 0 & -4.005275 & 3.618501 & 0.476872 \\
\hline 1 & 0 & -4.279394 & 1.425697 & -3.221626 \\
\hline 1 & 0 & -4.118194 & -2.765739 & 1.942273 \\
\hline 1 & 0 & -0.825740 & -1.673109 & 4.495970 \\
\hline 1 & 0 & 1.547895 & -0.347573 & -4.226088 \\
\hline 1 & 0 & 1.163437 & -3.972482 & -1.931158 \\
\hline 1 & 0 & 2.470153 & 2.207707 & 2.973652 \\
\hline 1 & 0 & 2.440261 & 3.523297 & -1.112516 \\
\hline 1 & 0 & 4.418121 & 3.667211 & 3.431146 \\
\hline 1 & 0 & 4.384656 & 4.989433 & -0.655622 \\
\hline 1 & 0 & 5.383252 & 5.060977 & 1.616811 \\
\hline
\end{tabular}




$\begin{array}{ccccc}7 & 0 & 2.519288 & -0.923476 & 0.694288 \\ 6 & 0 & 2.595625 & -2.105164 & 1.326556 \\ 6 & 0 & 3.218127 & -0.636377 & -0.416965 \\ 6 & 0 & 4.069246 & -1.583722 & -0.949526 \\ 6 & 0 & 3.435478 & -3.085281 & 0.832408 \\ 6 & 0 & 4.176976 & -2.821980 & -0.317938 \\ 1 & 0 & 1.850112 & -0.204101 & 1.013732 \\ 1 & 0 & 1.966954 & -2.222560 & 2.196437 \\ 1 & 0 & 3.046612 & 0.343153 & -0.838667 \\ 1 & 0 & 4.624590 & -1.358100 & -1.849533 \\ 1 & 0 & 3.493696 & -4.040909 & 1.335551 \\ 1 & 0 & 4.830952 & -3.582860 & -0.726841\end{array}$

$\begin{array}{llrrr}\mathrm{B}\left(\mathrm{C}_{6} \mathrm{~F}_{5}\right)_{3}+\mathrm{Ph}-\mathrm{C} \equiv \mathrm{CH}+\mathrm{Py} & & & \\ 6 & 0 & -4.000637 & 2.600204 & -1.624800 \\ 6 & 0 & -3.659835 & 2.610370 & -0.280126 \\ 6 & 0 & -2.645068 & 1.779544 & 0.171301 \\ 6 & 0 & -1.920092 & 0.921333 & -0.653941 \\ 6 & 0 & -2.314630 & 0.932468 & -1.987176 \\ 6 & 0 & -3.323982 & 1.749323 & -2.483421 \\ 5 & 0 & -0.717502 & -0.001917 & -0.019379 \\ 6 & 0 & -1.310051 & -1.188235 & 0.961950 \\ 6 & 0 & 0.282104 & -0.608125 & -1.194202 \\ 6 & 0 & -2.631900 & -1.624506 & 0.988658 \\ 6 & 0 & -3.104499 & -2.594334 & 1.867439 \\ 6 & 0 & -2.236664 & -3.189992 & 2.768091 \\ 6 & 0 & -0.902947 & -2.808960 & 2.765231 \\ 6 & 0 & -0.482758 & -1.836771 & 1.873346 \\ 6 & 0 & 1.069612 & 0.264846 & -1.945759 \\ 6 & 0 & 2.022617 & -0.144063 & -2.866059 \\ 6 & 0 & 2.218531 & -1.499641 & -3.086150 \\ 6 & 0 & 1.437165 & -2.409557 & -2.394322 \\ 6 & 0 & 0.491060 & -1.953846 & -1.479903 \\ 9 & 0 & -2.402906 & 1.803538 & 1.499689 \\ 9 & 0 & -3.545900 & -1.134583 & 0.124590 \\ 9 & 0 & -4.393167 & -2.965463 & 1.845355 \\ 9 & 0 & -4.321580 & 3.414470 & 0.568055 \\ 9 & 0 & 1.616064 & -3.724837 & -2.595663 \\ 9 & 0 & 2.773079 & 0.752691 & -3.527934 \\ 9 & 0 & -0.224035 & -2.921469 & -0.866671 \\ 9 & 0 & 0.938916 & 1.599607 & -1.790615 \\ 9 & 0 & -0.035682 & -3.394414 & 3.608758 \\ 9 & 0 & 0.856644 & -1.569486 & 1.892285 \\ 9 & -1.737288 & 0.107104 & -2.892065\end{array}$




\begin{tabular}{|c|c|c|c|c|}
\hline 9 & 0 & -3.653452 & 1.717440 & -3.785407 \\
\hline 9 & 0 & -4.976926 & 3.394753 & -2.084170 \\
\hline 9 & 0 & -2.672708 & -4.127577 & 3.618581 \\
\hline 6 & 0 & 0.191554 & 0.948093 & 0.875859 \\
\hline 6 & 0 & 0.902042 & 1.675003 & 1.540368 \\
\hline 9 & 0 & 3.154007 & -1.919576 & -3.948173 \\
\hline 6 & 0 & 1.784007 & 2.523291 & 2.272659 \\
\hline 6 & 0 & 2.058764 & 3.826131 & 1.818669 \\
\hline 6 & 0 & 2.428838 & 2.057984 & 3.432457 \\
\hline 6 & 0 & 2.956876 & 4.635239 & 2.506170 \\
\hline 6 & 0 & 3.327124 & 2.872905 & 4.113425 \\
\hline 6 & 0 & 3.596050 & 4.161788 & 3.652671 \\
\hline 1 & 0 & 1.557009 & 4.191315 & 0.929776 \\
\hline 1 & 0 & 2.211690 & 1.058851 & 3.793973 \\
\hline 1 & 0 & 3.155519 & 5.640068 & 2.149115 \\
\hline 1 & 0 & 3.814203 & 2.503560 & 5.009522 \\
\hline 1 & 0 & 4.294105 & 4.796368 & 4.187641 \\
\hline 7 & 0 & 3.076556 & -0.175115 & 0.428083 \\
\hline 6 & 0 & 3.816454 & 0.839622 & -0.054364 \\
\hline 6 & 0 & 3.399863 & -1.467230 & 0.251239 \\
\hline 6 & 0 & 4.540981 & -1.791090 & -0.458740 \\
\hline 6 & 0 & 4.965780 & 0.565231 & -0.768593 \\
\hline 6 & 0 & 5.329056 & -0.765185 & -0.977045 \\
\hline 1 & 0 & 2.189258 & 0.072913 & 0.895856 \\
\hline 1 & 0 & 3.444722 & 1.834724 & 0.144873 \\
\hline 1 & 0 & 2.724075 & -2.191585 & 0.679953 \\
\hline 1 & 0 & 4.797119 & -2.831123 & -0.609196 \\
\hline 1 & 0 & 5.555957 & 1.380654 & -1.163825 \\
\hline 1 & 0 & 6.219889 & -1.001196 & -1.546503 \\
\hline
\end{tabular}

Reference:

[1] V. Rozyyev, D. Thirion, R. Ullah, J. Lee, M. Jung, H. Oh, M. Atilhan, C. T. Yavuz, Nat. Energy 2019, 4, 604-611.

[2] a) Y. K. Hwang, D. Y. Hong, J. S. Chang, S. H. Jhung, Y. K. Seo, J. Kim, A. Vimont, M. Daturi, C. Serre, G. Ferey, Angew. Chem. Int. Ed. 2008, 47, 4144-4148; b) E. A. Ekimov, V. A. Sidorov, K. I. Maslakov, B. P. Sirotinkin, M. D. Krotova, Y. V. Pleskov, Diamond Relat. Mater. 2018, 89, 101-107.

[3] a) C. W. Ong, H. Huang, B. Zheng, R. W. M. Kwok, Y. Y. Hui, W. M. Lau, J. Appl. Phys. 2004, 95, 3527-3534; b) S. Liu, M. Wang, T. Qian, H. Ji, J. Liu, C. Yan, Nat. Commun. 2019, 10, 3898.

[4] M. Wang, F. Nudelman, R. R. Matthes, M. P. Shaver, J. Am. Chem. Soc. 2017, 139, 14232-14236.

[5] S. Grimme, S. Ehrlich, L. Goerigk, J. Comput. Chem. 2011, 32, 1456-1465.

[6] R. Sure, J. Antony, S. Grimme, J. Phys. Chem. B 2014, 118, 3431-3440. 
[7] M. J. Turner, S. Grabowsky, D. Jaytilaka, M. A. Spackman, J. Phys. Chem. Lett. 2014, 5, 4249-4255.

[8] Z. Li, K. Su, J. Ren, D. Yang, B. Cheng, C. K. Kim, X. Yao, Green Chem., 2018, 20, 863-872.

[9] M. J. Frisch, G. W. Trucks, H. B. Schlegel, G. E. Scuseria, M. A. Robb, J. R. Cheeseman, J. A. Montgomery, Jr., T. Vreven, K. N. Kudin, J. C. Burant, J. M. Millam, S. S. Iyengar, J. Tomasi, V. Barone, B. Mennucci, M. Cossi, G. Scalmani, N. Rega, G. A. Petersson, H. Nakatsuji, M. Hada, M. Ehara, K. Toyota, R. Fukuda, J. Hasegawa, M. Ishida, T. Nakajima, Y. Honda, O. Kitao, H. Nakai, M. Klene, X. Li, J. E. Knox, H. P. Hratchian, J. B. Cross, V. Bakken, C. Adamo, J. Jaramillo, R. Gomperts, R. E. Stratmann, O. Yazyev, A. J. Austin, R. Cammi, C. Pomelli, J. Ochterski, P. Y. Ayala, K. Morokuma, G. A. Voth, P. Salvador, J. J. Dannenberg, V. G. Zakrzewski, S. Dapprich, A. D. Daniels, M. C. Strain, O. Farkas, D. K. Malick, A. D. Rabuck, K. Raghavachari, J. B. Foresman, J. V. Ortiz, Q. Cui, A. G. Baboul, S. Clifford, J. Cioslowski, B. B. Stefanov, G. Liu, A. Liashenko, P. Piskorz, I. Komaromi, R. L. Martin, D. J. Fox, T. Keith,M. A. Al-Laham, C. Y. Peng, A. Nanayakkara, M. Challacombe, P. M. W. Gill, B. G. Johnson, W. Chen, M. W. Wong, C. Gonzalez, J. A. Pople, GAUSSIAN 03, Gaussion, Inc., Pittsburgh, PA, 2009. 